Universidade de Brasília

Faculdade de Ciências da Saúde

TESE DE DOUTORADO

COMPARAÇÃO DOS CUSTOS E BENEFÍCIOS DO TRATAMENTO DA HIDROCEFALIA COM IMPLANTE DE VÁLVULA E COM CIRURGIA NEUROENDOSCÓPICA.

Benicio Oton de Lima

Brasília, DF

2014 
Universidade de Brasília

Faculdade de Ciências da Saúde

\section{COMPARAÇÃO DOS CUSTOS E BENEFÍCIOS DO TRATAMENTO DA HIDROCEFALIA COM IMPLANTE DE VÁLVULA E COM CIRURGIA NEUROENDOSCÓPICA.}

Doutorando: Benicio Oton de Lima

Orientador: Prof. Dr. Riccardo Pratesi

Tese apresentada ã banca examinadora como requisito parcial para obtenção do título de Doutor em Ciências da Saúde pela Universidade de Brasília.

Brasília, DF

2014 
OTON-DE LIMA, Benicio

Comparação dos custos e benefícios do tratamento da hidrocefalia com implante de válvula e com cirurgia neuroendoscópica / Benicio Oton de Lima Brasília, DF, Universidade de Brasília, Faculdade de Ciências da Saúde, 2014. Tese (Doutorado) - Faculdade de Ciências da Saúde, Universidade de Brasília.

1. Hidrocefalia 2. Neuroendoscopia 3. Derivação ventrículo-peritoneal 4. Custos 5. Tese

i. Universidade de Brasília

II, Título 
Those which are Masters and Professors chosen to performe the like operation, ought indeede to have a Lyons heart, a Ladies hand, and a Haukes eye, for that it is a worke of no small importance.

William Clowes, 1602 
DEDICATÓRIA

Aos meus pais, Augusto Lima e Geralda, que sempre me estimularam a dar o melhor de mim, tanto na vida pessoal como no trabalho. E que sempre deram apoio e se orgulharam de todos os seus filhos em todos os momentos. 


\section{AGRADECIMENTOS}

A todos que de alguma maneira contribuíram para a realização de publicação deste trabalho. Agradecimento especial ao professor Riccardo Pratesi, pelo seu apoio, amizade e paciência 


\section{SUMÁRIO}

\begin{tabular}{|c|c|c|}
\hline \multicolumn{2}{|c|}{ DEDICATÕRIA } & $v$ \\
\hline \multicolumn{2}{|c|}{ AGRADECIMENTOS } & vi \\
\hline \multicolumn{2}{|c|}{ RESUMO } & $\mathrm{xi}$ \\
\hline \multicolumn{2}{|c|}{ ABSTRACT } & xiii \\
\hline \multicolumn{2}{|r|}{ 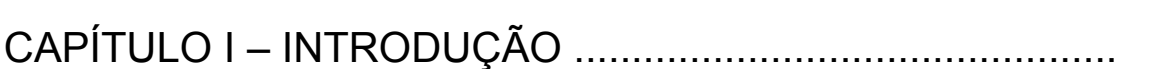 } & 1 \\
\hline & 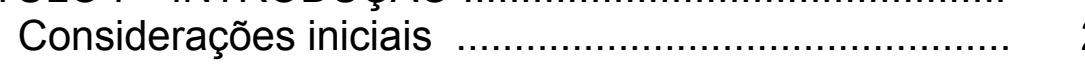 & 2 \\
\hline & Histórico ......................... & 4 \\
\hline 1.2.1 & Período Árabe e Bizantino & 6 \\
\hline 1.2 .2 & Renascimento ....................... & 8 \\
\hline & Idade Moderna e Contemporânea & 10 \\
\hline 1.2.4 & História do tratamento clínico da hidrocefalia & 2 \\
\hline 1.2 .5 & Tratamento cirúrgico da hidrocefalia nos tempos modernos & \\
\hline & Epidemiologia da hidrocefalia & 28 \\
\hline & Producão, circulação e absorção do LCR & 30 \\
\hline & Etiologia e Patofisiologia da hidrocefalia . & 33 \\
\hline 1.5 .1 & Etiologia congênita da hidrocefalia & 36 \\
\hline 1.5 .2 & Etiologia da hidrocefalia adquirida .. & 37 \\
\hline & 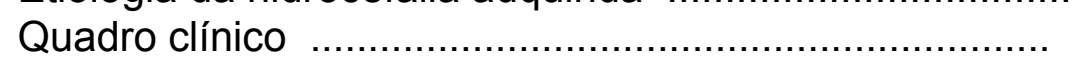 & 38 \\
\hline & Diagnóstico por imagem & 41 \\
\hline 1.7 .1 & Ultrassom & 41 \\
\hline 1.7 .2 & Tomografia computadorizada de crânio & 44 \\
\hline 1.7 .3 & Ressonância magnética de crânio & 45 \\
\hline & Diagnóstico diferencial & 46 \\
\hline & Tratamento ..................... & 47 \\
\hline 1.9 .1 & Custos do tratamento & .. 52 \\
\hline & 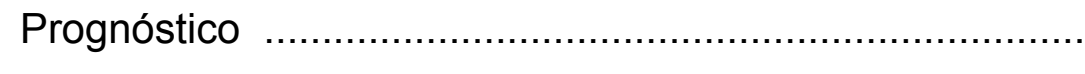 & 53 \\
\hline \multicolumn{2}{|c|}{ CAPÍTULO II - OBJETIVOS } & 56 \\
\hline \multicolumn{3}{|c|}{ CAPÍTULO III - MÉTODOS E PACIENTES } \\
\hline & População estudada & 61 \\
\hline & 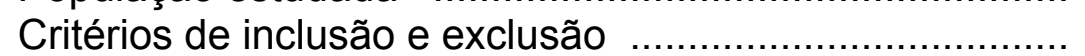 & 62 \\
\hline & Obtenção dos casos para estudo . & 63 \\
\hline & Técnicas operatórias & 63 \\
\hline & Tempo de internação & 67 \\
\hline
\end{tabular}


3.6 Aspectos clínicos pós operatórios ………………........ 67

3.7 Custos dos procedimentos …………………............ 68

CAPÍTULO IV - RESULTADOS ........................................ 72

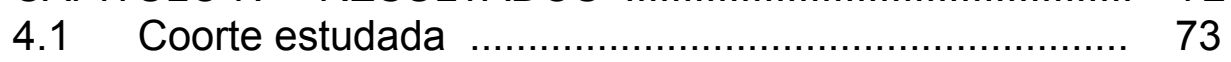

4.2 Tempo de internação hospitalar ................................ 77

4.3 Falha do procedimento .......................................... 77

4.4 Complicações que não necessitaram nova cirurgia .... 78

4.5 Sobrevida do sistema de derivação liquórica .............. 80

4.6 Custos dos tratamentos ……................................ 82

4.7 Perímetro cefálico e melhora neurológica ................... 82

CAPÍTULO V - DISCUSSÃO ............................................. 88

$5.1 \quad$ População estudada .............................................. 89

5.2 Tempo de internação hospitalar ................................. 92

$5.3 \quad$ Falha do procedimento ............................................ 93

5.4 Complicações que não necessitaram nova cirurgia ..... 96

5.5 Sobrevida do sistema de derivação liquórica .............. 98

5.6 Custos dos tratamentos ……………………......... 99

5.7 Perímetro cefálico e melhora neurológica .................. 104

CAPÍTULO VI - CONCLUSÕES .......................................... 106

CAPÍTULO VII - REFERÊNCIAS BIBLIOGRÁFICAS ............ 110

CAPÍTULO VIII - APÊNDICES ......................................... 123

Aprovação pelo Comitê de Ética em Pesquisa ....................... 124

Exame neurológico evolutivo - Denver II adaptado ................. 125

Índice de Saúde Útil ............................................................ 130

Ficha de coleta de dados …………............................... 131 


\section{SUMÁRIO DAS FIGURAS}

1. Visão através do endoscópio no ventrículo lateral ....... 21

2. Exames de neuroimagem de hidrocefalia ................ 34

3. Transiluminação transcraniana ............................. 40

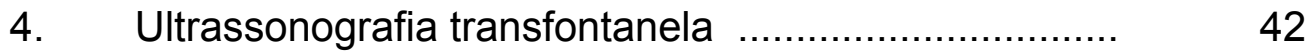

5. Visão endoscópica do ventrículo lateral direito .......... 65

6. Gráfico da idade média dos pacientes ..................... 75

7. Gráfico da distribuição de idade no grupo .................. 76

8. Curva de sobrevida da cirurgia ........................... 81

9. Tratamento em crianças com mais de um ano de vida. 83

10. Tratamento em crianças abaixo de um ano ............... 84

11. Gráfico do perímetro cefálico ................................... 85

12. Gráfico do perímetro cefálico das crianças operadas.... 86 


\section{SUMÁRIO DAS TABELAS}

1. Preços SUS dos procedimentos ……………............

2. Etiologias das hidrocefalias tratadas ……................. 74

3. Etiologias dos casos estudados ................................ 77

4. Causas de falha do tratamento .................................... 80 
RESUMO

Contexto: A cirurgia da hidrocefalia é a mais frequente em neurocirurgia pediátrica. Desde a introdução dos implantes de válvula na década de 1950, essa tem sido a modalidade de tratamento da hidrocefalia mais utilizada em todo o mundo. Com o desenvolvimento das técnicas neuroendoscópicas para o tratamento da hidrocefalia obstrutiva, surgiu uma alternativa ao uso das válvulas. Este é o primeiro estudo realizado no Brasil comparando os custos do tratamento da hidrocefalia em um Hospital Público, numa tentativa de orientar a escolha do melhor uso do dinheiro público. Recursos Públicos limitados são um desafio para o tratamento adequado de várias patologias, incluindo a hidrocefalia.

Objetivo: Comparar os resultados e custos do tratamento cirúrgico da hidrocefalia com implante de válvula com a realização de terceiro ventriculostomia endoscópica em crianças.

Desenho: Coorte prospectiva

Sujeitos: Cento e três crianças portadoras de hidrocefalia que foram tratadas pela primeira vez no Hospital de Base do Distrito Federal nos anos de 20072008.

Medidas mais importantes dos resultados: Custos finais do tratamento por um ano desde a primeira cirurgia para tratar a hidrocefalia, incluindo novas internações por complicações.

Métodos: Foram estudadas 103 crianças com hidrocefalia, 52 tratadas com terceiro ventriculostomia endoscópica e 51 com derivação ventrículo peritoneal com interposição de válvula. As crianças foram acompanhadas prospectivamente por um ano desde a cirurgia. Foram 
comparados os custos do tratamento durante o tempo de acompanhamento, somando-se os custos por internações subsequentes.

Resultados: Vinte $(38,4 \%)$ das 52 crianças tratadas com derivação ventrículo-peritoneal necessitaram de outra cirurgia por disfunção da válvula, comparado a $11(21,5 \%)$ das 51 crianças do grupo tratado com cirurgia neuroendoscópica. Os custos médios dos pacientes no grupo tratado com implante de válvula foi de USD\$2.890,68 $\pm 2.835,02$ comparados ao custo médio de USD\$2.177,66 \pm 517,73 naquelas crianças tratadas com terceiro ventriculostomia endoscópica. Em relação ao resultado clínico, a resposta ao tratamento foi similar nos dois grupos, independente da técnica cirúrgica empregada.

Conclusão: No presente trabalho não houve diferença significativa de custos entre os grupos de crianças tratados com implante de válvula ou com neuroendoscopia. Da mesma maneira, não foram observados diferentes resultados clínicos independente do tratamento empregado. Entretanto, observou-se uma maior frequência de complicações naquelas crianças tratadas com derivação ventrículo peritoneal, resultando numa tendência a um custo maior do tratamento com o passar do tempo. Para confirmar essa tendência, torna-se necessário um estudo clínico com maior tempo de seguimento. 
ABSTRACT

Background: Surgical treatment of hydrocephalus is the most common in pediatric neurosurgery. Since the introduction of the valve implants in 1950, this has been the most used method of treatment of hydrocephalus worldwide. With the development of neuroendoscopic techniques for the treatment of obstructive hydrocephalus, there is an alternative to the use of valves. This is the first study conducted in Brazil comparing the treatment costs of hydrocephalus in a public hospital in an attempt to guide the choice of the use of public money. Public limited resources are a challenge for the proper treatment of many diseases, including hydrocephalus.

Objective: To compare the results and costs of surgical treatment of hydrocephalus with valve implantation versus the endoscopic third ventriculostomy in children.

Design: Prospective cohort study.

Subjects: One hundred and three children with hydrocephalus who were treated for the first time in the Hospital de Base do Distrito Federal in the years 20072008.

Most important outcome measures: Final costs of treatment for one year from the first hydrocephalus surgery, including new hospitalizations for complications.

Methods: We studied 103 children with hydrocephalus, 52 treated with endoscopic third ventriculostomy and 51 with ventricle peritoneal shunt with the use of valve. The children were followed prospectively for one 
year from surgery. The costs of treatment during follow-up were compared, adding the costs for subsequent hospitalizations.

Results: Twenty $(38.4 \%)$ of 52 children treated with ventricular shunt required another surgery for valve dysfunction, compared to $11(21.5 \%)$ of the 51 children in the group treated with endoscopic surgery. The average costs of patients in the group treated with valve implantation was USD $\$ 2890.68 \pm 2835.02$ compared to the average cost of USD \$ $2177.66 \pm 517.73$ in children treated with endoscopic third ventriculostomy. The clinical outcome and response to treatment was similar in both groups, regardless of the surgical technique.

Conclusion: In this study there was no significant difference in costs between groups of children treated with valve implant or with endoscopy. There was no difference in the clinical results with the two ways of treatment. However, there was a higher incidence of complications in the children treated with ventricular peritoneal shunt, showing a tendency towards higher costs of treatment over time. Further studies with long lasting follow up are needed to confirm this tendency. 
CAPÍTULO I - INTRODUÇÃO 


\subsection{Considerações iniciais}

Hidrocefalia é o aumento de volume de liquor dentro do crânio e geralmente é associada a dilatação do sistema ventricular. A hidrocefalia ocorre em todas as idades, mas é um problema extremamente frequente em unidades de neurocirurgia pediátrica, porque a maior frequência de hidrocefalia ocorre mesmo antes do nascimento. Pode também estar associada a várias condições pediátricas como tumores do sistema nervoso central, hemorragia ventricular da prematuridade, mielomeningocele e outros defeitos congênitos do sistema nervos central. $O$ tratamento da hidrocefalia tem evoluído com o passar do tempo, atualmente a forma mais comum de cirurgia para hidrocefalia é a derivação ventricular com interposição de uma válvula. Embora tal cirurgia salve vidas, é associada a grande número de complicações, a maioria devida a disfunção da válvula ou infecções. Tais complicações são mais comuns na população pediátrica que em adultos e entre as crianças são mais frequentes em neonatos. Nos últimos anos, passou-se a utilizar com mais e mais frequência a terceiro ventriculostomia endoscópica no tratamento das hidrocefalias obstrutivas.

E por que estudar custos de diferentes procedimentos para se tratar uma mesma doença? Os gastos no setor de saúde são cada vez maiores, decorrentes das inovações tecnológicas, do advento de novos procedimentos, do desenvolvimento de novos medicamentos, do aprimoramento no tratamento de doenças graves, associado a dificuldade em se obter dinheiro para financiamento do setor. As novas tecnologias quase sempre são 
associadas a aumento dos custos. Há poucos trabalhos associando os custos do tratamento da hidrocefalia com suas diferentes formas de tratamento.

Verifica-se hoje que tanto os usuários do sistema quanto os prestadores de serviços de saúde estão ávidos pela utilização de tecnologias e exames complementares que deixaram de ser complementares e passaram a ser essenciais ao diagnóstico e tratamento. Em termos de saúde pública, para se utilizar uma nova tecnologia ou ela deve ser superior à técnica usada anteriormente ou deve ter menores custos para melhor gestão dos já escassos recursos financeiros.

A avaliação dos custos de diferentes maneiras de se tratar uma mesma doença - no caso, a hidrocefalia - pode ajudar na decisão de como obter uma melhor eficiência na aplicação do dinheiro público. Recentemente o Ministério da Saúde, o Conselho Nacional de Secretários de Saúde e o Conselho Nacional de Secretarias Municipais de Saúde definiram que o desenvolvimento de metodologias, instrumentos e sistemas para a apuração de custos, que possibilitem estimar os recursos financeiros para o custeio global do Sistema Único de Saúde (SUS), é essencial ao aprimoramento da gestão. Nesse contesto insere-se o Programa Nacional de Gestão de Custos, um conjunto de ações que visão promover a gestão de custos, utilizadas como subsídio para a otimização do desempenho de atenção em saúde do SUS.

A preocupação com custos em saúde tem estado presente em praticamente todos os países do mundo, sem diferença entre ricos e pobres. Novas tecnologias devem se mostrar superiores às antigas ou terem menores custos. Tanto os profissionais de saúde 
quanto os gestores devem zelar pelos recursos necessários para um bom padrão de saúde para a população.

Ainda não existe hoje um estudo definitivo comparando os resultados da TVE com a DVP para esclarecer a situação e determinar o tratamento ideal da hidrocefalia na população em geral. A maioria dos neurocirurgiões pediátricos acredita que a TVE deva ser oferecida a todas as crianças com hidrocefalia obstrutiva. No mínimo, as famílias deveriam ter a chance de optar entre a TVE e a DVP, quando indicado.

É possível que pacientes operados com implante de válvula tenham um custo de tratamento maior pelo fato de serem submetidos a várias operações e internações. A TVE implica em um custo inicial maior para compra do equipamento. As complicações mais frequentes da DVP são disfunções da válvula e infecção. Quando há infecção da válvula, pode ocorrer prejuízo nas funções mentais do paciente. É possível que os pacientes tratados com TVE tenham melhor qualidade de vida em longo prazo quando comparado àqueles tratados com DVP.

\subsection{Histórico}

Nos primórdios da humanidade os processos de cura eram essencialmente empíricos. A medicina se desenvolveu em estreita relação com o aprendizado por observação de um lado e as crenças em magia de outro. Observando os povos primitivos atuais temos um retrato do passado mais remoto. A prática da magia se confundia com a religião e com a medicina. Provavelmente no dia 
que surgiu o primeiro mago, surgiu também o primeiro sacerdote e o primeiro médico (AGUIAR, 2003).

A China produziu os textos médicos mais antigos conhecidos. Fu-Hsi viveu nos meados do século 29 antes de Cristo e criou a filosofia fundamental do yang e do yin. Shen-Nung que por muitos é considerado o pai da medicina chinesa viveu em torno do ano 2.700 a.C. e escreveu uma obra classificando raízes e ervas que são usadas para tratamento de diferentes doenças até hoje. Mas os chineses não tinham conhecimento da anatomia pela proibição da dissecção de cadáveres. Se o corpo não se mantivesse íntegro não poderia ser recebido no reino dos mortos. Até hoje a tradicional medicina chinesa associa a hidrocefalia a disfunção dos rins e sugere tratamento com acupuntura e ervas.

A hidrocefalia é uma doença tão comum e tem manifestações clínicas tão evidentes em crianças que é provável que já começo da humanidade tenha sido observada e notado que geralmente tal problema leva à morte precoce. Achados patológicos em esqueletos datados desde o período de 2.500 a. C. já mencionam vários crânios hidrocefálicos (RICHARDS \& ANTON, 1981).

A hidrocefalia tem desafiado os médicos ao longo da história da medicina. Uma das maneiras mais interessantes de estudar a hidrocefalia é rever a história do tratamento dessa patologia, pois nela está documentado o desenvolvimento paralelo da medicina de uma maneira global. Na evolução do tratamento da hidrocefalia, fica patente como é importante a relação entre o conhecimento científico básico e o tratamento de uma determinada doença. Apesar de a hidrocefalia estar presente provavelmente desde 0 tempo da pré-história, acredita-se que Hipócrates, no século 5 a. C. 
tenha sido o primeiro médico a documentar o tratamento da hidrocefalia (DRAKE \& SAINTE-ROSE, 2005). Ele descreveu os sintomas associados à hidrocefalia, como cefaleia, vômitos, diplopia e baixa acuidade visual, explicando a doença como uma liquefação do cérebro causado por crises epilépticas (ASCHOFF et al., 1991). Naquela época, ele teria tentado o tratamento com a realização de punções ventriculares para aliviar a pressão intracraniana. Alguns acham que ele simplesmente realizou punções subdurais ou subaracnoideas, pois cunhou pela primeira vez o termo "hidrocefalia" imaginando que as coleções líquidas intracranianas eram extra-cerebrais, em vista do pouco conhecimento anatômico da época.

Galeno de Pérgamo, que viveu de 129-200 depois de Cristo, foi provavelmente o mais talentoso médico investigativo do período romano. Ele começou a escrever aos 13 anos de idade e tem uma extensa obra que corresponde a mais de $80 \%$ da literatura médica da antiguidade que sobreviveu até os tempos atuais. Suas teorias influenciaram a ciência médica da antiguidade por mais de um milênio. Ele seguia a escola hipocrática, baseando-se em dissecção anatômica em macacos pois a dissecção humana não era permitida na sua época. Galeno descreveu a hidrocefalia como um acúmulo de água extra-axial e não por alargamento dos ventrículos cerebrais (TORACK, 1981) seguindo os conceitos de Hipócrates, mas foi o primeiro a descrever o líquido céfalo raquiano (LCR) em detalhes, fazer a hipótese que seria produzido no plexo coroide e descrever o aqueduto cerebral. Ele descreveu o manto cortical fino na hidrocefalia e a comunicação entre os ventrículos, mas acreditava que a "alma" contida nessas estruturas passava por um processo de purificação e os resíduos eram depositados na 
glândula pituitária (FISHER, 1951). O tratamento da hidrocefalia sempre foi angustiante para os cirurgiões da antiguidade, pois os pacientes não sobreviviam ao tratamento. A obra de Galeno no mundo antigo ficou como um dogma e poucos avanços foram feitos até os trabalhos de Vesalius, já em 1500.

\subsubsection{Período Árabe e Bizantino}

Depois do período greco-romano, os centros intelectuais migraram para as culturas arábica e bizantina. A Europa foi governada por povos bárbaros e o avanço cultural ficou estagnado. A medicina do mundo árabe foi muito influenciada pelos escritos de Hipócrates e Galeno, ao invés de ser inovativa. O pai da cirurgia entre os muçulmanos, Albucasis (Abu Al-Qasin ou Al-Zahrawi), cirurgião que viveu de 936-1013, em seus tratados descreveu que a causa da hidrocefalia seria por compressão do crânio pela mãe. Pelo acúmulo de água os ossos do crânio não se fechavam e havia aumento diário do crânio. A recomendação era drenagem do LCR através de três aberturas no crânio, deixar o líquido fluir, depois suturar a incisão e fazer um curativo compressivo (EL KHAMLICHI, 1998). Albucasis descreveu esse método com uma riqueza tão grande de detalhes que provavelmente essa terapia era empregada na época. Mas o resultado era quase sempre a morte da criança. Apesar de quase todos os pacientes morrerem, Albucasis atribuía os resultados ruins não à cirurgia em si mas ao relaxamento do cérebro que levaria a paralisia. O Kitab al-Tasrif, ou O Método de Medicina, foi uma enciclopédia árabe em medicina e cirurgia, escrita perto do ano 1000 por Albucasis, que está disponível em tradução inglesa (ALBUCASIS, 1973) e também 
pode ser encontrado na Internet ${ }^{1}$. Ele chegou mesmo a desenvolver vários instrumentos cirúrgicos para realizar a drenagem liquórica, com abertura através da fontanela anterior (TURGUT, 2009). Albucasis também descreveu uma maneira de tratar clinicamente a hidrocefalia, comprimindo a cabeça com faixas e colocando a criança em uma dieta com restrição hídrica.

Anterior à Idade Média, tanto na medicina europeia quanto na oriental, o médico clínico era o que tinha maior cultura e ditava os métodos cirúrgicos para o cirurgião, geralmente de uma classe social inferior. Albucasis foi um clínico e um cirurgião e discutiu a questão porque os Árabes progrediram tão pouco em cirurgia. Ele atribuiu o pouco avanço cirúrgico à falta de um maior estudo anatômico, que seria a chave de uma cirurgia bem sucedida. Revendo o período bizantino e medieval, encontramos uma era de pouca inovação, baseada nos conceitos antigos de Hipócrates e Galeno. Um proeminente cirurgião do século XV, Leonardo de Bertapalia (1380?-1460), escreveu que uma das regras para o bom cirurgião seria "ser corajoso quando operando e cortando, mas tímido ao cortar na proximidade de nervos, tendões e artérias, e, de modo a não cometer erros, deveria estudar anatomia, que é a mãe dessa arte de realizar a cirurgia de forma inteligente e nunca operar a carne humana como se estivesse trabalhando em madeira ou couro". Mas os estudos anatômicos da época eram restritos as dissecações em animais ou releitura dos escritos de Galeno.

1 http://en.wikipedia.org/wiki/Al-Tasrif 


\subsubsection{Renascimento}

Novos avanços anatômicos só chegaram com a Renascença, quando dissecção de cadáveres humanos foram tolerados, além do advento da imprensa para divulgar melhor os novos conhecimentos. Mais do que isso, foi de fundamental importância o fim da subserviência aos conceitos da antiguidade, muitos deles errados. A primeira ilustração do sistema ventricular só foi publicada em 1510 por Leonardo da Vinci (GJERRIS \& SNORRASON, 1992), que também fez um modelo em cera dos ventrículos cerebrais, derramando cera líquida dentro dos ventrículos de um cérebro humano com um tubo para permitir a saída do ar. Leonardo da Vinci não era um cirurgião, mas estudou profundamente a anatomia para compreender melhor as relações da anatomia com arte e escultura. Ele ilustrou o aqueduto cerebral, que seria descrito em 1515 por Jacobus Sylvius (DE LANGE, 1977 ) na literatura médica.

Um dos grandes nomes da anatomia e cirurgia foi Andreas Vesalius (1514-1564), que fez uma das mais inovativas visões da dissecção anatômica. Ele argumentava que tais dissecções deveriam ser feitas sempre pelo professor e não por um patologista ignorante que seguia os conceitos de Galeno sobre anatomia. Vesalius foi nomeado professor de anatomia na Universidade de Pádua com 23 anos de idade e aos 28 anos publicou sua obra prima, De Humani Corporis Fabrica que recentemente foi traduzida para o inglês (VESALIUS, 2014). Na segunda edição de sua obra mestra, em 1555, Vesalius descreve o caso de uma criança com hidrocefalia: "Observei em Augsburg uma menina de dois anos de idade, cuja cabeça tinha crescido em sete meses a um tamanho 
que não foi superada em volume por nenhuma cabeça de qualquer homem que eu já tenha visto. Essa doença é a que os antigos chamaram de hidrocefalia, a partir da água que é coletada e armazenada gradualmente na cabeça. No caso dessa menina, no entanto, á água não tinha sido coletada entre o crânio e o seu exterior, membrana circundante ou pele, onde os livros médicos ensinam que á água é depositada, mas no ventrículo direito e esquerdo da cavidade cerebral. A amplitude dessas cavidades tinha aumentado tanto e o próprio cérebro estava tão distendido que eles continham cerca de nove libras de água, ou três medidas de vinho de Augsburg (cerca de 4,3 litros), que Deus me ajude." (TORAK, 1982). Vesalius notou que o manto cortical estava bem fino e que mesmo a calota do crânio estava adelgaçado. Mas em contraste com a calota, a base do crânio estava no seu estado natural, bem como o cerebelo e os nervos cranianos. Pela primeira vez, contrariando a interpretação de Hipócrates e Galeno, que persistiu como verdade científica por cerca de 2.000 anos, Vesalius descreveu que não encontrou água em outro local que não fosse dentro dos ventrículos cerebrais (RAIMONDI, 1987). Vesalius examinou a criança enquanto ela ainda estava viva, ficando surpreso ao observar que a menina usava todos os seus sentidos, apesar do grande volume da água distendendo o cérebro. 0 exame cuidadoso da ilustração do caso mostra pequenos querubins fazendo trepanações, mas Vesalius não descreveu um tratamento cirúrgico para a hidrocefalia (GOODRICH \& FLAMM, 2011). 


\subsubsection{Idade Moderna e Contemporânea}

Thomas Willis (1621-1675) acreditava que os ventrículos eram espaços que recebiam excreções do cérebro e postulou que tal qual a circulação sanguínea, o LCR deveria drenar dentro do sistema venoso (ASCHOFF, 1999). Ele foi um dos primeiros a sugerir que os plexos coroides produziam o líquido céfalo raquiano, contra um dos maiores paradigmas da época, que os ventrículos continham vapor durante a vida e que se condensava após a morte (LIFSHUTZ \& HOHNSON, 2001).

Pacchioni (1665-1726) foi o primeiro a descrever as granulações aracnoideas, sugerindo que elas seriam o local da secreção do LCR. A função de absorção do LCR pelas granulações de Pacchioni foram descobertas por Fantoni em 1738, após a morte de Pacchioni.

Em 1769 Giovanni Battista Morgagni (1682-1771) publicou achados de necropsia de pacientes com hidrocefalia, incluindo a associação a hérnia de amígdalas cerebelares e hidromielia. Albrecht von Haller (1708-1777) descobriu os foramina de Luschka e apresentou a teoria moderna de circulação liquórica, embora sem comprovação científica (TORAK, 1982).

François Magendie (1783-1855) descreveu com detalhes a abertura medial do IV ventrículo já descrita por Galeno, mas que tinha passado despercebida por Vesalius, Willis e outros. Ele propôs uma teoria reversa da circulação cerebral, sugerindo que o LCR era produzido na superfície cerebral, entrava no sistema ventricular pelo forâmen de Magendie e era absorvido pelos plexos coroides. Sugeriu que obstrução dos orifícios do IV ventrículo 
poderiam causar hidrocefalia. Ele foi o primeiro a medir a pressão liquórica, realizando uma punção suboccipital em um cachorro.

A teoria moderna da circulação liquórica só foi proposta em 1875 por Ernst Axel Hendrik Key (1832-1901) e Magnus Gustav Retzius (1842-1919), demonstrando de maneira científica que o LCR era secretado pelos plexos coroides, saía do sistema ventricular pelos foramina de Luschka e Magendie, sendo absorvido pelas vilosidades aracnoides e granulações de Pacchioni, num estudo que até hoje permanece válido (KEY \& RETZIUS, 1875).

Quincke foi o primeiro a medir a pressão intracraniana com um manômetro de água em 1891, tanto por punção ventricular quanto lombar. Walter Dandy e Kenneth Blackfan criaram o primeiro modelo animal de hidrocefalia em 1913, bloqueando o aqueduto em cães com pequenos tufos de algodão (DANDY \& BLACKFAN, 1929).

Pelo pouco conhecimento da fisiopatologia da hidrocefalia, as tentativas de tratamentos resultavam em fracasso na maioria das vezes. O conhecimento sobre anatomia e fisiologia dos ventrículos e do líquido céfalo raquiano avançou muito no século XIX. Apenas quando o conhecimento que a causa da hidrocefalia era um distúrbio hidráulico da circulação liquórica cerebral, sob o ponto de vista teórico, o tratamento poderia ser feito pela redução da produção do LCR pelos plexos coroides (remoção cirúrgica, farmacológica ou radioterápica), reabertura das vias liquóricas bloqueadas (desvio do fluxo liquórico ou remoção cirúrgica da causa da obstrução) ou aumentando a capacidade de absorção do LCR (derivando o LCR para outras cavidades corporais onde possa ser absorvido). 
Novas informações sobre a fisiopatologia da hidrocefalia foram adquirida durante o século $\mathrm{XX}$, com o conhecimento das taxas de produção e absorção liquórica, além da formação de LCR extra coroide, o aumento da permeabilidade periventricular na hidrocefalia hipertensiva (MILHORAT et al., 1970), fato que mais tarde foi demonstrado nos exames de neuroimagem de pacientes com hidrocefalia hipertensiva não tratada.

\subsubsection{História do tratamento clínico da hidrocefalia}

Entre os tratamentos clínicos para a hidrocefalia, provavelmente o mais antigo foi a compressão craniana por faixas para reduzir o crânio de lactentes. Essa técnica foi abandonada por sua ineficácia e risco de aumentar a pressão intracraniana no início do século XX. Entretanto mesmo na era moderna ainda se tentou tratar a hidrocefalia neonatal com compressão cerebral (EPSTEIN et al., 1973). Tal procedimento, mesmo com auxílio de registro telemétrico da pressão intracraniana (EPSTEIN et al., 1974), demonstrou que poderia ser controlada a macrocefalia às custas de uma lesão cerebral permanente e foi abandonado.

Publicações dos séculos XVIII e XIX recomendavam dietas com restrição hídrica, diuréticos e laxativos. Até injeções intraventriculares de iodo foram propostas. Nenhuma dessas formas de tratamento clínico se mostrou eficaz (HENLE, 1986).

Em 1954 Tschirgi mostrou que acetazolamida reduzia a produção de LCR em animais de experimentação. Essa droga passou a ser utilizada em 1957 e até hoje é uma forma de tratamento adjuvante da hidrocefalia (DE LANGE, 1977). A radioterapia foi usada em 1952 para irradiar os plexos coroides e 
reduzir a produção de LCR, mas foi abandonada pelos efeitos adversos no sistema nervoso central.

\subsubsection{Tratamento cirúrgico da hidrocefalia nos tempos modernos}

PUNÇÃO VENTRICULAR. Considerando que na antiguidade as cirurgias para hidrocefalia eram baseadas no conceito equivocado que o problema era causado por uma coleção extra cerebral de líquido, a primeira punção ventricular documentada foi realizada em 1744 por Le Cat (HEYNES, 1913). Depois de realizar a punção, ele deixou um dreno por algum tempo, podendo ser considerado como o primeiro caso documentado de derivação ventricular externa. Infelizmente, quase todos os casos publicados nos séculos XVIII e XIX de tratamento da hidrocefalia com uso de punção ventricular causaram a morte do paciente, exceto um publicado por Fantoni em 1769, que foi relatado como ter produzido a cura do paciente.

A história da punção ventricular sob condições assépticas começa com Wernicke que puncionou o trígono ventricular com um trocar usando um acesso lateral em 1881 (WERNICKE, 1881). A punção coronal descrita por Kocher e a punção occipital descrita por Krause e Dandy são as mais comumente utilizadas atualmente.

No começo do século $X X$, vários trabalhos sobre punção ventricular no tratamento da hidrocefalia foram publicados. Apesar de algumas vezes ter sido relatado benefício terapêutico, havia complicações severas, geralmente por infecção. Após evolução técnica com a introdução de agulhas com mandril e atraumáticas como descritas por Krause, Dandy e Cushing, a punção ventricular 
se tornou um procedimento seguro e praticado em várias regiões do mundo. Com a introdução da ventriculografia gasosa por Dandy em 1918, que teve a ideia de usar gás como método diagnóstico após observar um paciente com pneumoencéfalo traumático, a punção ventricular tornou-se 0 procedimento padrão para diagnóstico de dilatação ventricular com uso da pneumoencefalografia (DANDY, 1918), até ser substituída pela tomografia computadorizada nos anos 1980.

DERIVAÇÃO VENTRICULAR EXTERNA (DVE). Wernicke algumas vezes deixou uma cânula ventricular para permitir a drenagem externa, método que foi seguido por vários outros cirurgiões. O aparato usado para drenagem ventricular incluía agulhas metálicas, tubos de borracha e guta percha, além de pavios feitos de categute, seda ou crina de cavalo. Em 1902, Oppenheim alertava que o procedimento de punção ventricular seguido de drenagem como recomendado por Wernicke, von Bergmann, Keen, Kocher, Broca, Robsen e Watson-Cheyne era extremamente perigoso, relatando que 20 de 23 pacientes morreram após tal procedimento (OPPENHEIM, 1928).

Krause em 1911 conseguiu drenar externamente ventrículos dilatados por um período de até 8 semanas sem infecção liquórica, em casos de cirurgia da fossa posterior. O desenvolvimento de cateteres simples em um sistema de drenagem fechado regulado por pressão foi feito por Ingraham em 1941 (INGRAHAM \& CAMPELL, 1941), conceito que vem sendo usado até hoje, principalmente na medicina intensiva neurocirúrgica. Os sistemas de drenagem ventricular externa disponível para uso atualmente seguem a ideia de um circuito fechado regulado por pressão. 
Os conjuntos de drenagem ventricular externa atualmente são facilmente encontrados na indústria de produtos médicos, permitindo drenagem contínua e externa do LCR, registro da pressão intracraniana, colheita de LCR ventricular para exames, injeção intraventricular de medicamentos, sejam antibióticos, quimioterápicos ou trombolíticos, além de poder ser usado raramente para ventriculografia com contraste positivo ou uso de radioisótopos para diagnóstico de fístulas liquóricas. São extremamente úteis como maneira de drenar o LCR em caso de derivações ventriculares internas infectadas. Atualmente há mesmo sistemas de DVE implantadas por neuronavegação, simuladores de realidade virtual para implante de DVE por residentes e cateteres impregnados de antibióticos (SRINIVASAN et al. 2014).

DRENAGEM LOMBAR CONTÍNUA. Em 1873, Paget realizou uma laminectomia cervical e criou uma fístula externa para drenar LCR, mas tal tratamento não funcionou. A drenagem lombar externa como conhecemos atualmente foi descrita por Vour'ch em 1963 e continua a ter novos desenvolvimentos tecnológicos, podendo ser usada como parte do arsenal terapêutico seja temporário ou permanente (NANIDIS, 2014). No caso de drenagem lombar permanente, geralmente é realizado uma derivação lomboperitoneal com interposição de válvula. É útil em algumas patologias neurológicas, como nos casos de pseudo tumor cerebral.

PUNÇÃO LOMBAR. A primeira punção lombar foi realizada por Corning em 1885 para injeção intratecal de medicamentos. O desenvolvimento da punção lombar veio com Quincke em 1891 que passou a realizar o procedimento de maneira sistemática. $O$ uso inicial foi terapêutico, para o tratamento da hidrocefalia, com 
uma sequência de punções, com benefício temporário. Em 1896 Fleischmann publicou uma série grande de casos de punções lombares com um número significativo de mortes logo após a realização da punção. Ele realizava punções em pacientes com tumores cerebrais e outras patologias, incluindo hidrocefalia. Um terço dos pacientes morreu no primeiro dia após a punção, alguns mesmo durante a realização do procedimento. Os casos foram documentados com autópsias que demonstraram a presença de hérnias cerebrais. A diferença entre hidrocefalia comunicante e não comunicante não podia ser feita naquela época porque não havia ainda a pneumoencefalografia ou outros métodos de neuroimagem. Assim, o uso da punção lombar como terapia para a hidrocefalia carregava o risco de herniação e morte.

RESERVATÓRIO DE LCR SUBCUTÂNEO. Ommaya introduziu essa técnica em 1963, inicialmente para quimioterapia intratecal, depois para alívio temporário da hidrocefalia, como é conduta aceita nos casos de hemorragia ventricular do pré-maturo (MARLIN, 1980).

DERIVAÇÃO VENTRÍCULO-SUBGALEAL. A primeira descrição desse tipo de derivação foi feita por Mikulicz, que em 1893 implantou um pavio de lã de vidro desde o ventrículo lateral de um lactente de seis meses de idade até o espaço subgaleal (HENLE, 1896). Essa foi a primeira derivação ventricular documentada da história da medicina. O perímetro cefálico da criança ficou sensivelmente menor no período pós operatório e se manteve assim por um ano. Dois anos após, em 1985, Mikulicz fez uma nova derivação ventrículo subgaleal usando um tubo de ouro de $3 \mathrm{~mm}$ de espessura em um segundo paciente, mas o paciente 
desenvolveu um abscesso cerebral e morreu dois meses após a operação.

Nos dias atuais a derivação ventrículo-subgaleal continua a ser utilizada para controle temporário da hidrocefalia, quando a derivação ventrículo peritoneal não está indicada seja porque o peritônio não tem condições de receber um cateter de válvula de hidrocefalia, como acontece nos bebês prematuros, ou quando o LCR tem aumento de proteínas, sangue ou celularidade, como acontece nas hidrocefalias pós hemorrágicas ou pós infecciosas (FULMER et al., 2000).

DERIVAÇÃO VENTRÍCULO-SUBARACNOIDE. Em 1908 Payr implantou a primeira derivação ventrículo-subaracnoide com sucesso. Ele usou uma artéria bovina fixada em formalina para derivar do ventrículo lateral à fissura inter-hemisférica em um paciente de 16 anos. Conforme sua descrição, essa derivação funcionou perfeitamente por 11 anos (PAYR, 1919). Depois dele, vários outros usaram diferentes materiais para realizar a mesma derivação, com tubos de vidro, cobre, prata, metal, guta-percha, látex, além de pavios de seda, prata trançada ou categute (HAYNES, 1913; HEILE, 1914; KRAUSE, 1911; PUDENZ, 1981; VOUR'CH, 1963).

A partir de 1953 Lazorthes usou um cateter para realizar a ventrículo cisternostomia transcalosa em 50 casos, comunicando o ventrículo lateral com o espaço subaracnóideo através da porção anterior do corpo caloso (LAZORTHES et al., 1957). Na mesma época Kluzer propôs realizar a derivação ventrículo cisternal usando a porção posterior do corpo caloso (JONES, 1967). Outros tentaram na década de 50 derivar o ventrículo para a cisterna 
supra quiasmática, hipotálamo e até mesmo para o espaço subdural (FORREST et al, 1957).

AQUEDUTOPLASTIA. Dandy em 1920 realizou a recanalização retrógrada do aqueduto, usando um cateter introduzido a partir do IV ventrículo (DANDY, 1920). Quase 30 anos após Leksell sugeriu utilizar a técnica de Seldinger para passar um cateter do IV ao III ventrículo via aqueduto, ajudado também por estereotaxia (LEKSELL, 1949). Atualmente as técnicas de aquedutoplastia são realizadas geralmente por via endoscópica e principalmente para casos clínicos de IV ventrículo isolado, deixando-se um stent de silástico comunicando o IV ventrículo ao III ventrículo (OGIWARA \& MOROTA, 2013). Tal procedimento pode ser realizado tanto anteriormente quanto posteriormente ao aqueduto.

VENTRÍCULO-CISTERNOSTOMIA. Também conhecido como derivação de Torkildsen, que em 1938 realizou a derivação do corno occipital do ventrículo lateral para a cisterna magna, usando um cateter simples, sem válvula (TORKILDSEN, 1939). O procedimento de Torkildsen funcionou em muitos casos, tornandose uma maneira muito utilizada de tratar a hidrocefalia obstrutiva até os anos 1970.

TERCEIRO VENTRICULOSTOMIA. Em 1908 foi descrita uma técnica de tratamento da hidrocefalia abrindo-se uma passagem pelo corpo caloso, comunicando o terceiro ventrículo com a fissura interhemisférica, sem uso de cateteres ou válvulas (ANTON \& BRAMANN, 1908). O procedimento, que na verdade era uma punção do corpo caloso com um perfurador especial, teve resultados ruins. Em 1922 Dandy abriu o assoalho do III ventrículo numa cirurgia que requeria à época o sacrifício de um dos nervos 
ópticos (DANDY, 1922). Mixter em 1923 introduziu um endoscópio na cavidade ventricular e perfurou o assoalho do III ventrículo (MIXTER, 1923). Entretanto, ele só realizou esse procedimento em um único paciente. Scarff e Stookey em 1936 desenvolveram a técnica de fenestrar a lamina terminalis, realizando uma ventriculostomia anterior através do acesso subfrontal, ganhando acesso ao interior do III ventrículo e completando a cirurgia com perfuração do assoalho do III ventrículo, comunicando-o com a cisterna interpeduncular (SCARFF, 1963).

Várias variações da terceiro ventriculostomia foram descritas, incluindo abertura para a cisterna ambiens lateralmente (HYNDMAN, 1946), ou através de acesso transcaloso. Com o advento das técnicas microcirúrgicas nos anos 1970, há proposições que em casos especiais se faça a terceiro ventriculostomia com abertura da lâmina terminalis, como por exemplo durante a microcirurgia para aplicar um clip em aneurismas intracranianos (LEHTO et al., 2009) associado a hemorragia ventricular importante.

Todas essas formas de realizar a terceiro ventriculostomia foram substituídas por um acesso através de uma trepanação na região coronal (MCNICKLE, 1947), com acesso através do forâmen de Monro até o assoalho do III ventrículo, que passou a ser aberto resultando numa comunicação com a cisterna pré pontina. Houve um refinamento técnico com uso de radioscopia com intensificador de imagem, estereotaxia e finalmente com a neuroendoscopia (FUKUSHIMA et al., 1973). O grande desenvolvimento tecnológico com novos sistemas ópticos para os endoscópios, câmeras, iluminação propiciaram um grande aumento nessa técnica a partir do final dos anos 1980. 
TERCEIRO VENTRICULOSTOMIA ENDOSCÓPICA. No tratamento da hidrocefalia, o endoscópio foi utilizado inicialmente por Lespinasse em 1910. Ele usou um cistoscópio para coagular o plexo coroide em duas crianças com hidrocefalia. Dandy, 12 anos após, utilizou-se de um ventriculoscópio e realizou a primeira terceiro ventriculostomia endoscópica (TVE). Nos anos que se seguiram, muitos neurocirurgiões tentaram utilizar a endoscopia no tratamento da hidrocefalia, mas se defrontaram com um alto índice de mortalidade e morbidade e não houve muito desenvolvimento da técnica. $\mathrm{Na}$ ocasião, a pouca iluminação e magnificação tornavam o procedimento muito difícil e arriscado (ENCHEV \& OI, 2008).

Apenas no final dos anos 1980, com melhor tecnologia óptica e de iluminação, houve um retorno ao uso da neuroendoscopia, que passa a integrar o arsenal neurocirúrgico não só para o tratamento da hidrocefalia, mas também de outras patologias neurocirúrgicas (PETTORINI \& TAMBURRINI, 2007). Atualmente a TVE é o procedimento neuroendoscópico mais comum no tratamento da hidrocefalia. Trata-se de uma derivação interna que tem particular utilização nos casos de hidrocefalia obstrutiva (Fig. 1).

As técnicas neuroendoscópicas, realizadas principalmente para a terceiro ventriculostomia, se expandiram para o tratamento de formas complexas de hidrocefalia com a realização de septostomias em caso de ventrículos septados e mesmo a aquedutoplastia, além do uso em cistos intracranianos e tumores intraventriculares. 


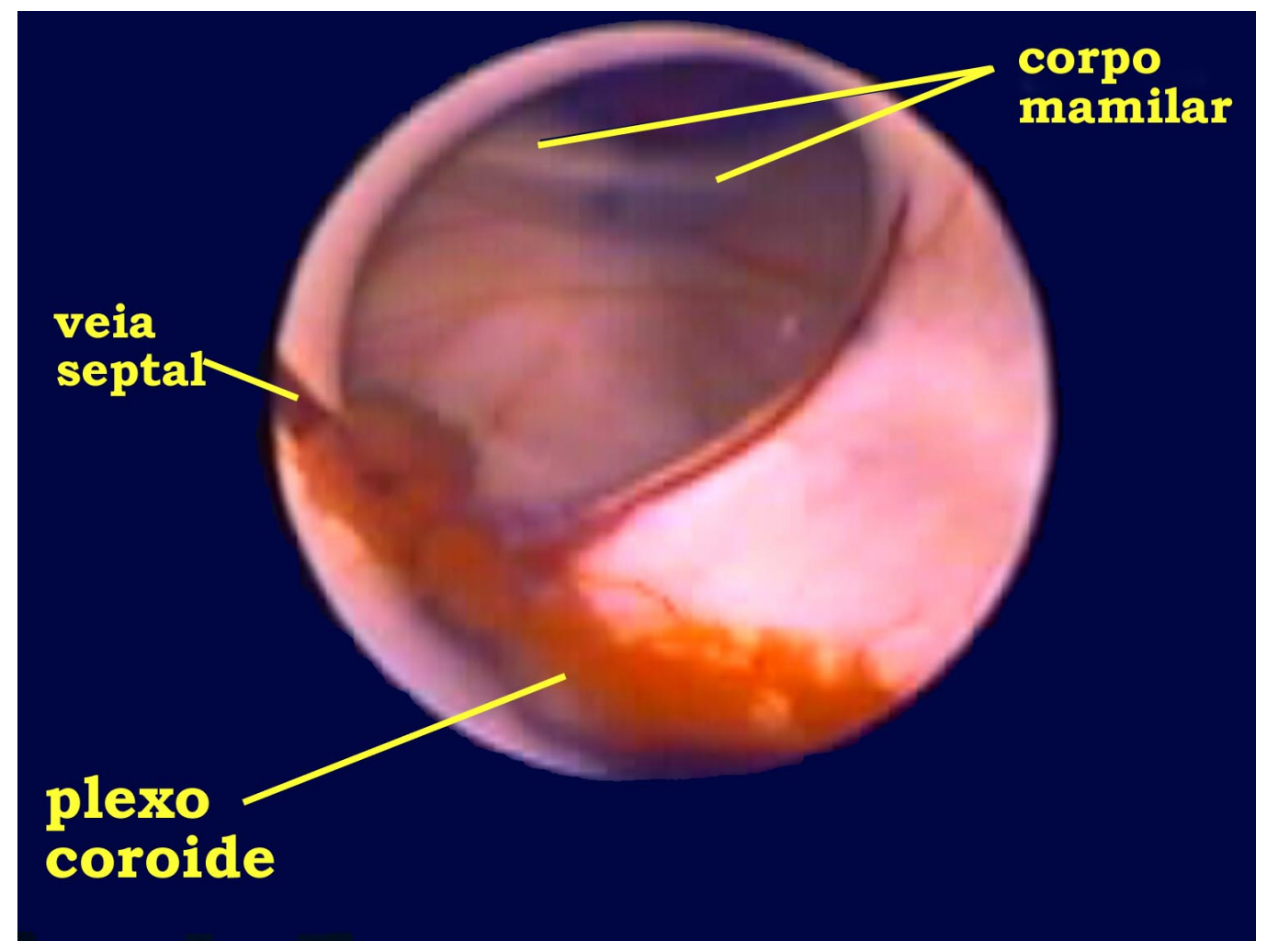

Figura 1 - Visão através do neuroendoscópio introduzido no ventrículo lateral direito, com os pontos de referência anatômica para se chegar ao assoalho do III ventrículo: plexo coroide, veia septal, coluna do fórnix. 
Hoje, devido ao progresso da neuroendoscopia, é o tratamento de primeira escolha nos casos de hidrocefalia obstrutiva em adultos e crianças maiores de dois anos de idade na maior parte dos Centros que dispõem desse método. O procedimento pode ser realizado também em lactentes com hidrocefalia obstrutiva, mas há uma menor taxa de sucesso.

DESTRUIÇÃO DO PLEXO COROIDE. Lespinasse, um cirurgião de Chicago que realizava cirurgia urológicas e tinha experiência em cistoscopia, descreveu a destruição do plexo coroide utilizando-se a ventriculoscopia em 1913 durante uma de suas conferências. Infelizmente não houve publicação desse trabalho pioneiro. Dandy foi o primeiro a publicar a técnica de ablação e remoção dos plexos coroides para reduzir a produção de LCR e tratar a hidrocefalia (DANDY, 1918). Ele fez craniotomia aberta para ressecar os plexos coroides de quatro pacientes depois de trabalho experimental em cães. Ele publicou que três pacientes faleceram e um ficou curado da hidrocefalia.

Em 1934 Putnam publicou uma série de casos onde realizou a coagulação de plexos coroides utilizando o endoscópio, com uma taxa de mortalidade de 25\% (PUTNAM, 1934). Nos anos que se seguiram, houve uma redução sensível na taxa de mortalidade. Scarff publicou uma mortalidade de 5\% em 1970 (SCARFF, 1970). Com o passar dos anos, esse tipo de tratamento foi sendo paulatinamente abandonado porque dois terços dos pacientes tratados com coagulação do plexo coroide necessitam de derivação ventricular com o passar do tempo (POPLE \& GRIFFITH, 1993).

Nos últimos anos a coagulação endoscópica ou microcirúrgica dos plexos coroides voltou a ser realizada com 
sucesso, inicialmente em pacientes portadores de hidranencefalia (SHITSAMA et al., 2014), depois passou a ser realizada também, com uso de endoscópio flexível, complementando a terceiro ventriculostomia endoscópica, com resultados mais favoráveis que a realização somente da abertura do assoalho do III ventrículo (STONE \& WARF, 2014).

DERIVAÇÃO LIQUÓRICA PARA COMPARTIMENTOS CORPORAIS DE BAIXA PRESSÃO. A partir de 1920 os autores passaram a descrever vários espaços corporais como sítio para drenagem ventricular. Dentre esses locais, foi tentado a gordura retro-orbital, a fossa infra temporal, o espaço subgaleal, os seios aéreos das mastoides, a gordura bucal de Bichat (entre o bucinador e o masseter), o duto parotídeo, a cavidade pleural, o duto torácico, o ureter após nefrectomia, a trompa de Falópio, a vesícula biliar, o espaço peridural raquiano e até mesmo a porção esponjosa do corpo das vértebras lombares. Até derivações para o sistema gastrointestinal já foi usado, sem muito sucesso. A maioria desses procedimentos tem apenas interesse histórico pelo baixo índice de sucesso e alto índice de complicações. Algumas dessas técnicas ainda são utilizadas, como a derivação ventrículo-vesícula biliar em casos onde o peritônio não está apto a receber uma derivação ventricular ou quando o LCR tem alto teor de proteínas (GIROTTI, 2009). É peculiar a observação de Matson, que é considerado por muitos como o pai da neurocirurgia pediátrica, advogando a favor do uso da derivação ventrículo ureteral com nefrectomia, que a criança com hidrocefalia tem "dois bons rins, dois pais inteligentes, um pediatra experiente que está sempre disponível e um bom hospital nas proximidades" (MATSON, 1951). 


\section{DERIVAÇÃO LIQUÓRICA PARA SEIOS VENOSOS} INTRACRANIANOS. Em 1907 Payr fez uma derivação ventrículo venosa para o seio sagital superior em uma menina de 9 anos de idade (PAYR, 1908). Ele usou um segmento da veia safena para fazer a derivação e a criança teria melhorado. Ele tentou uma segunda derivação ventrículo venosa no ventrículo contralateral, mas houve complicações com formação de fístula liquórica e a criança faleceu por meningite 7 meses após a operação. A necropsia revelou que ambas as veias estavam patentes, e que 0 sangue não entrou nas cavidades ventriculares. Depois de mais dois casos com óbitos, Payr modificou sua técnica, passando a realizar derivações ventrículo venosas para a veia jugular ou realizar derivação ventrículo subaracnoide. Essa técnica foi revisitada nos anos seguintes sem sucesso pelas altas taxas de trombose. Nos últimos anos voltou a ser utilizada com resultados similares às demais derivações ventriculares (EL SHAFEI \& EL SHAFEl, 2005). Nesses casos, foi descrito que as manifestações de hipertensão intracraniana desaparecem, mas os ventrículos se mantém alargados.

DERIVAÇÃO LIQUÓRICA PARA A CAVIDADE PERITONEAL. Essa ideia foi utilizada inicialmente por Ferguson em 1898, que ressecou uma parte da quinta lâmina lombar, fez um orifício no corpo da vértebra para dentro da cavidade peritoneal, e comunicou o espaço subaracnóideo lombar com a cavidade peritoneal usando um arame de prata (FERGUSON, 1898). Tal procedimento foi realizado por outros autores, incluindo Cushing em 1905, que utilizava uma cânula de prata. Os resultados, entretanto, foram desapontadores. 
Kausch utilizou um tubo de látex para fazer uma derivação ventrículo peritoneal (DVP) em 1905, mas o paciente sobreviveu apenas algumas horas (KAUSCH, 1908). A necropsia mostrou que o manto cortical desse paciente tinha apenas $3 \mathrm{~mm}$ de espessura. Hartwell em 1910 empregou fios de prata como um pavio para realizar uma DVP e a criança sobreviveu por dois anos após a cirurgia. A necropsia demonstrou que houve formação de fibrose ao redor dos fios de prata (DAVIDSON, 1976). Provavelmente foi Abbé o primeiro cirurgião a realizar uma DVP, embora não tenha publicado seus casos. A experiência com a realização da DVP foi frustrante até os anos 1950, quando foi introduzido o uso de silástico na confecção dos dispositivos de drenagem liquórica e a interposição de válvula, pois até então as derivações eram realizadas sem válvula e com materiais diversos. A partir daí, a DVP ganhou rapidamente mais e mais adeptos, passando a ser a forma mais comum de tratamento da hidrocefalia em todo o mundo.

DERIVAÇÃO LIQUÓRICA COM VÁLVULA. Nos anos 1950 surgiram as primeiras válvulas unidirecionais, com um sistema antirefluxo. Em 1949 Nulsen construiu uma válvula com uma esfera dentro de um cone com uma mola helicoidal, acoplada a uma câmara de látex para bombeamento entre elas (NULSEN \& SPITZ, 1952) que foi implantada pela primeira vez em maio de 1949 por Spitz no Hospital da Criança da Filadélfia, usando um cateter de polietileno para derivar o LCR até a veia cava superior. Essa criança foi seguida por dois anos e meio confirmando a eficácia do sistema. Em 1955 Pudenz implantou uma válvula de teflon com fendas distais numa criança, realizando uma derivação ventrículo atrial (DVA) que funcionou por dois anos (PUDENZ et al., 1957). 
A revolução na tecnologia das válvulas para hidrocefalia surgiu com Holter, um técnico cujo filho nasceu com hidrocefalia associada a mielomeningocele. Nulsen e Spitz já haviam demonstrado que a derivação ventrículo atrial poderia funcionar, mas precisavam de um sistema de derivação unidirecional mais prático. Em poucas semanas Holter projetou e construiu uma válvula de fenda de silástico (silicone elástico) que foi implantada por Spitz em março de 1956. Essa válvula mostrou-se tão eficaz que sua produção em série começou no mesmo ano e até hoje a fabricação da maioria das modernas válvulas para hidrocefalia segue basicamente o mesmo conceito: válvula anti-refluxo, por diferencial de pressão, feitas de silástico (BOOCKVAR, LOUDON \& SUTTON, 2001). Holter fundou uma companhia, Holter-Hausner International, para fabricação de válvulas para hidrocefalia. Embora não tenha conseguido salvar seu filho, a válvula projetada por Holter continua a ser usada com sucesso em várias partes do mundo.

Além da válvula de fenda de silástico, válvulas de fenda distal, válvulas com diafragma de silástico e válvulas com esferas e molas surgiram na mesma época, usando sempre o silástico como - material para sua construção. O silástico mostrou-se biocompatível, resistente a trauma mecânico, sendo o elemento ideal para a tecnologia de construção das válvulas para hidrocefalia. O silástico é o grande responsável pelo fato de o implante de válvulas para hidrocefalia tornar-se o procedimento padrão para o tratamento desse problema a partir dos anos 1950.

Desde a introdução do silástico nos anos 1950 um número grande de válvulas tornou-se disponível no mercado. A maioria 
delas opera por diferença de pressão utilizando-se de esfera e mola, diafragma, fenda proximal ou fenda distal.

A segunda geração de válvulas foi projetada para tentar evitar o problema da hiperdrenagem liquórica quando o paciente fica em posição ortostática: válvulas auto reguláveis ou reguladas pelo fluxo, sistema anti-sifão, válvulas "gravitacionais" e válvulas ajustáveis.

Apesar do avanço da neuroendoscopia, hoje em dia as válvulas ainda constituem a forma de tratamento mais usada na hidrocefalia, embora carreguem ainda risco de complicações, principalmente infecção e disfunção do sistema (hipodrenagem, hiperdrenagem ou obstrução).

TRATAMENTO ANTE-NATAL. Com o desenvolvimento dos exames de imagem pré natais, o diagnóstico da hidrocefalia ainda intra útero desencadeou várias tentativas de tratamento com cirurgia fetal. A ideia foi que o tratamento precoce poderia prevenir a progressão da hidrocefalia. Vários procedimentos como derivações ventrículo amnióticas e cefalocenteses foram realizadas para tratar a ventriculomegalia (SUTTON et al., 2001). As altas taxas de mortalidade e morbidade mostraram que os resultados eram piores do que quando o tratamento da hidrocefalia era realizado após o nascimento da criança. Atualmente as derivações ventriculares internas são realizadas apenas em caso de pesquisa clinica. Cefalocenteses eventualmente são realizadas em casos de grandes macrocefalias para permitir o parto da criança, seja cesariano ou transvaginal.

O campo do tratamento cirúrgico da hidrocefalia ainda não está encerrado. Nós devemos os grandes avanços atuais aos grandes pesquisadores da história, cujos estudos permitiram 0 
desenvolvimento da neurocirurgia. Novos avanços para deter a hidrocefalia ainda estão por surgir, seja no campo da genética, de novas tecnologias ou novos procedimentos cirúrgicos.

\subsection{Epidemiologia da hidrocefalia}

A frequência exata da hidrocefalia não é conhecida, pois geralmente é secundária a um outro problema como infecção, trauma, prematuridade, tumor intracraniano ou malformação congênita. As taxas descritas em recém nascido variam de 0,3 a 4 casos por 1.000 nascidos vivos. Quando ocorre isoladamente, a incidência de hidrocefalia publicada vai de 0,9 a 1,5 por 1.000 nascidos vivos (FERNELL \& HAGBERG, 1998). Essa frequência já foi descrita como tão alta quanto 3,1:1.000 nascidos vivos (MELO et al., 2013). Esses números refletem apenas os casos de hidrocefalia congênita. A hidrocefalia pode ser adquirida por várias causas, incluindo tumores, traumas, infecções e hemorragias ventriculares. As estatísticas sugerem que nos Estados Unidos há aproximadamente 125.000 pessoas vivendo com derivações ventriculares e que sejam realizadas cerca de 33.000 cirurgias para implante de válvula para hidrocefalia por ano (BONDURANT \& JIMENEZ, 1995). No mundo estima-se que 160.000 válvulas para hidrocefalia são implantadas anualmente (OTON-DE LIMA, 2008).

Nos países desenvolvidos a frequência de casos de hidrocefalia congênita tem diminuído nos últimos anos. Uma das explicações postuladas seria que com o diagnóstico antenatal precoce e interrupção da gravidez, muitos casos de hidrocefalia congênita e de malformações congênitas associadas a hidrocefalia 
tiveram sua incidência reduzida (DRAKE, 2008). Além disso, houve também redução na incidência de defeitos do tubo neural pela suplementação de ácido fólico à mãe, diagnóstico antenatal precoce principalmente pelos grandes avanços no diagnóstico por imagem e interrupção da gravidez. Mesmo nos casos de bebês com defeitos do tubo neural nascidos vivos o uso de sistemas de derivação caiu em frequência provavelmente por uma conduta mais conservadora e porque os casos com mielomeningocele mais baixa - lombossacra ou sacra - são mais frequentes, pois casos de localização mais alta - toracolombar ou torácica - geralmente tem a gravidez interrompida. É sabido que quanto mais alto o nível do defeito do tubo neural, maior a associação com hidrocefalia (CHAKRABORTY et al., 2008).

Da mesma maneira, a incidência de hidrocefalia associada a hemorragia intraventricular do prematuro vem diminuindo com o passar do tempo, principalmente devido ao melhor cuidado oferecido nas Unidades de Terapia Intensiva Neonatal. O melhor conhecimento da fisiopatologia da hemorragia da matriz germinal do prematuro, cuidados com a hemostasia, avanços tecnológicos, melhor treinamento da equipe de cuidados ao recém nascido prematuro vem reduzindo $O$ risco de sangramento $e$ consequentemente de hidrocefalia (COEN, 2013). Isso vem ocorrendo apesar do aumento do número de crianças que nascem prematuras (RÜEGGER et al., 2012). O cuidado oferecido conseguiu reduzir também a frequência de outras patologias comuns nessa faixa etária, como displasia broncopulmonar e enterocolite necrotizante. 


\subsection{Produção, circulação e absorção do LCR}

A maior parte do LCR é formada dentro dos ventrículos cerebrais, nos plexos coroides, através de um mecanismo ativo com gasto de energia, numa taxa de $0,35 \mathrm{ml} /$ minuto. A produção liquórica em espaço subaracnoideo e através da rota transependimária já foi documentado. Pelo menos $20 \%$ do LCR é oriundo do fluido extracelular cerebral, produzido como um subproduto do metabolismo cerebral (BERING, 1962). Em condições normais, a taxa de produção diária de LCR, cerca de $500 \mathrm{ml}$, são equivalentes à taxa de absorção. Uma vez que o volume liquórico total é cerca de $60-140 \mathrm{ml}$ em crianças e 90-150 $\mathrm{ml}$ em adultos, isso significa que o volume total do LCR é trocado cerca de três vezes ao dia.

O líquido amniótico está inicialmente presente nas vesículas encefálicas primordiais do embrião. O plexo coroide se desenvolve logo após o fechamento dos neuroporos anterior e posterior e passa a ser determinante na fabricação do LCR. Na embriogênese, o primórdio do plexo coroide é formado por dobras do mesênquima em contato com o neuroepitélio do tubo neural. Esses eventos acontecem nos locais onde a parede do tubo neural é fina, com nos tetos do III e IV ventrículos. O plexo coroide é encontrado nos ventrículos laterais, no III e no IV ventrículo. Na região supratentorial o crescimento do plexo coroide se inicia no teto do III ventrículo. Já a partir da sexta semana de vida surgem os primórdios dos plexos coroides, que nessa etapa são apenas uma invaginação do mesênquima vascular que irá formar os plexos coroides dos ventrículos laterais. No quarto ventrículo, tais invaginações que irão se desenvolver nos plexos coroides podem 
ser encontradas a partir da quarta semana de vida intrauterina. $O$ aparecimento de vilosidades nos plexos coroides surgem na sétima semana de vida intrauterina, ao mesmo tempo que os plexos coroides se diferenciam e se projetam nos ventrículos até a região hipocampal no corno temporal (SHUANGSHOTI \& NETSKY, 1966).

O processo de formação do LCR inclui ultrafiltragem do plasma e secreção. É um processo realizado com gasto de energia, onde são importantes os enzimas adenosina trifosfato sódiopotássio e anidrase carbônica que regulam a secreção liquórica (POLLAY, 1977). A produção do LCR se mantém constante na faixa normal de pressão intracraniana. De maneira diversa, a absorção do LCR não se faz por um processo com uso de energia e sim por um gradiente de pressão. Conhecimentos advindos da análise de imagens de ressonância magnética (RM) mostram que - LCR tem movimentos pulsáteis dentro dos ventrículos provocados principalmente pela pulsação dos plexos coroides. Esse movimento de vai e vem do LCR é o responsável pela circulação liquórica dos ventrículos até o ponto de absorção (FEINBERG \& MARK, 1987).

O principal local de absorção liquórica são as vilosidades dentro das granulações aracnoides que podem ser encontradas não só nas leptomeninges que cobrem o cérebro e a medula, mas principalmente dentro do seio sagital superior (ALKSNE \& LOVINGS, 1972). Esse processo é passivo, sem gasto de energia. Uma camada de endotélio dentro das vilosidades aracnoideas separa o espaço liquórico do venoso. Por essa camada de endotélio, água e eletrólitos passam livremente. Como há normalmente uma diferença de pressão de 5 a $7 \mathrm{~mm} \mathrm{Hg}$ entre 0 
espaço subaracnoideo e o intravenoso, acredita-se que essa diferença de pressão seja a responsável pela absorção liquórica. Entretanto, o processo não é puramente sem gasto de energia. Proteínas e outras macromoléculas não conseguem atravessar as junções intercelulares da camada endotelial, sendo transportadas seletivamente através do citoplasma dessas células por micropinocitose (WELCH, 1975). O processo de absorção liquórica é uma das maneiras de proteção cerebral contra aumentos temporários da pressão intracraniana. Recém nascidos não tem granulações aracnoides mas mesmo assim tem uma circulação liquórica normal. Uma rota de absorção liquórica que provavelmente seja até mais importante que a realizada pelas granulações aracnoideas é através dos nervos olfatórios, placa cribiforme e linfáticos do nariz (JOHNSTON et al., 2004). Absorção liquórica através dos capilares cerebrais também foi proposto (GREITZ, 2004).

A produção de LCR é bem menor em recém nascidos e lactentes embora poucos estudos sejam disponíveis. Acredita-se que em lactentes a produção seja de 0,1 a 2,6 ml por hora (YASUDA et al., 2002). A produção liquórica aumenta rapidamente com o tempo e peso da criança. A produção de LCR de um recém nascido é de cerca de $25 \mathrm{ml} / \mathrm{dia}$, aumentando progressivamente e rapidamente com o tempo. O volume total de LCR ao nascer é em torno de 25-30 ml, aumentando para $50 \mathrm{ml}$ em lactentes, comparado com o volume de $150 \mathrm{ml}$ em adultos. A produção liquórica continua a despeito da ocorrência de hipertensão intracraniana. 


\subsection{Etiologia e Patofisiologia da hidrocefalia}

A hidrocefalia ocorre por um desbalanço entre a produção e a absorção liquórica. Pode surgir secundária a um grande número de desordens, como tumores, infecções e hemorragias. Também pode ocorrer como o único problema da criança. Quase todas as causas da hidrocefalia são por obstrução à circulação liquórica ou por problemas na absorção do LCR, exceto nos casos raros de tumores de plexo coroide, onde a produção liquórica pode ser extremamente elevada. Atualmente há alguns casos publicados de produção idiopática exagerada de LCR como causa da hidrocefalia (ANEl et al., 2011, TREVISI et al, 2014). Nesses relatos, houve hiperprodução de LCR comprovada pela coleta em bolsas de derivação ventricular externa de até $1.500 \mathrm{ml} / \mathrm{dia}$, volume extremamente aumentado para um lactente.

Antigamente várias formas de hidrocefalia eram catalogadas como idiopáticas. Hoje com a qualidade dos exames de neuroimagem, principalmente da RM de crânio, é possível ter muitas informações sobre a causa da hidrocefalia. Com os exames de imagem podemos documentar adequadamente o ponto de bloqueio à absorção liquórica, que pode ser: obstrução do átrio ventricular, causando dilatação apenas do corno temporal (Fig. 2A), a obstrução do forâmen de Monro, causando dilatação apenas de um dos ventrículos laterais (Fig. 2B), bloqueio de ambos os foramina de Monro ou da porção anterior do III ventrículo causando dilatação de ambos os ventrículos laterais (Fig. 2C), bloqueio ao 

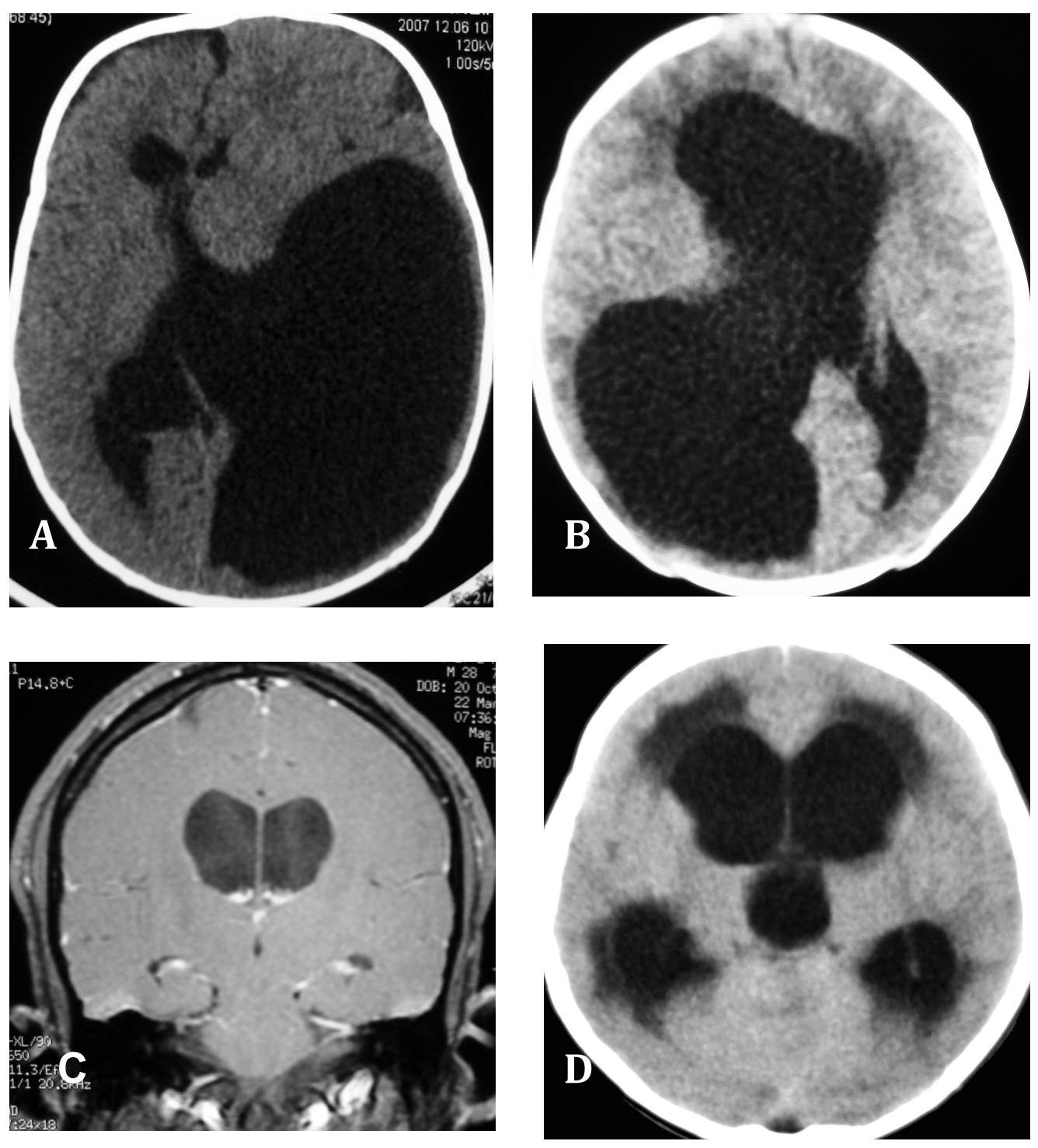

Figura 2 - Exames de neuroimagem com bloqueio à circulação liquórica no átrio ventricular causando dilatação do corno temporal e occipital em A, bloqueio no forâmen de Monro à direita causando dilatação apenas do ventrículo lateral direito em $\mathbf{B}$, bloqueio dos dois foramina de Monro com dilatação de ambos os ventrículos laterais permanecendo o III ventrículo de tamanho normal em $\mathbf{C}$ e bloqueio do aqueduto cerebral, com dilatação dos ventrículos laterais e do III ventrículo em $\mathbf{D}$. 
nível do aqueduto cerebral ou porção posterior do III ventrículo, provocando dilatação triventricular (ventrículos laterais + III ventrículo), que é a forma mais comum de hidrocefalia (Fig. 2D).

Obstruções nos orifícios de saída do LCR do IV ventrículo (Luschka e Magendie) vão determinar hidrocefalia com dilatação não só do IV ventrículo como dos ventrículos supratentoriais, ou seja, haverá dilatação dos quatro ventrículos. Bloqueio à circulação liquórica nas cisternas aracnoides podem causar hidrocefalia comunicante. Mesmo bloqueio à circulação venosa dos seios durais, como a trombose dos seios venosos e disostoses cranianas com compressão dos foramina jugulares podem também causar ventriculomegalia e dilatação dos espaços subaracnoideos, ou seja, hidrocefalia comunicante. Alguns casos de insuficiência cardíaca direita que determinam retrogradamente aumento da pressão venosa dos seios venosos durais podem causar ventriculomegalia.

Dentre as causas mais comuns no período neonatal se incluem a hidrocefalia associada a mielomeningocele, estenose de aqueduto e hemorragia ventricular do prematuro (DRAKE, 2008). Com o passar do tempo, surgem outras causas de hidrocefalia, como tumores, traumas, hemorragias espontâneas, infecções e parasitoses do sistema nervoso central.

A hidrocefalia causa estiramento do epêndima que reveste as paredes dos ventrículos cerebrais, seguido de edema e necrose da substância branca periventricular (WELLER \& SHULMAN, 1972). Há proliferação glial e gliose reativa ao redor dos ventrículos. Dependendo da causa da hidrocefalia, podemos encontrar outros achados patológicos. Nos casos de hidrocefalia pós hemorragia da matriz germinal, há uma concentração de citocinas pro inflamatórias, ferro livre e outras substâncias que podem gerar 
radicais livres altamente reativos, que podem ser medidos no LCR ventricular (SÄVMAN et al., 2002).

Com a rotura da camada ependimária, aumenta a permeabilidade ventricular, aparecendo edema periventricular que pode ser documentado aos exames de neuroimagem como a TC e a RM. A ventriculomegalia progressiva achata os giros cerebrais comprimindo os sulcos. A progressão da hidrocefalia pode desencadear hérnias cerebrais com risco de disfunção de tronco cerebral e morte. A substância branca, por estar mais próxima à cavidade ventricular dilatada, é mais sensível que a substância cinzenta à hidrocefalia progressiva podendo ocorrer necrose do parênquima cerebral.

\subsubsection{Etiologia congênita da hidrocefalia}

Mais da metade dos casos da hidrocefalia tem causas congênitas. A estenose de aqueduto primária é responsável por cerca de $5 \%$ de todos os casos de hidrocefalia, enquanto a estenose de aqueduto por tumores, infecções ou hemorragia é responsável por mais $5 \%$ dos casos ( $\mathrm{CHI}$ et al., 2005). Bloqueio à saída dos foramina de Luschka e Magendie causam hidrocefalia congênita em cerca de $4 \%$ dos casos. Nos casos de mielomeningocele, 80 a $90 \%$ das crianças tem hidrocefalia, a maioria delas manifestando-se já ao nascimento. A hidrocefalia pode fazer parte de quadros de malformações cerebrais como encefalocele, esquizencefalia e holoprosencefalia, além de poder estar associada a distúrbios metabólicos incluindo acondroplasia e doença de Hurler. Infecções congênitas também podem ser associadas a hidrocefalia, bem como outras malformações 
intracranianas como tumores congênitos, cistos aracnoides, malformações vasculares.

\subsubsection{Etiologia da hidrocefalia adquirida}

Uma das causas mais comuns da hidrocefalia são as infecções do sistema nervoso central, principalmente as meningites bacterianas, que podem causar hidrocefalia seja por um processo inflamatório do aqueduto cerebral ou por aderências em leptomeninges. Doenças parasitárias, principalmente a cisticercose também é causa de hidrocefalia em regiões do globo onde essa parasitose é prevalente. A hidrocefalia causada por hemorragia ventricular, frequente na criança prematura mas também podendo ocorrer secundária a trauma ou por sangramento de uma malformação vascular ou coagulopatias.

Os tumores são responsáveis por $20 \%$ dos casos de hidrocefalia adquirida na infância. Uma característica dos tumores intracranianos na infância é que cerca da metade deles ocorre na fossa posterior, favorecendo assim o bloqueio da circulação liquórica e aparecimento da hidrocefalia, enquanto os tumores supratentoriais na infância tem uma tendência a se localizar na linha média, onde também pode ocorrer obstrução à circulação liquórica, como é o caso dos craniofaringiomas e astrocitomas hipotalâmicos, tumores que tem prevalência caracteristicamente maior em crianças que em adultos.

Em pessoas idosas ocorre a hidrocefalia de pressão normal, acompanhada da tríade clínica característica de dificuldade na marcha, distúrbio urinário e déficit de memória. Nesses casos não há associação de sinais clínicos clássicos de hipertensão 
intracraniana como ocorre na maioria das demais formas de hidrocefalia.

\subsection{Quadro clínico}

A manifestação clínica da hidrocefalia depende da idade da manifestação do quadro. A hipertensão intracraniana causada pela hidrocefalia, quando ocorre em uma criança com as suturas da calota craniana ainda abertas, geralmente tem apresentação clínica mais insidiosa, com atraso na aquisições neuropsicomotoras e crescimento exagerado do perímetro cefálico. Pode ocorrer ainda irritabilidade, vômitos que algumas vezes podem ser confundidos com refluxo gástrico principalmente se não houver uma macrocefalia evidente, ataques de perda de fôlego, fontanela anterior tensa e abaulada.

O exame clínico provavelmente mostrará que o perímetro cefálico estará acima do percentil 98 esperado para a idade, as veias do couro cabeludo estarão ingurgitadas, a pele do couro cabeludo ficará brilhante, as suturas cranianas estarão abertas à palpação. Aparece o "olhar de sol poente", onde se consegue observar a porção branca da esclera dos globos oculares em sua porção mais superior.

Em casos mais graves com manto cortical muito fino é possível realizar a transiluminação do crânio. Esse procedimento deve ser feito em um ambiente escuro, aplicando-se uma lanterna ou outra fonte de luz sobre o crânio da criança (Fig. 3). A confirmação do quadro de hidrocefalia se faz com exames de neuroimagem. 
Papiledema não é um achado comum em lactentes com hidrocefalia, mas pode ser encontrado paralisia do olhar vertical para cima e o olhar do sol poente. Em crianças com mais de seis meses pode ocorrer espasticidade dos quatro membros, mais intensa em membros inferiores, com tendência a postura em hiperextensão. Em crianças que desenvolveram hidrocefalia após hemorragia ventricular da prematuridade, pode ser encontrado hipotonia ou hipertonia dos membros. Algumas crianças com quadro claro de hidrocefalia demonstrado aos exames de imagem podem não apresentar os achados clínicos descritos acima, talvez porque a instalação da hidrocefalia ocorreu de maneira lenta e gradual.

Crianças com mais de dois anos de idade geralmente não desenvolvem macrocefalia porque as suturas cranianas já estão fechadas nessa idade. Podem apresentar sinais clínicos de hipertensão intracraniana semelhantes aos encontrados nos adultos, com a tríade clássica de cefaleia, vômitos e papiledema. Outros sinais podem estar presentes, como baixo rendimento escolar, distúrbios de comportamento, sonolência, distúrbios da marcha, estrabismo convergente por paralisa do nervo abducente. Dependendo da causa da hidrocefalia, outros sinais neurológicos podem ser encontrados tanto na história como no exame clínico. 


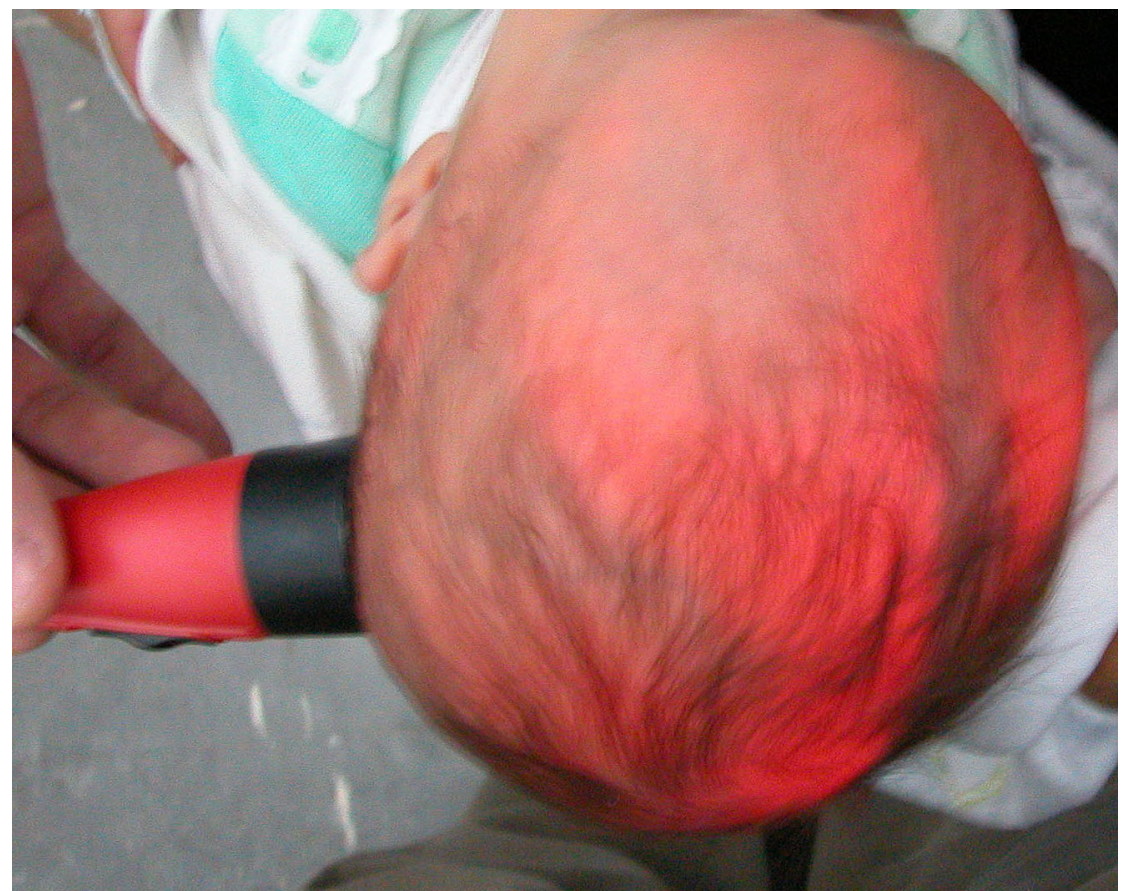

Figura 3 - Transiluminação transcraniana em um caso de hidrocefalia máxima. 


\subsection{Diagnóstico por imagem}

O rápido desenvolvimento tecnológico das técnicas de neuroimagem nos últimos anos vieram facilitar tremendamente 0 diagnóstico e seguimento das crianças portadores de hidrocefalia. É possível realizar o diagnóstico etiológico na maioria das vezes ou pelo menos diagnosticar o ponto de obstrução à circulação liquórica. Além disso os exames de neuroimagem se tornaram mais acessíveis à maioria da população, sendo ofertado pelo SUS (Serviço Único de Saúde).

\subsubsection{Ultrassom}

Ultrassonografia é um método rápido eficaz e barato de demonstrar o tamanho dos ventrículos em lactentes através da fontanela anterior. É de grande utilidade em prematuros com suspeita de hidrocefalia secundária a hemorragia da matriz germinal (LEVENE, 1981), quando o exame é realizado no ambiente da Unidade de Terapia Intensiva (UTI) neonatal. Isso evita que uma criança muitas vezes instável clinicamente seja transportada para o Setor de Radiologia do Hospital. Não é necessário realizar sedação da criança e o procedimento pode ser repetido várias vezes sem nenhum risco para a criança (Fig. 4). Os atuais aparelhos de ultrassonografias permitem obtenção de imagens com grande definição. Ao mesmo tempo, os aparelhos são menores e de fácil manuseio. 


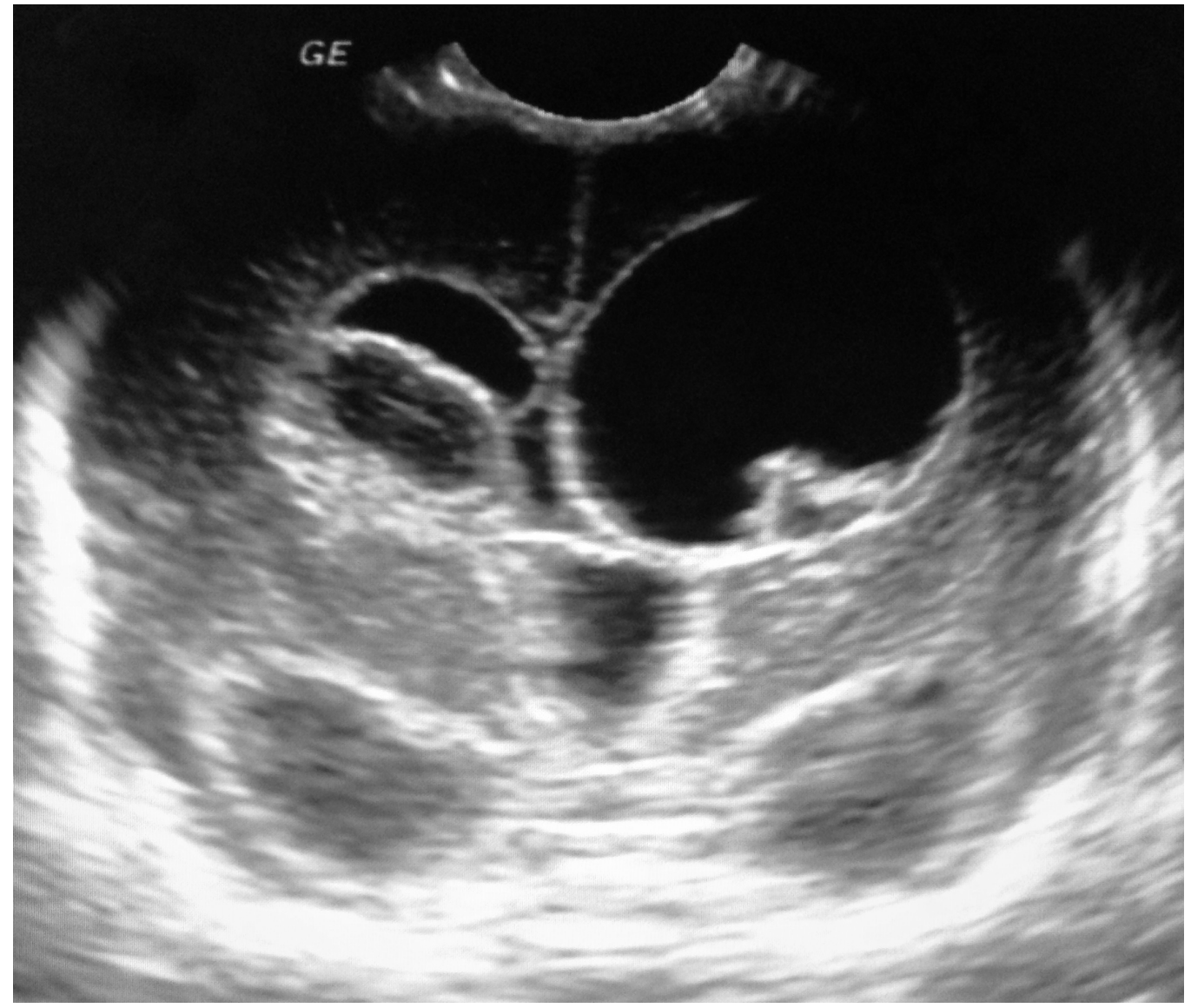

Figura 4 - Ultrassonografia transfontanela de um prematuro com quadro de hidrocefalia por hemorragia da matriz germinal. Há um coágulo dentro do ventrículo lateral direito e observa-se dilatação do III ventrículo. 
$\mathrm{Na}$ avaliação do tamanho ventricular, há uma medida padrão utilizada universalmente que é o índice ventricular ou índice de Evans (EVANS, 1942), que é obtido dividindo-se a distância entre as extremidades dos cornos frontais e o diâmetro biparietal, no ultrassom com cortes coronais. Um índice maior que 0,3 é sugestivo de hidrocefalia. Em crianças prematuras com hidrocefalia secundária a hemorragia ventricular, o estudo ecográfico repetido é mais fidedigno para diagnóstico da hidrocefalia que a medida diária do perímetro cefálico, sendo o índice de Evans utilizado até os dias atuais (INGRAM et al., 2014).

A ultrassonografia é extremamente importante no diagnóstico da hidrocefalia intra-útero já a partir da $17^{\mathrm{a}}$ semana (BENACERRAF \& BIRNHOLZ, 1987). O exame é realizado de rotina e pode ser repetido sempre que necessário.

A criança que nasce com hidrocefalia muitas vezes é submetida a um número grande de exames de imagem, notadamente a tomografia computadorizada de crânio, para avaliar o tamanho dos ventrículos. Atualmente existe uma grande preocupação com as doses de radiação que a criança recebe para realizar esses exames e com os riscos a longo prazo que essa radiação pode causar na criança. A criança é mais radiosensível que $\mathrm{o}$ adulto e tem uma expectativa de vida mais longa o que pode aumentar o risco de efeitos tardios da radiação. Crianças abaixo de um ano tem na fontanela anterior uma janela acústica para visualização de estruturas intracranianas com ultrassom, que pode e deve em várias ocasiões substituir 0 uso da tomografia computadorizada de crânio (MANDIWANZA et al, 2013).

A recomendação é que em ambientes de berçário e Unidades de Terapia Intensiva Neonatal haja a facilidade de uso 
da ultrassonografia como método diagnóstico. Muitos neonatologistas fazem treinamento e se dedicam ao exame de imagem ecográfica transfontanela. De uma maneira geral, pelo grande desenvolvimento tecnológico dos aparelhos de imagem ultrassonográfica, é possível para o médico que trabalha com recém nascidos o uso e interpretação das imagens. Isso inclui não só o pediatra como o neurocirurgião que atende tais crianças. A facilidade e qualidade das imagens obtidas permite diagnosticar e tomar decisões médicas ou cirúrgicas. A grande vantagem é que tal informação diagnóstica pode ser repetida a qualquer momento, várias vezes ao dia, sem risco ao pequeno paciente.

\subsubsection{Tomografia computadorizada de crânio}

A tomografia computadorizada (TC) demonstra claramente a morfologia dos ventrículos e tem melhor resolução de imagem que o ultrassom para a fossa posterior. É um exame facilmente disponível em vários locais, acessíveis aos pacientes. Ultimamente tem havido uma preocupação em não realizar tomografias computadorizadas repetidas em crianças com hidrocefalia, que como regra necessitam exames de neuroimagem frequentes, pela exposição à radiação (DAVIS et al., 2011).

É um exame largamente utilizado pela sua facilidade de realização, geralmente não é necessário sedação pois os aparelhos modernos tem um tempo curto para aquisição das imagens e na maioria das vezes identifica a etiologia da 
hidrocefalia, demonstrando de maneira clara os ventrículos e leucomalácia periventricular.

\subsubsection{Ressonância magnética de crânio}

Com a RM obtém-se a melhor definição morfológica dos ventrículos, consegue-se dar o diagnóstico etiológico com melhor acurácia, muitas vezes identificando pequenas lesões que não são percebidas pela TC. Tem melhor resolução que a TC principalmente no estudo da fossa posterior, definindo com detalhes malformações como o Chiari ou pequenas obstruções no aqueduto cerebral. Com a realização de técnicas só disponíveis na RM, como a cine-RM, podemos demonstrar a patência da fenestração realizada no terceiro ventrículo em casos de TVE ou o fluxo de LCR pelo aqueduto cerebral. A resolução obtida com a RM de crânio permite avaliar não só o tamanho dos ventrículos como o estado do parênquima cerebral. Considerando que em casos de hidrocefalia infantil e principalmente nos casos congênitos pode ocorrer a associação com malformações do tecido cerebral, o exame muitas vezes é de grande ajuda não só no diagnóstico como no prognóstico dessas crianças. Defeitos de migração neuronal como heterotopias ou defeitos de formação dos giros cerebrais são bem documentados com a RM.

Uma das limitações da RM é que crianças mais jovens necessitam de sedação por anestesiologista para realização do exame. Crianças que foram tratadas com implante de válvulas programáveis ou ajustáveis, como a programação é realizada por métodos magnéticos, necessitam de nova programação da válvula 
após a realização da RM. Algumas válvulas disponíveis no mercado já são resistentes a RM de até 1,5 Tesla.

Apesar dos avanços no diagnóstico por neuroimagem, é de fundamental importância correlacionar com os achados clínicos e com os achados de imagem de exames anteriores. Por exemplo, uma criança com passado de hidrocefalia e implante de válvula que desenvolva sinais clínicos de hipertensão intracraniana, mas com exames de imagem com ventrículos pequenos. A correta interpretação da história clínica bem como da avaliação de exames de imagem anteriores pode levar ao diagnóstico da síndrome de ventrículos em fenda hipertensivo. Nesses casos, não ocorre ventriculomegalia pela baixa complacência cerebral num quadro análogo ao pseudo tumor cerebral (BATEMAN, 2013). A indicação de tratamento seria a revisão da derivação ventricular

Da mesma maneira, crianças que tem ventriculomegalia mas sem manifestações clínicas não necessitam ter seus ventrículos reduzidos a qualquer custo, sob pena de ocorrer complicações pela hiperdrenagem liquórica. Assim, é de fundamental importância o julgamento da hidrocefalia baseado em dados clínicos e de exames de imagem anteriores, pois o tamanho ventricular por si só não é definitivo para indicar um tratamento, seja clínico ou cirúrgico. É importante documentar crescimento ventricular ou hipertensão intracraniana.

\subsection{Diagnóstico diferencial}

Existem outras causas de aumento do tamanho da cabeça além da hidrocefalia, como hematoma subdural crônico, efusão subdural crônica, pseudotumor cerebral, neurofibromatose, 
distúrbios metabólicos da calota craniana ou cerebral, gigantismo cerebral também conhecido com síndrome de Sotos (KO, 2013).

A macrocrania benigna da infância é razoavelmente frequente, associada a aumento dos espaços subaracnoideos da convexidade com ventrículos de tamanho normal ou levemente dilatados. Recebe outras denominações como efusões subdurais benignas da infância, hidrocefalia externa benigna da infância. Quando uma criança tem um quadro clínico de macrocefalia, muitas vezes os pais se angustiam pelas informações que geralmente são obtidas na internet, há uma expectativa negativa em relação ao futuro cognitivo da criança. Geralmente há uma história familiar. A evolução é quase sempre benigna, estabilizando-se em torno dos 12-18 meses de idade. Alguns casos podem apresentar atraso neuropsicomotor (ZAHL et al, 2011). Geralmente o portador da macrocrania da infância tem um perímetro cefálico acima ou no limite do percentil 98.

A agenesia do corpo caloso pode também cursar com leve aumento do perímetro cefálico. Nesses casos pode ser feito erroneamente o diagnóstico de hidrocefalia durante o período gestacional pela leve ventriculomegalia. É claro que não há necessidade nem indicação de tratamento cirúrgico.

\subsection{Tratamento}

O tratamento da hidrocefalia é o evento mais comum na prática diária da neurocirurgia pediátrica. Já está estabelecido que o tratamento clínico da hidrocefalia não é eficaz. As opções cirúrgicas de tratamento da hidrocefalia mais utilizadas atualmente são as derivações ventriculares com válvula e as derivações 
internas (ventrículo-cisternais) por via endoscópica. Das derivações com válvula, a mais comum é a DVP. Dos procedimentos endoscópicos, o mais utilizado é a TVE.

Uma criança que teve sua hidrocefalia tratada com implante de válvula provavelmente necessitará de várias revisões cirúrgicas do procedimento durante a sua vida. As causas mais frequentes de mal funcionamento dos sistemas de derivação com válvula são a obstrução e a infecção.

Uma criança que teve sua hidrocefalia tratada com métodos neuroendoscópicos terá uma chance menor de ser reoperada, quando o procedimento tem sucesso. Isso traz uma falsa impressão de cura da hidrocefalia, mas o seguimento neurocirúrgico do paciente se faz necessário, pois há vários relatos de obstrução da terceiro ventriculostomia mesmo anos após o procedimento funcionar adequadamente (LAM et al., 2014). As obstruções ocorrem uma média de três meses após o procedimento, havendo uma segunda leva de obstruções da TVE cerca de três anos após a cirurgia, principalmente nos casos associados a tumor (MASSIMI et al., 2006) ou estenose congênita do aqueduto. Os apologistas da técnica neuroendoscópica para o tratamento da hidrocefalia chegam mesmo a publicar que não é ético deixar de oferecer o tratamento neuroendoscópico a uma criança maior de dois anos de idade portadora de hidrocefalia obstrutiva (SGOUROS, KULKHARNI \& CONSTANTINI, 2006).

Como a hidrocefalia se faz acompanhar de hipertensão intracraniana com risco de agravo à saúde do paciente e mesmo risco de morte, a opção cirúrgica deve ser realizada o mais breve possível assim que o diagnóstico da hidrocefalia for confirmado. $\mathrm{Na}$ maioria das vezes a indicação de tratamento cirúrgico com 
derivação ventricular, seja com uso de válvula ou por neuroendoscopia é bem clara e objetiva. Entretanto, nem todas as crianças com ventriculomegalia tem indicação de tratamento cirúrgico.

Crianças cuja hidrocefalia é secundária a um tumor que esteja obstruindo a circulação liquórica, a ressecção do tumor pode levar a resolução da hidrocefalia, sem necessidade de realizar uma derivação. Se a ventriculomegalia é leve, um período de observação se torna necessário e prudente para confirmar que a hidrocefalia é progressiva e que há realmente necessidade de tratamento cirúrgico.

Hidrocefalia hipertensiva descompensada é uma emergência neurocirúrgica. Dependendo do caso, algumas medidas temporárias podem ser tomadas, como uma punção ventricular transfontanela de alívio, uso de DVE ou punção lombar nas hidrocefalia pós hemorrágicas ou pós infecciosas. O tratamento cirúrgico definitivo passa pela escolha entre TVE ou DVP.

A hidrocefalia tem prevalência elevada em todas as regiões do globo. Como a produção liquórica é realizada durante toda a vida do indivíduo, o tratamento da hidrocefalia consiste em derivar o LCR dos ventrículos para outro local onde possa ser absorvido (LIFSHULTZ \& HOHNSON, 2001). Desde a década de 1950, temse derivado o LCR dos ventrículos para a cavidade peritoneal (DVP) ou para o átrio direito do coração (derivação ventrículo-atrial - DVA). Nos dias atuais a DVA é pouco utilizada. Desde a década de 1980, com o avanço tecnológico que permitiu a miniaturização dos endoscópicos, melhor iluminação, vídeo-câmeras, avanços na neuroimagem, têm-se também a opção de fazer uma derivação 
liquórica intracraniana, dos ventrículos para as cisternas aracnoides, com uso do neuroendoscópio (TVE). O neuroendoscópio tem sido usado também para o tratamento de várias outras patologias intraventriculares (CINALLI et al, 2006).

Nas últimas décadas a TVE tem sido o procedimento de escolha no tratamento da hidrocefalia obstrutiva infantil em muitos centros, substituindo a DVP. Após 5 anos de seguimento, a taxa de não funcionamento da TVE é 26\% (RIBAUPIERRE et al, 2007). As complicações da DVP são bem conhecidas e temidas pelos neurocirurgiões que implantam válvulas. Cerca de $40 \%$ das válvulas deixam de funcionar após um ano, $50 \%$ após dois anos. As complicações mais comuns são obstrução e infecção. Há muitas complicações tardias, como hipertensão pulmonar, nefrite, síndrome de ventrículo em fenda (VERNET \& RILLIET, 2001). Todas essas complicações implicam em uma nova cirurgia, às vezes com tempo de internação prolongado.

A TVE apesar de ser uma escolha bem atraente, não é isenta de complicações, que pode chegar até 18\% (ERSAHIN \& ARSLAN, 2008). Para reduzir a taxa de complicações é necessário treinamento, experiência e técnica cirúrgica meticulosa. Entre as complicações mais comuns incluem-se as hemorragias ventriculares, bradicardia ao abrir o estoma no III ventrículo, fístula liquórica, infecção, distúrbios hormonais, distúrbios do apetite e febre de origem central.

É comum que os pacientes com hidrocefalia que foram operados com implante de válvula (DVP) sejam reoperados. No primeiro ano pós-operatório, 25 a $40 \%$ dos pacientes serão reoperados. Em 10 anos, a sobrevida média de uma válvula é 30$37 \%$ (DRAKE \& SAINTE-ROSE, 1995). A cirurgia 
neuroendoscópica (TVE) tem índice de sucesso em torno de $70 \%$. Em longo prazo, o sucesso da TVE é mais duradouro que da DVP.

Para muitos neurocirurgiões os benefícios da TVE resolvem a obstrução liquórica da hidrocefalia, enquanto que para outros ainda existe alguma incerteza. Vários pacientes portadores de hidrocefalia obstrutiva ainda recebem derivação ventrículoperitoneal ou ventrículo-atrial pelo ceticismo de alguns neurocirurgiões quanto a complicações e eficácia da técnica em longo prazo.

Como a DVP implica numa taxa de reoperações elevada, além do uso de válvulas, com novas internações, uso de conjuntos de derivação ventricular externa, é possível que o custo final do implante da válvula seja maior que o da TVE, que tem menor taxa de reoperações, mesmo contando com o custo maior da aparelhagem para realizar a cirurgia endoscópica. Aparentemente o implante de uma válvula causa menor potencial de sequelas imediatas (PERETA et al., 2006). Entretanto, as válvulas têm risco aumentado de infecção (Ragel et al, 2006), que afetam o desenvolvimento da criança, além de serem propensas a novas cirurgias para revisão, cada nova cirurgia com seus próprios riscos (TULI et al., 2000). Os custos relacionados à TVE geralmente são os iniciais, com a compra do equipamento necessário e treinamento da equipe.

$\mathrm{Na}$ literatura, o critério mais usado para aferir o sucesso da TVE tem sido a independência da válvula (KOMBOGIORGAS \& SGOUROS, 2006; JALLO et al., 2005). A decisão quanto à independência da válvula passa pela avaliação clínica e pela realização de exames de neuroimagem. 


\subsubsection{Custos do tratamento}

Sem considerar os custos de internação e medicamentos, o preço de uma válvula para o SUS situa-se abaixo de $R \$ 1.000,00$ (um mil reais), enquanto numa cirurgia por neuroendoscopia utilizase um cateter Fogarty ${ }^{2}$, que custa menos de $\mathrm{R} \$ 200,00$ (duzentos reais). Além disso, para a realização da cirurgia neuroendoscópica é necessário o material de uso permanente: o endoscópio, fonte de luz, câmera de TV miniaturizada, monitor de vídeo, cabo de fibra óptica, tendo esse conjunto um preço estimado em torno de $\mathrm{R} \$ 40.000,00$ (quarenta mil reais).

Como os recursos para tratamento da saúde não são ilimitados, é importante a otimização desses recursos sem comprometer a qualidade do tratamento. Como primeira medida para melhor gerenciamento e tomada de decisões, é importante obter informações sobre os custos.

No nosso país há além dos custos com o tratamento os custos sociais de uma criança com deficiência. A Lei Orgânica de Assistência Social fornece um benefício em dinheiro para portadores de deficiência. Há também a possibilidade de obter um passe livre de ônibus urbano e interestadual não só para a criança como para seu acompanhante. Vários medicamentos também podem ser obtidos sem ônus para o paciente e sua família.

Warf publicou em 2005 uma série de pacientes com hidrocefalia em Uganda, onde pela falta de válvulas foi tomada a decisão de fazer a TVE em todas as formas de hidrocefalia, obstrutivas ou não. $O$ resultado foi superior àquele esperado com

\footnotetext{
${ }^{2}$ Cateter Fogarty 4F fabricado por Edwards Lifescience LCC, Irvine CA, USA
} 
uso de válvulas (WARF, 2005), com um custo reduzido, pois deixou de utilizar as válvulas, parte do tratamento de custo bastante elevado.

\subsection{Prognóstico}

Antes dos anos 1950 o prognóstico de uma criança com hidrocefalia era péssimo. A maioria das crianças não conseguia completar os 10 anos de vida. Entre os sobreviventes, apenas $38 \%$ tinham QI maior que 85 (LAURENCE \& COATES, 1962). O desenvolvimento das válvulas para hidrocefalia melhorou substancialmente o prognóstico dos pacientes com essa patologia, mas carrega consigo problemas peculiares. A maioria das crianças com hidrocefalia são submetidas a múltiplas cirurgias para revisão das válvulas. Apesar da grande melhora nas taxas de mortalidade e morbidade, a dependência da válvula carrega uma mortalidade anual de $1 \%$ (SAINTE-ROSE et al., 1992). Uma das maiores causas de morte dos portadores de válvula para hidrocefalia é a presença de infecção da válvula, que ocorre tanto em centros desenvolvidos como em países mais pobres. A taxa de mortalidade pode ser de até $12 \%$ em 10 anos (TULI et al., 2004). Algumas etiologias da hidrocefalia parecem ser mais propensas a complicações incluindo morte, como a hidrocefalia associada a mielomeningocele.

A qualidade de vida das crianças com hidrocefalia que alcançam a idade adulta foi motivo de vários estudos retrospectivos. As dificuldades neurológicas e intelectuais dependem de vários fatores, incluindo a etiologia e severidade da hidrocefalia, o grau de destruição da substância branca 
periventricular (FLETCHER et al, 1992), necessidade de implante de válvula e outras malformações cerebrais associadas. Patologias como hemorragia ventricular da prematuridade, infecção do sistema nervoso central, hipóxia podem ser importantes causadores de dano neurológico, provavelmente mais que a hidrocefalia. Crianças com hidrocefalia secundária a meningite ou hemorragia ventricular necessitam mais de estimulação precoce e frequentar o ensino especial que aquelas com hidrocefalia congênita por estenose de aqueduto.

A epilepsia é mais prevalente entre os portadores de hidrocefalia, mas as complicações das cirurgias para implante de válvula e suas revisões cirúrgicas não parecem ser o principal fator causador da epilepsia.

As deficiências intelectuais são difíceis de serem determinadas em pacientes com hidrocefalia. Geralmente tais crianças conseguem se adaptar bem durante o período escolar, mas apresentam dificuldade no mercado de trabalho e podem não obter independência financeira durante a vida adulta. Em um estudo na Califórnia que abrangeu 403 casos de hidrocefalia que alcançaram a idade adulta (GUPTA et al., 2007), foi constatado que $75 \%$ conseguiram terminar o ensino secundário, 33\% concluíram a universidade e 10\% concluíram uma pós graduação. Nesse grupo, $54 \%$ dos pacientes foram submetidos a mais de 4 revisões cirúrgicas do sistema de derivação ventricular da infância até a idade adulta. Sintomas depressivos estavam presentes em $45 \%$ dos pacientes. Não foram realizados testes neuropsicológicos para avaliar a capacidade de inteligência, mas indicadores sociais de integração mostraram que $32 \%$ dos casos estavam casados, $60 \%$ tinham habilitação para dirigir automóveis e $57 \%$ estavam 
empregados. Esses marcadores sociais indicam que uma criança com hidrocefalia tem $45 \%$ de chance de ser totalmente integrado na sociedade, com atividade sexual, carteira de motorista e ganhando o suficiente para prover a própria subsistência sem auxílio da família ou de Serviços Sociais Governamentais. 
CAPÍTULO II - OBJETIVOS 
Comparar os benefícios e custos em longo prazo entre o tratamento neuroendoscópico da hidrocefalia e o implante de válvula.

Após avaliação dos resultados, sugerir qual a melhor forma de tratamento da hidrocefalia a ser utilizado em Serviços Públicos de Saúde. 
CAPÍTULO III - MÉTODOS E PACIENTES 
O desenho do trabalho é o de uma coorte prospectiva. Pacientes portadores de hidrocefalia obstrutiva foram separados em dois grupos conforme o tratamento empregado: DVP ou TVE. Foi feito uma avaliação pré-operatória em cada paciente de ambos os grupos, para que os grupos pudessem ser os mais semelhantes possíveis. Todos os pacientes foram submetidos a exame de neuroimagem prévia, para confirmar a hidrocefalia obstrutiva. Uma tomografia computadorizada de crânio no mínimo foi realizada. Sempre que possível, uma ressonância magnética foi feita, preferencialmente com estudo do fluxo liquórico, para determinar o local da obstrução da circulação do liquor.

Os grupos foram pareados quanto à etiologia da hidrocefalia obstrutiva, idade ao tratamento, sexo.

A seleção para o tratamento com DVP ou TVE foi feita de acordo com o cirurgião responsável pelo procedimento do dia da operação. Eventuais complicações das cirurgias foram anotadas na ficha de coleta de dados para posterior análise.

Todos os pacientes foram acompanhados por um ano desde o momento da primeira cirurgia para tratamento da hidrocefalia, no ambulatório de neurocirurgia pediátrica do Hospital de Base do DF.

Naqueles pacientes até sete anos de idade foi realizado um exame neurológico evolutivo, usando uma adaptação do exame de Denver (FRANKENBERG \& DODDS, 1967). Foi anotado na ficha de coleta de dados como normal para a idade ou abaixo para a idade. Esse exame foi repetido aos 6 e aos 12 meses pósoperatório, registrado no prontuário do paciente. Crianças mais velhas e adultos foram avaliados utilizando-se o Índice de Saúde Útil (FEENY et al., 1995), que também foi repetido aos 6 e aos 12 meses pós-operatórios. A coleta de informações foi realizada no 
ambulatório de Neurocirurgia do Hospital de Base, onde os pacientes operados são regularmente acompanhados. As visitas semestrais são rotina após cirurgias para hidrocefalia.

Complicações foram registradas no estudo. O padrão de declarar falha no tratamento inicial tentou ser o mais homogêneo possível. Para aqueles que o tratamento inicial falhou, a reoperação foi por decisão pontual do cirurgião assistente. Um exame de neuroimagem pós-operatório foi obrigatório nos primeiros 12 meses do tratamento. O seguimento avaliou: número de cirurgias, morbidade, tempo total de hospitalização nos primeiro ano após a operação, a necessidade de exames de neuroimagem, mortalidade, complicações, infecções, déficits focais, sangramentos, epilepsia, tamanho ventricular e outras anormalidades que por acaso vieram a ocorrer.

É sabido que o tempo de internação dos pacientes submetidos a qualquer uma das duas cirurgias (TVE e DVP) se equivalem, bem como os medicamentos utilizados. A diferença é o custo do uso da válvula na DVP e o custo do equipamento para neuroendoscopia. Os custos de cada procedimento foram registrados tomando-se como base o número de dias de internação, número de novos exames solicitados devido a complicações, reinternações, novas cirurgias. Os valores foram aqueles repassados pelo Serviço Único de Saúde (SUS) do Ministério da Saúde do Brasil à Secretaria de Saúde do Distrito Federal. Dentre os custos foram também calculados os gastos realizados com exames de imagem, com internação de acompanhantes, sempre levando em consideração os preços repassados pelo SUS. 


\subsection{População estudada}

Pacientes com até 12 anos de vida com hidrocefalia obstrutiva que foram atendidos no Hospital de Base do DF (HBDF) nos anos 2007 e 2008 para tratamento foram elegíveis para participar do estudo. Foram considerados para o estudo apenas as crianças que estavam recebendo o primeiro tratamento cirúrgico para a hidrocefalia. As crianças foram seguidas por um ano após a operação. O acompanhamento das crianças foi realizado no ambulatório de Neurocirurgia Pediátrica do HBDF. No ambulatório foram agendados novos exames de imagem quando necessário. As reinternações para tratamento de eventuais complicações foram indicadas a partir de atendimentos realizados ou no ambulatório ou no Pronto Socorro do HBDF.

A coorte estuda consistiu de 103 crianças, 52 delas tratadas com DVP e 51 com TVE. As variantes estudadas incluíam idade, sexo, etiologia da hidrocefalia, exames de imagem realizados, cirurgia utilizada para tratamento da hidrocefalia (TVE ou DVP), complicações cirúrgicas, duração do tempo de internação hospitalar após a cirurgia, complicações tardias, hospitalizações por falhas do procedimento fosse ele TVE ou DVP a partir do primeiro dia após a primeira cirurgia, seguimento ambulatorial durante o primeiro ano pós operatório, perímetro cefálico no momento da cirurgia e após um ano e custos totais pagos pelo SUS. Casos de falha precoce do tratamento ocorridos durante a primeira semana pós operatória, enquanto a criança ainda estava internada, foram computados como uma nova internação hospitalar para fins de cálculo dos custos. 


\subsection{Critérios de inclusão e exclusão}

Foram incluídos os pacientes na faixa etária pediátrica com hidrocefalia obstrutiva, sem tratamento prévio, submetidos a cirurgia utilizando TVE ou DVP. Os critérios de inclusão incluem gestação a termo (mais que 36 semanas) com exame de tomografia computadorizada ou ressonância magnética préoperatório confirmando a hidrocefalia obstrutiva e que foram seguidos por pelo menos um ano após o primeiro tratamento cirúrgico para hidrocefalia.

A inclusão dos novos pacientes era por procura espontânea para tratamento ou casos encaminhados de outras unidades de saúde para tratamento no HBDF. O HBDF é o hospital da Secretaria de Saúde do Governo do Distrito Federal (SES-DF) de referência para tratamento de patologias neurocirúrgicas. Foram incluídos pacientes que residiam foram do Distrito Federal desde que fossem acompanhados ambulatorialmente após a cirurgia por um mínimo de 12 meses.

A etiologia da hidrocefalia foi um dos critérios de exclusão. Crianças portadoras de espinha bífida aberta, malformação de Dandy-Walker, prematuridade, síndrome hipóxico-isquêmica perinatal, malformações importantes do sistema nervoso central (como agenesia do corpo caloso, heterotopias, porencefalia) e tumores malignos foram excluídas do estudo. A justificativa de excluir tais crianças foi porque nesses casos a melhor indicação de tratamento é o implante de válvula. A frequência de sucesso da TVE nessas etiologia de hidrocefalia é muito baixa. Se os pacientes portadores dessas causas de hidrocefalia fossem incluídos haveria um grande viés de inclusão. 


\subsection{Obtenção dos casos para estudo}

A coleta de novos casos foi sistemática durante os anos de 2007 e 2008 na expectativa que todo novo caso de hidrocefalia obstrutiva admitido no HBDF durante o período de estudo fosse incluída. Os resultados foram avaliados comparando-se principalmente o custo do tratamento das crianças tratadas com DVP comparadas às tratadas com TVE.

O resultado do tratamento também foi observado, comparando o estado de desenvolvimento neurológico evolutivo dos pacientes tratados com as duas técnicas.

\subsection{Técnicas operatórias}

A TVE foi realizada com o uso de um neuroendoscópio rígido (JALLO et al., 2005) inserido no ventrículo lateral, quase sempre do lado direito, a mão livre. O endoscópio rígido tem melhor qualidade de imagem e permite utilizar mais de um canal de trabalho, por isso foi preferido ao endoscópio flexível. A preferência por operar o lado direito deve-se ao fato de esse ser o hemisfério não dominante na maioria das pessoas e eventuais acidentes durante a cirurgia não afetariam funções corticais superiores. A abertura do couro cabeludo e realização da trepanação foi feita da maneira habitual. A dura mater era aberta, sendo coagulado a pia mater com bipolar antes da sua abertura. $O$ ventrículo lateral era alcançado e a partir daí por visualização direta era realizado o restante do procedimento. Os seguintes pontos de referência anatômica dentro do ventrículo lateral eram 
vistos: plexo coroide do ventrículo lateral, veia tálamo estriada, veia septal. Seguindo-se uma dessas referências anatômicas se conseguia chegar ao forâmen de Monro, circundado pela coluna do fórnix (Fig. 5).

O neuroendoscópio era então navegado através do forâmen de Monro para dentro do III ventrículo e novas referências anatômicas eram encontradas no assoalho do III ventrículo: corpos mamilares, infundíbulo da hipófise, quiasma óptico. $O$ assoalho do III ventrículo era aberto na linha média com a utilização de um cateter de balão Fogarty, calibre $4 \mathrm{French}^{3}$, logo adiante dos corpos mamilares e posterior ao infundíbulo da hipófise. Após perfuração do assoalho do III ventrículo, o balão era suavemente insuflado com soro fisiológico para alargar a comunicação entre o III ventrículo e a cisterna interpeduncular. Pequenos sangramentos eram contidos com uma nova insuflação do balão. Após abertura do assoalho do III ventrículo, o estoma era inspecionado e confirmado se a membrana de Liliequist, sob o assoalho do III, havia sido aberta. Caso a membrana de Liliequist estivesse íntegra, era perfurada e o novo orifício alargado da mesma maneira como havia sido aberto o assoalho do III ventrículo. O procedimento só era considerado um sucesso com a confirmação da abertura da membrana de Liliequist, com a visão da artéria basilar, de algum de seus ramos ou o trajeto do III nervo na cisterna interpeduncular.

${ }^{3}$ Cateter balão de endoscopia Pogarty 4F, Edwards Lifesciences LCC, Irvine, CA, USA 


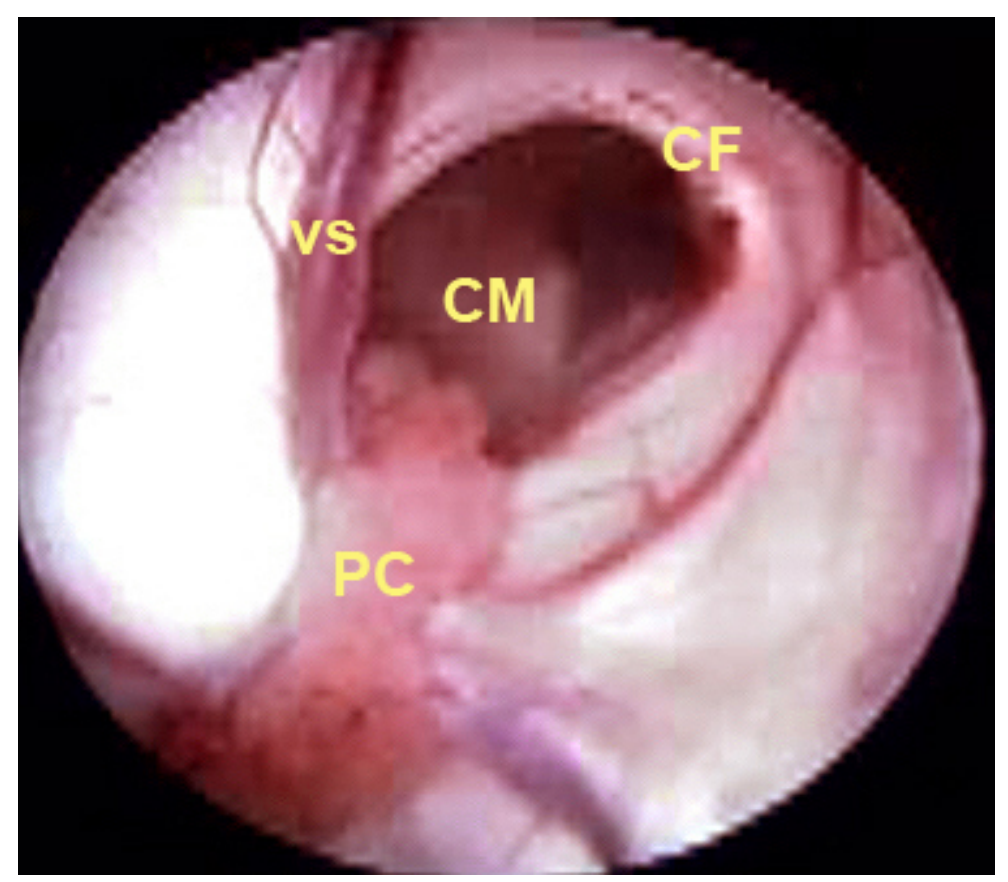

Figura 5 - Visão do ventrículo lateral direito através do endoscópio. CF = Coluna do Fórnix; CM = Corpo Mamilar; PC = Plexo Coroide; VS = Veia Septal. 
Uma outra indicação de sucesso era o aparecimento do "sinal da bandeira" quando após a abertura do assoalho do III ventrículo, esse passava a se movimentar como uma bandeira balançada pelo vento. No caso, os movimentos do assoalho do III ventrículos eram causados pela pulsação do LCR.

A DVP era realizada com implante de uma válvula de pressão fixa disponível no momento da cirurgia ${ }^{4}$. A escolha da pressão da válvula ficou a critério do neurocirurgião que realizava o procedimento, geralmente de pressão média ou baixa. A criança era posicionada em decúbito dorsal e o implante da válvula era realizado quase sempre do lado direito. A opção de implantar o sistema de derivação à esquerda era feita quando havia acesso venoso profundo à direita ou escaras na pele e couro cabeludo que interferissem com o implante da válvula do lado direito. Uma incisão abdominal era realizada no sentido transverso na região paramediana retal supraumbelical direita. Era aberto a fáscia do músculo reto, feito divulsão romba suas fibras e cerclagem da fáscia interna. A seguir era feito uma incisão parietal direita, descolado o periósteo e feito um orifício no crânio. A dura mater era coagulada, aberta e introduzido o cateter ventricular a mão livre dentro da cavidade do ventrículo lateral direito. Era passado o cateter distal por um túnel subcutâneo entre as duas incisões (a craniana e a abdominal). O cateter ventricular era conectado à válvula e esta ao cateter distal, sendo o conjunto fixado ao periósteo. Cerca de $30-40 \mathrm{~cm}$ do cateter distal era introduzido no peritônio.

4 Válvula fabricada por Ventura Biomédica, São José do Rio Preto, SP ou por Phoenix Biomedical, PA, EEUU 


\subsection{Tempo de internação}

O número de dias de internação hospitalar era computado a partir da primeira cirurgia para tratamento da hidrocefalia. A falha do procedimento, fosse ele DVP ou TVE foi definida como qualquer necessidade de nova cirurgia para derivação liquórica ou morte secundária à hidrocefalia (DRAKE, 2007), como já havia sido proposto antes. Se houvesse uma falha no tratamento ainda durante o período de internação, a nova cirurgia foi computada como se fosse uma nova admissão hospitalar. Os dias de internação foram computadas em duas maneiras: tempo de internação após a cirurgia e dias totais de internação naquelas crianças que foram submetidas a mais de um tratamento cirúrgico.

\subsection{Aspectos clínicos pós operatórios}

As crianças eram acompanhadas no ambulatório de neurocirurgia pediátrica e dentre os aspectos clínicos observados no período pós operatório para atestar o funcionamento do sistema de derivação ventricular estava o perímetro cefálico. Como havia crianças de diferentes idades incluídas no estudo, para fazer uma melhor comparação entre elas o perímetro cefálico foi considerado por percentil de acordo com a idade da criança. Aquelas crianças cujo perímetro cefálico estava acima do percentil 98 foram computadas adicionando-se o número de centímetros acima da curva ao percentil 98 . Não houve casos de crianças com perímetro cefálico abaixo do percentil 2. A escala de Denver é a mais utilizada em todo o mundo para avaliar o desenvolvimento neuropsicomotor da criança (FRANKENBERG \& DODDS, 1967). 
Nos casos estudados, o estado neurológico foi computado utilizando-se a escala de Denver adaptada para crianças até sete anos de idade, por ser mais prática de ser utilizada. Para aquelas crianças com mais de sete anos de idade foi utilizado o Índice de Utilitários de Saúde (TORRANCE et al, 1996).

As anotações sobre os aspectos clínicos foram feitos antes da cirurgia e com um ano de seguimento. Os registros foram comparados, anotando-se se houve ou não melhora nos aspectos clínicos da criança.

\subsection{Custos dos procedimentos}

Os custos do tratamento das crianças com hidrocefalia no nosso grupo foram calculados de acordo com os valores repassados pelo Governo Brasileiro à Secretaria de Saúde do DF, responsável pela manutenção do Hospital de Base do DF, onde as crianças foram tratadas. O Sistema de Saúde do Brasil provê tratamento médico gratuito para todos os cidadãos brasileiros conforme dita a constituição do país, que a saúde é um direito de todos e um dever do Estado. A maioria das pessoas que procuram tratamento para hidrocefalia nos hospitais públicos de Brasília tem baixa renda e não tem recursos econômicos para pagar um seguro de saúde privado. Muitos cidadãos brasileiros, mesmo sem contribuir para o sistema público de saúde, tem cobertura completa para atendimento nos hospitais públicos brasileiros.

Para fins de publicação em revista indexada, apesar de os pagamentos feitos pelo Sistema Único de Saúde (SUS) do Governo Brasileiro para a Secretaria de Saúde do DF terem sido feitos em moeda corrente brasileira, o real, os cálculos 
apresentados foram feitos em dólares americanos, em valores convertidos para a taxa de câmbio de 2008.

O SUS pagou o valor equivalente a USD\$ 1.760,89 (um mil, setecentos e sessenta dólares e oitenta e nove centavos) para cada paciente que foi submetido a tratamento com TVE. Nesse valor estão incluídos todos os gastos da hospitalização, incluindo alimentação e medicação, cuidados médicos e de enfermagem por um período de 3 (três) dias, podendo ser prorrogado para até 6 (seis) dias. O pagamento era realizado por procedimento e por paciente. Isso significa que se o paciente ficar menos de 3 (três) dias internado resultará num custo menor para o hospital prestador do serviço que aquele paciente que permanecer mais de 6 (seis) dias internado. Após seis dias de internação, o Hospital prestador de serviço passa a arcar com todos os custos, sem nenhuma remuneração do SUS.

Com isso, há uma tendência natural do prestador de serviço a tentar reduzir seus custos com a diminuição dos dias de hospitalização e tentando reduzir complicações do procedimento. A remuneração paga pelo SUS para eventuais complicações é baixa. Por exemplo, o tratamento clínico total para meningite é de USD\$ 145,00 (cento e quarenta e cinco dólares), podendo o paciente ficar internado por até 20 dias. Havendo internação em Unidade de Terapia Intensiva, os recursos repassados pelo SUS passaram a ser de USD\$282,57 (duzentos e oitenta e dois dólares e cinquenta e sete centavos) por dia de internação.

Nas crianças tratadas com DVP, o repasse do SUS foi de USD\$ 833,73 (oitocentos e trinta e três dólares e setenta e três centavos) para a realização da cirurgia e demais despesas hospitalares, também para um período de internação de até 6 dias. 
Houve um repasse extra de USD\$ 469,88 (quatrocentos e sessenta e nove dólares e oitenta e oito centavos) para o pagamento do dispositivo empregado na derivação ventricular (conjunto de válvula para hidrocefalia, cateter proximal e distal). Assim, o valor total de remuneração pelo SUS para o tratamento da hidrocefalia com DVP foi de USD\$1.303,61 (um mil, trezentos e três dólares e sessenta e um centavos). Os repasses feitos para a realização de uma tomografia computadorizada de crânio foi de USD\$ 54,13 (cinquenta e quatro dólares e treze centavos) e para uma ressonância magnética de crânio de USD\$ 148,89 (cento e quarenta e oito dólares e oitenta e nove centavos). Na Tabela 1 encontram-se resumidos os repasses feitos pelo SUS, em valores de dólares americanos calculados para a taxa de câmbio média do ano de 2008.

No presente estudo os custos foram calculados para cada paciente de acordo com o procedimento, realização de exames de imagem, tempo de internação hospitalar e complicações. Naquelas crianças que necessitaram de uma nova cirurgia por falha da DVP ou TVE, os custos do novo tratamento foram adicionados.

Não foram calculados no presente estudo os gastos realizados pela família da criança, nem feitos cálculos de perda de rendimento familiar porque algum dos provedores da família foi obrigado a permanecer no hospital para cuidar da criança.

Para análise dos dados foi utilizado o programa SPSS Advanced Statistics $20.0^{5}$.

5 SPSS Inc., Chicago, IL, USA 


\begin{tabular}{|l|c|c|c|}
\hline Procedimento & Valor & Tempo & Prorrogação \\
\hline DVP & 833,73 & 3 dias & Até 6 dias \\
\hline Válvula para hidrocefalia & 469,88 & & \\
\hline Preço total DVP & $1.303,61$ & 3 dias & Até 6 dias \\
\hline Preço DVP com neuroimagem & $1.357,75$ & 3 dias & Até 6 dias \\
\hline Revisão cirúrgica DVP & 772,57 & 3 dias & Até 6 dias \\
\hline Retirada de DVP & 448,90 & 3 dias & Até 6 dias \\
\hline DVE & 602,57 & 5 dias & Até 10 dias \\
\hline Conjunto de DVE & 291,67 & & \\
\hline Preço total DVE & 894,24 & 5 dias & Até 10 dias \\
\hline Preço DVE incluindo imagem & 984,94 & 5 dias & Até 10 dias \\
\hline Complicação de DVP - trat. Clínico & 251,76 & 4 dias & Até 8 dias \\
\hline Meningite & 261,00 & 10 dias & Até 20 dias \\
\hline Complicação grave da DVP & 341,65 & 7 dias & Até 14 dias \\
\hline TVE & $1.760,89$ & 3 dias & Até 6 dias \\
\hline Preço total TVE com neuroimagem & $1.963,91$ & 3 dias & Até 6 dias \\
\hline Diária de UTI Neonatal & 282,57 & & \\
\hline Diária de acompanhante & 4,44 & & \\
\hline
\end{tabular}

Tabela 1: Preços repassados pelo SUS para tratamento da hidrocefalia em dólares americanos para o ano de 2008. Na realização da TVE, o cateter Fogarty é pago pelo Hospital. 
CAPÍTULO IV - RESULTADOS 


\subsection{Coorte estudada}

Durante os anos de 2007 e 2008 foram operadas para tratamento de hidrocefalia no HBDF pela primeira vez 163 crianças. O grupo era composto de $77(47,5 \%)$ meninas e $85(52,5 \%)$ meninos. Havia diferentes etiologias para hidrocefalia, conforme demonstrado na Tabela 2. A idade ao momento da cirurgia dessas 162 crianças está demonstrada na Figura 6.

Todos os casos eram de hidrocefalia obstrutiva de diferentes etiologias. Foram submetidos a tratamento para hidrocefalia pela primeira vez no HBDF. 107 (66\%) foram tratados inicialmente com derivação ventrículo-peritoneal (DVP) e interposição de válvula e 55 (34\%) submetidos a terceiroventriculostomia endoscópica (TVE). A escolha do tratamento não foi randomizada, sendo determina a critério do neurocirurgião que realizou o procedimento.

Os casos de hidrocefalia associados a neurocisticercose, malformação de Dandy Walker, pós hemorragia ventricular do pré maturo e aquelas associadas a mielomeningocele foram excluídas do trabalho porque foram tratadas quase que totalmente com implante de válvulas para hidrocefalia.

A população estudada consistiu de 103 crianças com hidrocefalia com idade média de 24,6 \pm 25,2 meses. 52 dessas crianças foram tratadas com DVP (idade média de 17,6 \pm 18,3 meses) e 51 foram tratadas com TVE (idade média de 32,4 2 29,5 meses). A distribuição da idade ao momento da cirurgia nesse grupo está mostrada na figura 7 e a distribuição da etiologia da hidrocefalia neste grupo é mostrada na tabela 3 . 


\begin{tabular}{|l|c|c|c|}
\hline Etiologia & DVP & TVE & Total \\
\hline Neurocisticercose & 0 & 1 & 1 \\
\hline Pós traumática & 3 & 2 & 5 \\
\hline Pós infecciosa & 8 & 1 & 9 \\
\hline Malformação de Dandy Walker & 8 & 1 & 9 \\
\hline Tumor de fossa posterior & 4 & 6 & 10 \\
\hline Pós hemorrágica & 16 & 0 & 16 \\
\hline Mielomeningocele & 23 & 1 & 24 \\
\hline Obstrução congênita & 45 & 43 & 88 \\
\hline Total & 107 & 55 & 162 \\
\hline
\end{tabular}

Tabela 2 - Etiologias da hidrocefalia e tratamento realizado em todas as crianças ( DVP = Derivação Ventrículo Peritoneal; TVE = Terceiro Ventriculostomia Endoscópica). 


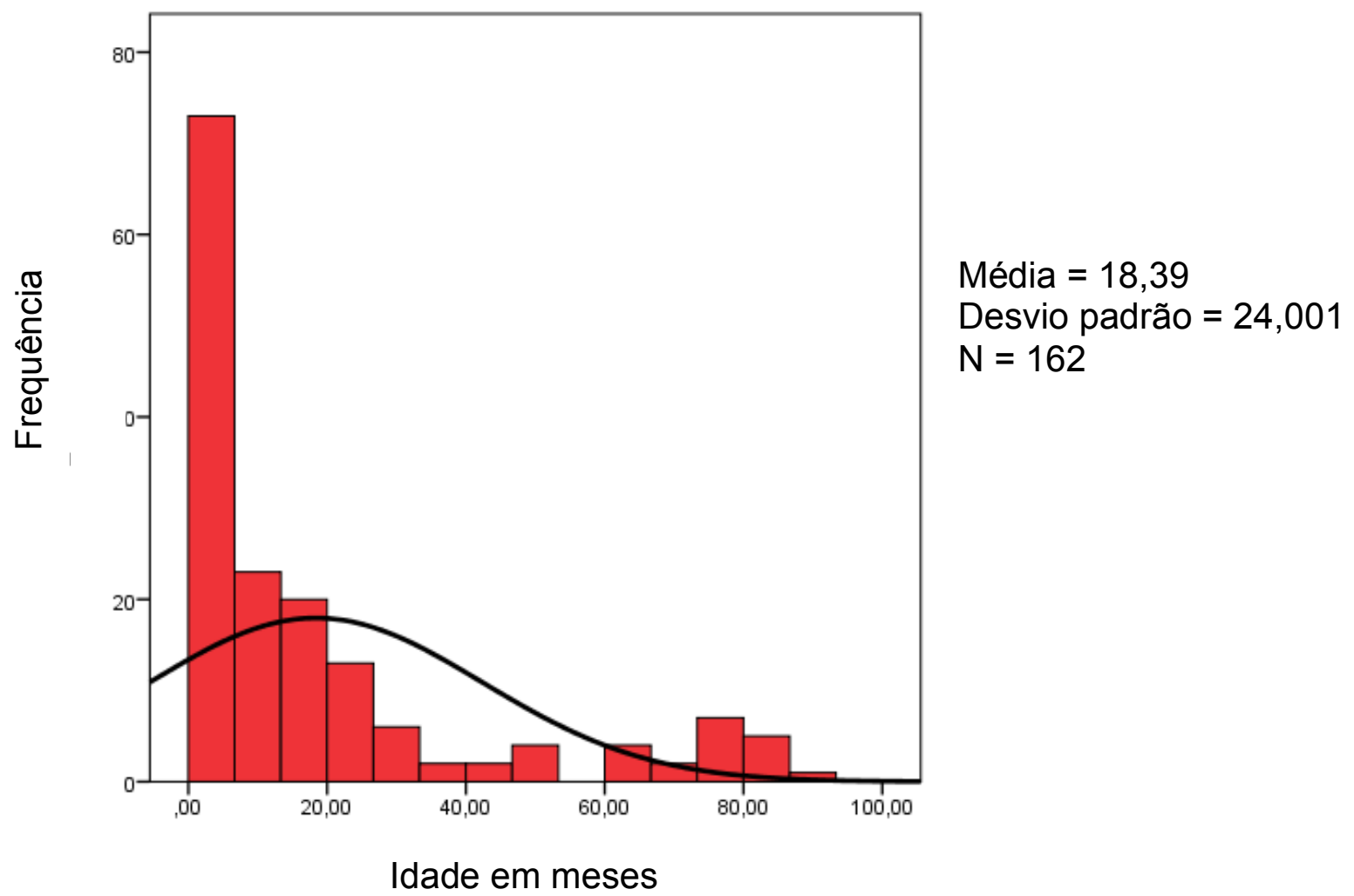

Figura 6 - Idade média ao tratamento da hidrocefalia de todos os casos 


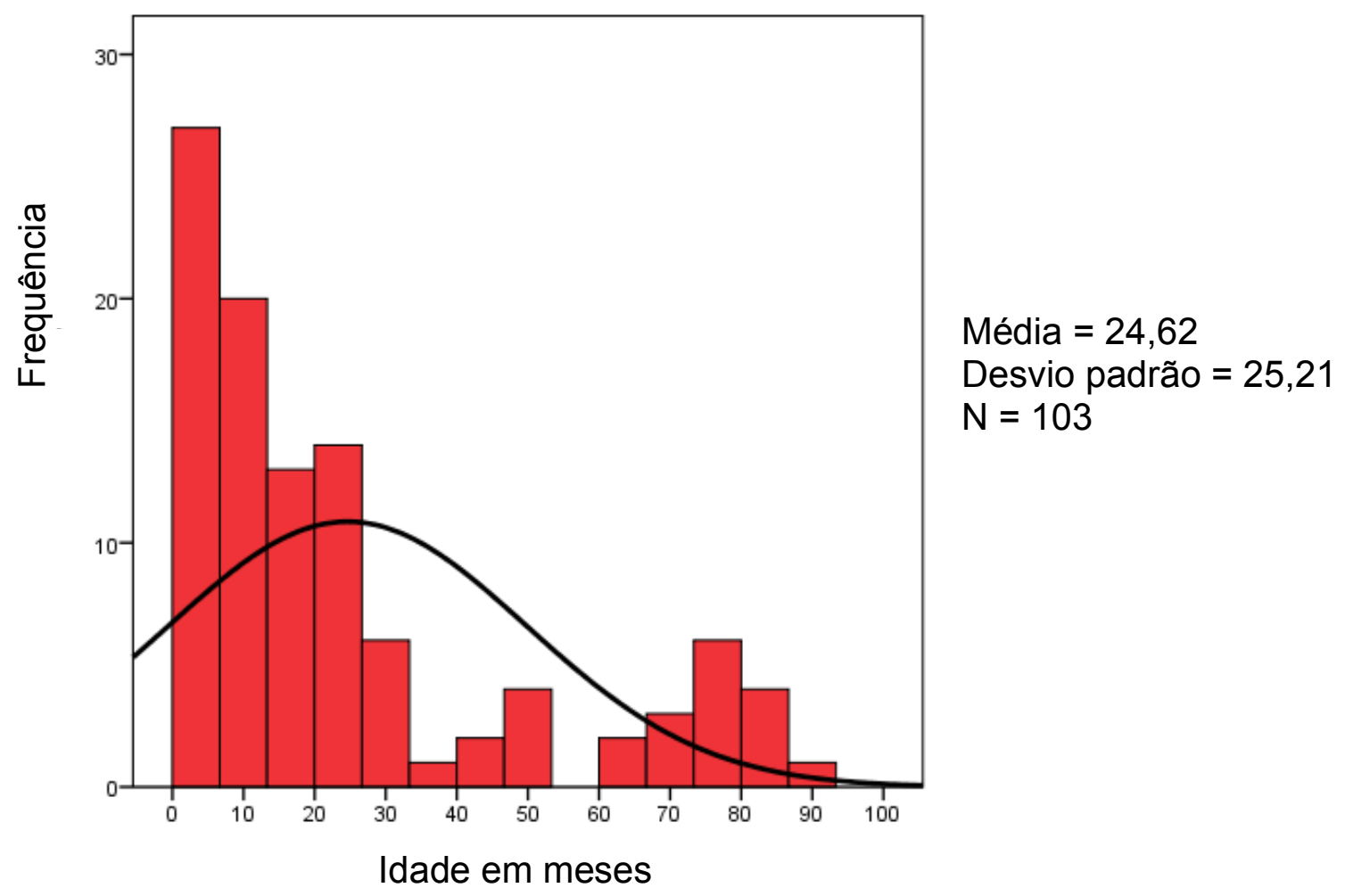

Figura 7 - Distribuição por idade no grupo estudado 


\begin{tabular}{|l|c|c|c|}
\hline Etiologia & DVP & TVE & Total \\
\hline Pós trauma & 3 & 2 & 5 \\
\hline Tumor de fossa posterior & 4 & 6 & 10 \\
\hline Obstrutiva congênita & 45 & 43 & 88 \\
\hline Total & 52 & 51 & 103 \\
\hline
\end{tabular}

Tabela 3 - Etiologias da hidrocefalia e tratamento realizado no grupo estudado ( DVP = Derivação Ventrículo Peritoneal; TVE = Terceiro Ventriculostomia Endoscópica). 
Sessenta e três dessas crianças foram submetidas a MR de crânio antes da cirurgia. Quarenta crianças foram estudadas apenas com TC de crânio como exame de neuroimagem antes da cirurgia. Todas as crianças tratadas com TVE foram submetidas a RM pré operatória. Várias crianças tratadas com DVP foram submetidas apenas a TC pré operatória.

\subsection{Tempo de internação hospitalar}

O tempo médio de internação hospitalar foi de 2,1 \pm 0,8 dias, variando de 1 a 4 dias, e foi semelhante nos dois grupos de tratamento. No grupo tratado com TVE, a média de dias de internação pós operatória foi de 2,24 \pm 0,6 dias e no grupo tratado com DVP a média de dias de internação pós operatória foi de 2,06 $\pm 0,8$ dias.

Casos de mal funcionamento precoce do procedimento foram considerados como uma nova admissão, mesmo quando ocorreram na primeira semana após a cirurgia.

\subsection{Falha do procedimento}

Em 30 crianças $(30 \%)$ a cirurgia não funcionou durante o período de seguimento e necessitaram de um novo procedimento. Dos 52 tratados com DVP, 20 (38\%) apresentaram disfunção no primeiro ano pós operatório, comparado a 11 (21,5\%) dos 51 tratados com TVE. Todas as 20 crianças com disfunção da válvula foram reoperadas. Dos 11 casos tratados com TVE e com sinais de disfunção do procedimento, um foi devido por fístula liquórica que foi tratada conservadoramente com sucesso e nesse caso não 
se tornou necessário uma nova cirurgia. Os outros 10 foram reoperados. As causas de disfunção do sistema de drenagem ventricular estão listados na tabela 4.

Foi considerado que ocorreu falha na cirurgia para tratamento da hidrocefalia quando houve necessidade de nova cirurgia para tratar a hipertensão intracraniana, independente do novo procedimento realizado.

As 11 crianças com falha na TVE foram submetidas a 10 novas cirurgias. As 20 crianças com falha na DVP foram operadas 61 vezes, variando de 1 a 10 novas cirurgias por criança. No total as 52 crianças que foram tratadas inicialmente com DVP foram operadas 113 vezes, e as 51 do grupo tratado inicialmente com TVE foram operadas 61 vezes.

\subsection{Complicações que não necessitaram nova cirurgia}

Algumas complicações mais leves não necessitaram nova cirurgia, como deformidades posicionais do crânio por superdrenagem liquórica, que ocorreram em nove crianças tratadas com DVP. A deformidade mais encontrada foi a plagiocefalia posicional, conduzida conservadoramente. Em duas dessas crianças chegou a ocorrer acavalgamento de suturas cranianas. Em duas outras crianças a hiperdrenagem liquórica causou uma depressão acentuada da fontanela anterior. Não ocorreu nenhum caso de deformidade posicional no crânio das crianças tratadas com TVE. 


\begin{tabular}{|l|c|c|}
\hline & DVP & TVE \\
\hline Fístula liquórica & 1 & 1 \\
\hline Infecção & 7 & 0 \\
\hline Obstrução & 12 & 10 \\
\hline Total & 20 & 11 \\
\hline
\end{tabular}

Tabela 4: Causas de falha do tratamento. DVP = Derivação Ventrículo Peritoneal; TVE = Terceiro Ventriculostomia Endoscópica 
Em duas crianças tratadas com DVP foi notado acumulação temporária de LCR no trajeto da válvula, mas como havia bom controle da hidrocefalia não houve necessidade de intervenção e elas foram conduzidas conservadoramente.

No grupo das crianças tratadas com TVE, uma delas apresentou quadro de hidrocefalia aguda cerca de 10 meses após a cirurgia e morreu. Não ocorreram mortes relacionadas à hidrocefalia ou a disfunção da cirurgia no grupo tratado com DVP durante o período do estudo. Houve um caso de hemiparesia transitória no grupo tratado com TVE e nenhum déficit motor, mesmo que transitório, foi observado no grupo tratado com DVP.

\subsection{Sobrevida do sistema de derivação liquórica}

A taxa de sobrevida da cirurgia de derivação liquórica, seja para o peritônio seja para as cisternas, definido como sucesso da cirurgia e de não haver necessidade de um novo procedimento para derivar o LCR ou bloquear a produção liquórica, foi de 78,4\% $\pm 5,8 \%$ para os casos tratados com TVE e de $61,5 \% \pm 6,7 \%$ para os casos tratados com DVP, após um ano de seguimento. Esses achados são mostrados na curva de sobrevida da Figura 8.

Não houve diferença estatística entre as duas curvas de sobrevida conforme o tratamento utilizado quando analisadas pelo Log Rang e teste Breslow de igualdade para distribuição de sobrevidas. 


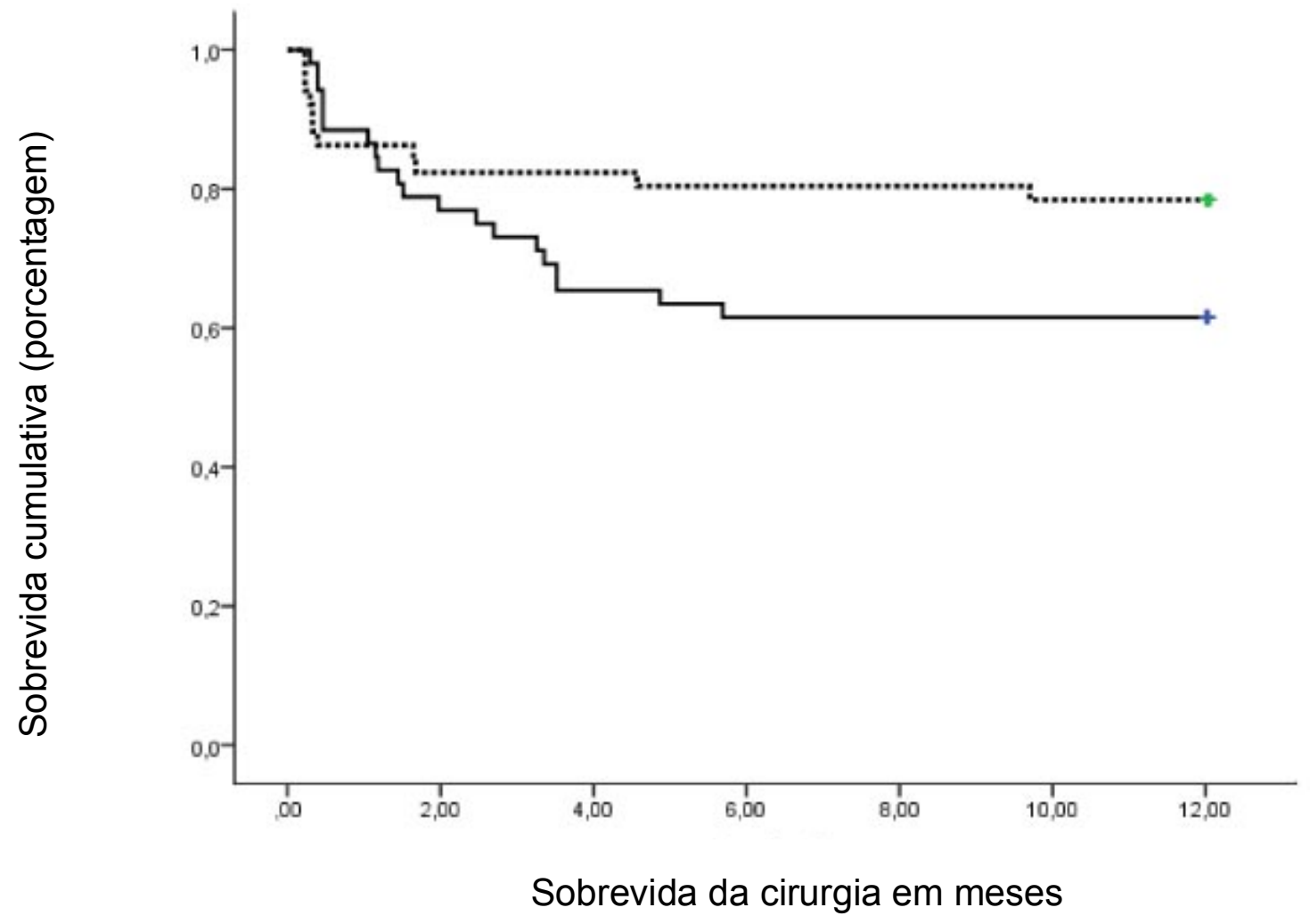

Figura 8 - Curva de sobrevida de Kaplan Meier para TVE e DVP. A curva de TVE é representada por linha pontilhada e a curva de DVP por linha contínua. 
Mesmo quando as crianças foram separadas por idade ao momento da cirurgia para hidrocefalia, continuamos a observar uma tendência de maior sobrevida do tratamento com TVE que o tratamento com DVP, seja com operações realizadas antes ou após o primeiro ano de vida (Fig. 9 e Fig. 10).

\subsection{Custos dos tratamentos}

O custo médio pago pelo SUS para o tratamento de casos de hidrocefalia em crianças no HBDF durante o período de estudo foi de USD $\$ 2.537,60 \pm 2.068,43$, variando de USD $\$ 1.357,75$ a USD $\$ 12.923,15$. O custo médio do tratamento da hidrocefalia com DVP foi de USD $\$ 2.890,69 \pm 2.835,02$ e para aqueles tratados com TVE foi de USD\$2.177,60 $\pm 517,73$.

Não houve diferença estatística nos custos dos dois grupos. Foi observado no presente estudo que após um ano de seguimento houve uma tendência a menores custos do tratamento com TVE em relação à DVP, apesar do custo inicial ser maior.

\subsection{Perímetro cefálico e melhora neurológica}

O perímetro cefálico pré operatório médio nas crianças que foram submetidas a tratamento com DVP estava no percentil 93,8 $\pm 15,7$ e no grupo que foi submetido a tratamento com TVE estava no percentil 91,1 $\pm 12,4$, sendo mostrado na Figura 11 .

O perímetro cefálico após o primeiro ano da cirurgia nas crianças tratadas com DVP estava no percentil 50,7 $\pm 41,2$ e nas crianças tratadas com TVE estava no percentil 76,9 \pm 17,6, conforme mostrado na figura 12. 
85

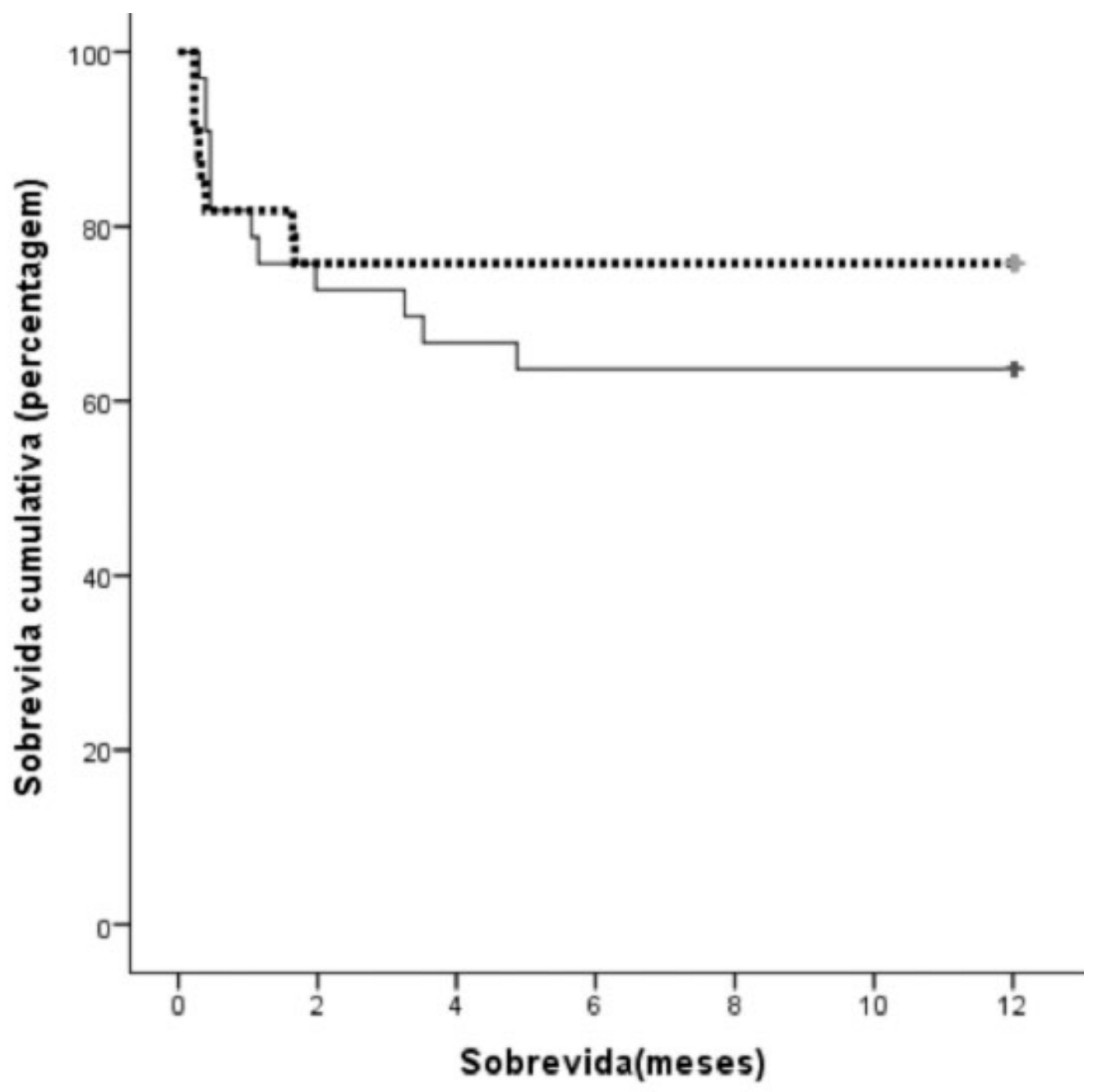

Figura 9 - Curva de sobrevida do tratamento da hidrocefalia em crianças com mais de um ano de idade. A linha pontilhada representa 0 tratamento realizado com TVE e a contínua com DVP 


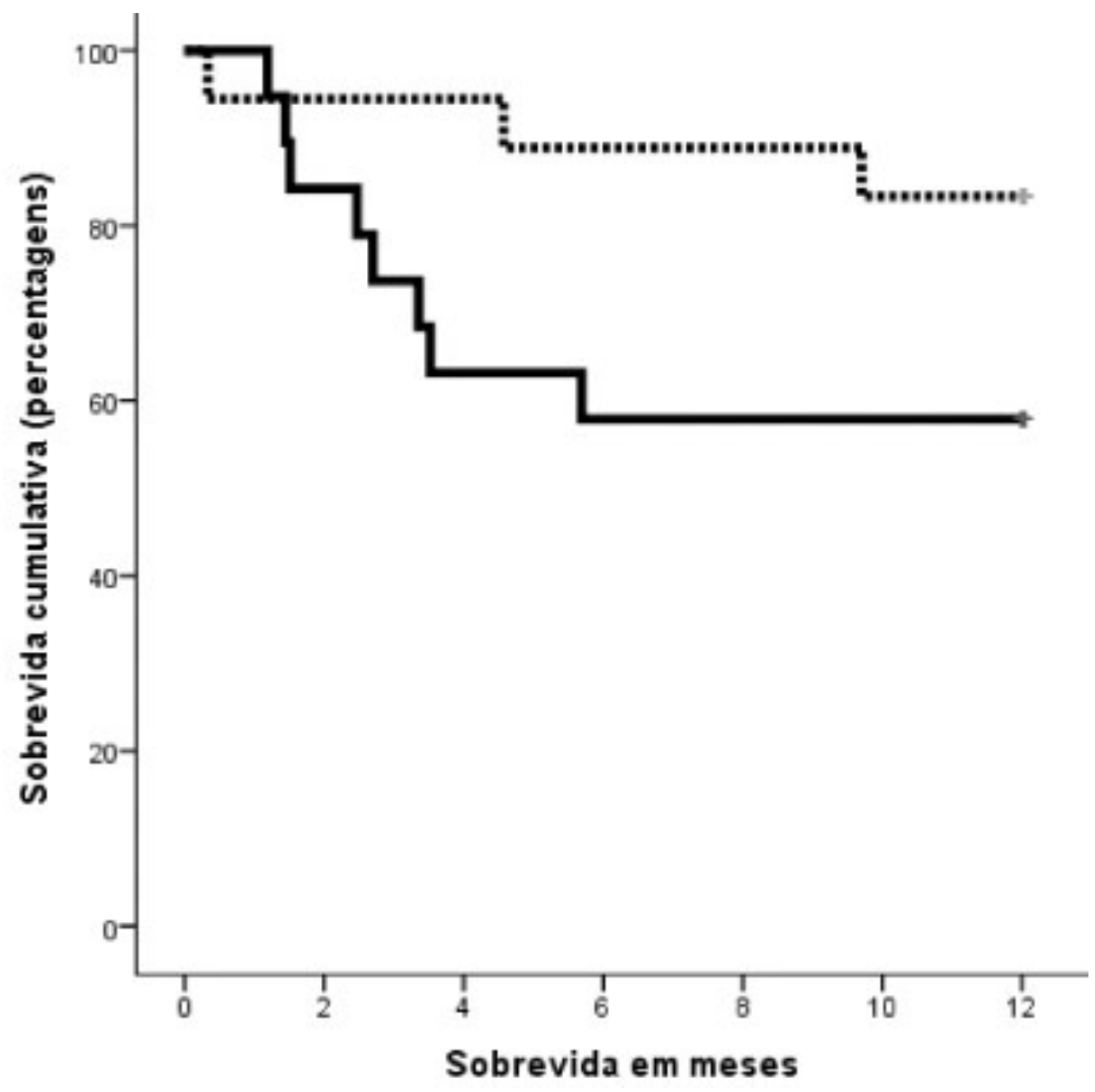

Figura 10 - Curva de sobrevida do tratamento da hidrocefalia em crianças com menos de um ano de idade. A linha pontilhada representa o tratamento com TVE e a contínua o tratamento com DVP. 


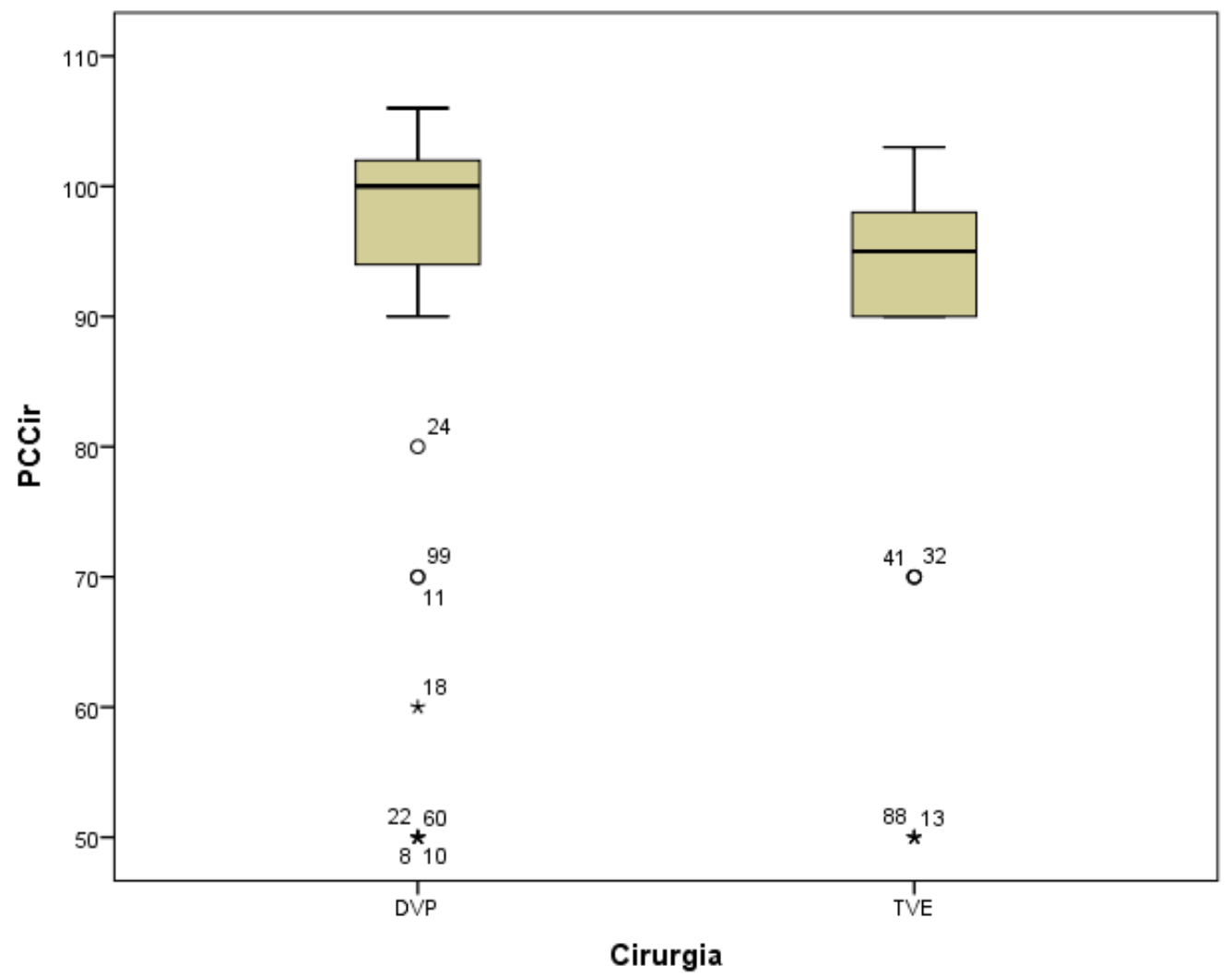


Figura 11 - Perímetro cefálico pré operatório das crianças operadas, mostrada em percentis.

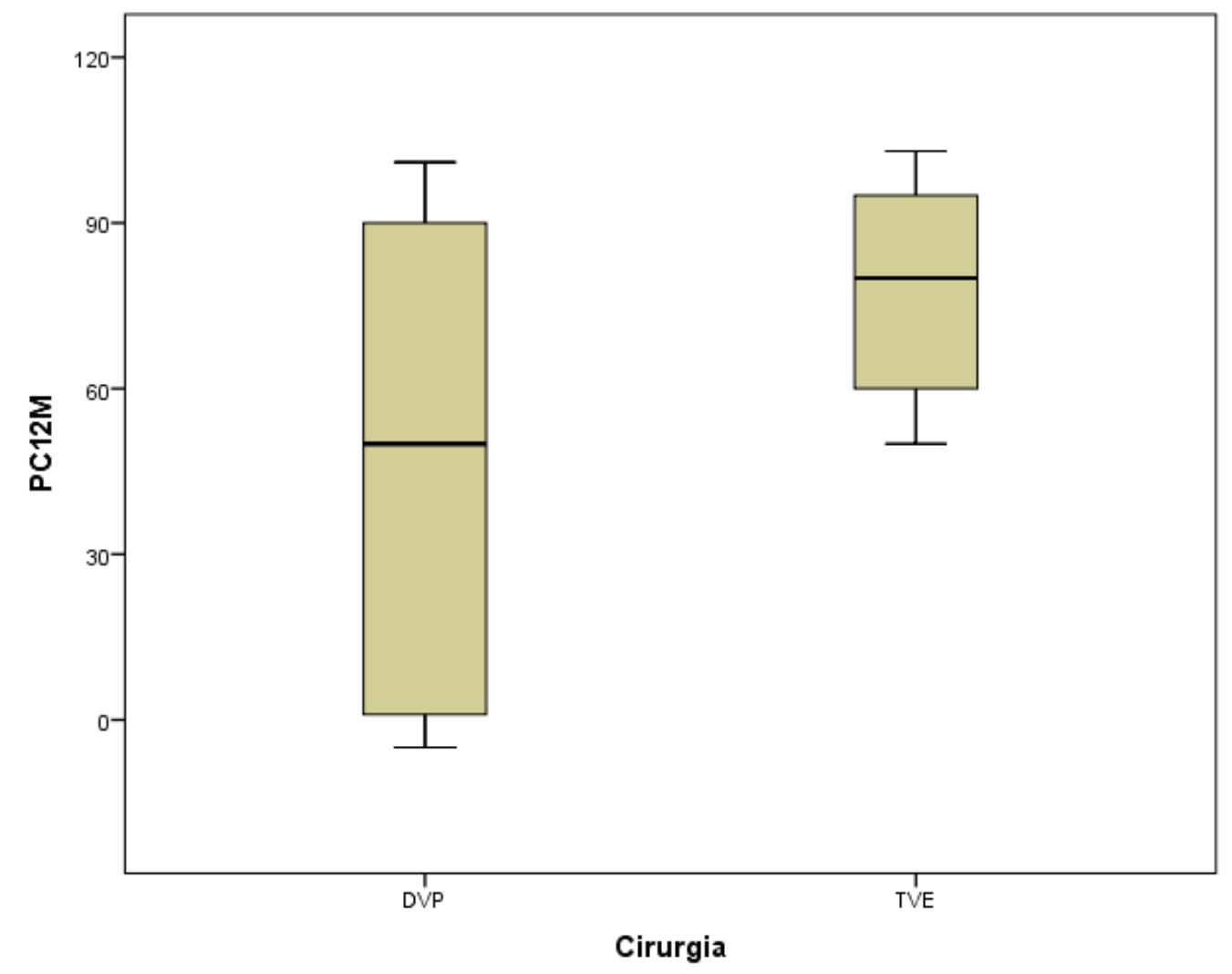

Figura 12 - Perímetro cefálico pós operatório mostrado em percentis. 
Não foi observada diferença na melhora neurológica entre o grupo tratado com DVP e o grupo tratado com TVE, utilizando-se como referência a escala de Denver modificada para crianças até 7 anos de idade e o índice de utilidades de saúde nas mais velhas. Da mesma maneira, não houve relato de familiares ou de problemas escolares que fossem mais acentuados em um dos grupos que em outro. Os resultados foram semelhantes tanto no grupo tratado com DVP quanto no grupo tratado com TVE, não foram observados diferenças clínicas dos grupos tratados com os dois métodos.. 
CAPÍTULO V - DISCUSSÃO 


\subsection{População estudada}

Desde a reintrodução da TVE ao final dos anos 1980, essa técnica ganhou em pouco tempo muitos entusiastas e se tornou rapidamente $\mathrm{o}$ procedimento preferido no tratamento da hidrocefalia obstrutiva em crianças mais velhas e adultos (PERETTA et al., 2006). TVE dá ao paciente a chance de ficar livre de uma válvula de hidrocefalia e de suas complicações potenciais (de RIBAUPIERRE et al., 2007). Todo paciente que tem uma válvula implantada recebe a informação que em algum momento de sua vida necessitará de uma cirurgia para revisão da válvula, o que pode ocorrer em qualquer momento. Por outro lado, a TVE, como não tem válvula, dá a falsa impressão que o paciente está curado da hidrocefalia, mas pode ocorrer obstrução tardia do estoma que comunica a cavidade ventricular com a subaracnoidea (LIPINA et al., 2007) ou outras causas de obstrução tardia.

Quando a TVE funciona adequadamente, evita-se o medo continuado de uma nova revisão cirúrgica para correção de mal funcionamento da válvula (BROCKMEYER et al., 1998). A maior parte das complicações da DVP são por disfunção mecânica da válvula ou de seus cateteres. A segunda maior causa de complicações das DVP são as infecções, particularmente sérias em crianças de tenra idade. É frequente também a ocorrência de disfunção da válvula por hiperdrenagem ou hipodrenagem de LCR (DI ROCCO et al., 2006).

A esperança de ficar livre da válvula transformou a TVE na maioria dos centros no tratamento de escolha para hidrocefalia, substituindo a DVP. Uma criança com disfunção de válvula gera mais visitas emergenciais, cria mais ansiedade para os pais e para 
os médicos e consume mais recursos de saúde que qualquer outro problema neurocirúrgico (DRAKE, 2009). Uma disfunção de válvula não tratada pode causar lesão cerebral por hipertensão intracraniana e até mesmo a morte do paciente (CHERN et al., 2010). A maioria dos neurocirurgiões pediátricos que trabalham com válvulas para hidrocefalia acreditam que a criança sem válvula é melhor que aquela com a melhor válvula do mundo. A maioria dos autores concordam que a TVE não tem muito sucesso nas crianças de tenra idade (DRAKE, 2007) e em algumas etiologias específicas da hidrocefalia.

Nos casos de criança de tenra idade, acredita-se que haja um problema quanto à capacidade de absorver o LCR nos espaços subaracnoideos. Assim, mesmo que a comunicação entre o III ventrículo e as cisternas aracnoides seja eficaz, a absorção liquórica deficiente não vai resultar em tratamento da hidrocefalia, sendo mais lógico realizar a derivação com válvula. Atualmente alguns autores vêm questionando tal posicionamento, realizando, além da TVE, a coagulação dos plexos coroides por via endoscópica. Para tal torna-se necessário um neuroendoscópio flexível para alcançar os plexos coroides nos cornos temporais, além de treinamento do cirurgião. É descrito um melhor sucesso do procedimento após uma curva de aprendizado (KULKARNI et al., 2014). A mesma teoria é proposta pelo baixo índice de sucesso das TVE nos casos de hidrocefalia associada a mielomeningocele, hidrocefalia pós infecciosa e hidrocefalia pós hemorragia ventricular (SACKO et al., 2010). Também aqui ultimamente tem se usado a coagulação de plexos coroides para aumentar a taxa de sucesso do procedimento neuroendoscópico. 
A maioria das publicações retrata o sucesso das TVE, poucas falam sobre complicações, riscos, insucessos (HANDLER et al., 1992, MELOT et al., 2013). As taxas de complicações do procedimento são variadas, de 2-15\% (BOURAS \& SGOUROS, 2013), sendo que a morbidade permanente é descrita em $3 \%$. Podem ocorrer complicações sérias e até mesmo fatais com a TVE. A mais grave é ruptura da artéria basilar. As morbidades podem ser secundárias a fístula liquóricas, infecções, distúrbios hormonais. É conhecida a piora tardia que pode levar à morte, cuja incidência não é conhecida, mas provavelmente é inferior a $0,1 \%$.

$\mathrm{Na}$ nossa série, entre as crianças tratadas pela primeira vez foram excluídas aquelas cuja etiologia da hidrocefalia já indicava que o tratamento deveria ser preferencialmente por implante de válvula. Havendo uma indicação médica para um dos procedimentos (DVP preferencial à TVE) não se poderia fazer a comparação entre eles. Os casos excluídos foram os associados a neurocisticercose, malformação de Dandy-Walker, hemorragia da matriz germinal dos prematuros e a mielomeningocele. É sabido do baixo índice de sucesso da TVE nesses casos. Nos últimos anos passou-se a utilizar a técnica de coagulação dos plexos coroides por via endoscópica somada à terceiro ventriculostomia para melhorar os índices de sucesso de crianças com mielomeningocele ou outras etiologias de hidrocefalia (WARF \& CAMPBELL, 2008). Essa técnica foi iniciada na África por Warf e ganhou muitos adeptos ao redor do mundo por sua eficácia. Já há estudos retrospectivos avaliando essa técnica (KULKARNI et al., 2014) confirmando sua melhor eficácia que a TVE sozinha principalmente naqueles casos onde não haveria indicação de TVE, como hemorragia ventricular da prematuridade e mielomeningocele. 
Para a realização da coagulação dos plexos coroides por via endoscópica como forma de tratamento da hidrocefalia, é necessário o uso de um endoscópio flexível. Após acesso ao ventrículo lateral, é feito a coagulação dos plexos coroides localizados ao longo do corpo do ventrículo lateral, no átrio ventricular e o localizado dentro do corno temporal. A seguir, é feito uma abertura no septo pelúcido e o processo é repetido do outro lado. Por falta de equipamento adequado - o endoscópio flexível não foi tentado essa técnica no presente estudo.

\subsection{Tempo de internação hospitalar}

Não houve diferença entre o tempo de internação hospitalar entre os dois grupos, sendo bastante curto nessa série, indicando que ambos os procedimentos foram bem tolerados pelas crianças. Casos que apresentaram disfunção precoce foram considerados como novos procedimentos e tiveram novo tempo de internação contados.

A comparação do tempo de internação hospitalar após a realização da cirurgia não foi indicador de qual procedimento seria melhor. Complicações infecciosas, como por exemplo quando a criança era submetida a retirada da válvula e implante de derivação ventricular externa, repercutiram em uma internação prolongada, mas não foi computado como tempo de internação pós operatório para fins de cálculo. Nesses casos, a nova internação foi tabulada como custos do procedimento, somando-se os gastos do tratamento da complicação com os gastos do procedimento inicial. 
Logo após a cirurgia, se a criança estivesse bem sem complicações pós operatórias imediatas, a programação era alta hospitalar em 24-48 horas.

\subsection{Falha do procedimento}

Houve uma maior frequência de complicações no grupo tratado com DVP comparado ao grupo tratado com TVE. Além do mais, o número de novas revisões cirúrgicas foi significativamente mais alto nas crianças que receberam DVP comparadas com aquelas submetidas a TVE.

Algumas crianças tiveram um número extremamente alto de novas operações. Duas das crianças tratadas inicialmente com DVP foram submetidas a 10 (dez) novos procedimentos cirúrgicos no primeiro ano após o primeiro implante de válvula. Considerando além do stress cirúrgico e anestésico de cada procedimento, há ainda uma sobrecarga emocional não só para a criança como para os pais a cada cirurgia e a cada expectativa que não seja necessário um novo procedimento. $O$ pensamento lógico é que o sofrimento emocional é bem maior nesse grupo que nas crianças tratadas com TVE, onde também ocorrem casos de falha do procedimento, mas as crianças não necessitaram um número tão alto de novas operações cirúrgicas.

No grupo com DVP observamos 7 casos de infecção que foram responsáveis por falha na drenagem liquórica. As infecções de válvula na infância já foram descritas anteriormente (OTON DE LIMA, 2008), sendo motivo de preocupação de todos os neurocirurgiões que fazem implantes de válvula. As taxas aceitas são elevadas, de $5-27 \%$. São mais comuns em crianças que em 
adultos, principalmente abaixo de um ano de idade. Em prematuros, as taxas de infecção de válvula são ainda mais altas. É um problema presente em todo o mundo. Com uma equipe de saúde comprometida em reduzir a taxa de infecção cirúrgica, o emprego de técnica cirúrgica rigorosa, preparo adequado do paciente, escolha da válvula mais apropriada para o determinado caso se consegue reduzir o nível de infecção da válvula, mas não se consegue eliminar tal risco.

As crianças que apresentam infecção após implante de DVP tem um quadro clínico mais grave, mais frequente e mais difícil de ser tratado que aquelas com infecção após serem tratadas com TVE. Essa observação concorda com relatos prévios (DI ROCCO et al, 2006). Na presente série, não houve nenhuma infecção liquórica nas crianças tratadas com TVE durante o tempo de estudo.

É sabido que a ventriculite pode comprometer a função cognitiva da criança (KANEV \& SHEEHAN, 2003). Este é mais um dado a ser levado em consideração quando vamos escolher entre uma TVE e uma DVP como o tratamento inicial para a hidrocefalia obstrutiva numa criança.

Existe uma complicação rara da TVE que é a obstrução tardia do estoma, com o desenvolvimento de hipertensão intracraniana de maneira aguda podendo ocorrer anos após a cirurgia podendo ser até causa de morte (HADER et al., 2002, JAVADPOUR et al, 2003). Um dos pacientes do grupo tratado com TVE apresentou uma piora do quadro e morte súbita, que pode ter sido por obstrução tardia do estoma criado na ocasião da cirurgia. Essa criança faleceu cerca de 10 meses após o procedimento inicial, tendo evoluído bem até o momento da morte. Embora não 
tenha sido confirmado que a morte foi pela hidrocefalia, como há casos semelhantes publicados, essa possibilidade é a mais provável. Quando uma criança é submetida a TVE existe uma falsa impressão de segurança e a sensação que a hidrocefalia foi curada porque não existe uma válvula (DRAKE et al., 2006). Numa tentativa de reduzir o aparecimento dessa complicação fatal várias sugestões tem sido propostas. Uma delas seria 0 acompanhamento regular da criança com TVE da mesma maneira que a criança com DVP é acompanhada, com exames de imagem seriados para acompanhar o tamanho ventricular. Os familiares e cuidadores devem ser orientados a reconhecer sinais e sintomas relacionados a aumento da pressão intracraniana e procurar um serviço de neurocirurgia se algum dos sinais aparece.

Pais de crianças portadoras de DVP geralmente sugerem o diagnóstico de disfunção de válvula quando levam a criança ao hospital por várias razões e solicitar e até exigir uma avaliação neurocirúrgica. Ao contrário, pais de crianças tratadas com TVE, com a falsa impressão de cura da hidrocefalia, quando procuram um serviço de saúde às vezes nem relatam que a criança foi submetida a tratamento para hidrocefalia. O acompanhamento de uma criança tratada com TVE deve ser pelo resto da vida, da mesma maneira que é acompanhada uma criança tratada com DVP.

Alguns autores chegam mesmo a recomendar o uso de um reservatório ventricular implantado no momento da cirurgia, pelo trajeto do neuroendoscópio, que ficaria sob o couro cabeludo da criança (AQUILINA et al., 2003; MOBBS et al., 2003). A ideia do reservatório seria para realizar uma punção e obter alívio rápido da hipertensão intracraniana no raro evento de obstrução aguda. Há 
outras recomendações, como sugerir que os pacientes residam próximo a uma cidade onde haja serviço de neurocirurgia, caso contrário implantar um reservatório naqueles que moram em locais mais distantes.

\subsection{Complicações que não necessitaram nova cirurgia}

No grupo estudado, houve alguns eventos associados a hiperdrenagem de LCR nas crianças tratadas com DVP, caracterizadas por plagiocefalia posicional, acavalgamento de suturas, depressão acentuada da fontanela anterior. Não ocorreu nenhum evento de hiperdrenagem nas crianças tratadas com TVE.

É sabido que o uso de DVP na maioria das vezes causa hiperdrenagem do LCR. Como as válvulas funcionam por uma diferença de pressão entre a cavidade ventricular e a cavidade abdominal, com a premissa que a cavidade abdominal tem pressão igual a zero, a drenagem de LCR com a diferença de pressão atestada pelo fabricante da válvula só ocorre quando o paciente está deitado, ou seja, as duas cavidades, a ventricular e a peritoneal, estão numa mesma altura. Quando o paciente fica sentado ou de pé, a altura da cabeça para o abdômen irá criar um diferencial que irá interferir na pressão nominal da válvula.

Por exemplo, se usamos uma válvula de pressão média-alta, com pressão de abertura de $140 \mathrm{~mm} \mathrm{H}_{2} \mathrm{O}$, quando a criança fica em posição ortostática, a diferença da altura da cabeça para o abdômen será de cerca de $30 \mathrm{~cm}$. Como o cateter distal está cheio de LCR, ele será puxado pela força da gravidade para baixo e a pressão de funcionamento da válvula será de $30 \mathrm{~cm}$ menos os 14 cm nominais da válvula. Ou seja, ao ficar sentado ou em pé essa 
criança terá uma pressão de drenagem da válvula negativa de menos $16 \mathrm{~cm}$ de $\mathrm{H}_{2} \mathrm{O}$. A pressão de uma válvula funciona na verdade em um sistema tipo "gangorra": quando a criança está deitada a drenagem liquórica é ditada pela pressão de fabricação da válvula; quando a criança está de pé, geralmente há uma hiperdrenagem do LCR.

Para reduzir esse problema, vários sistemas acoplados à válvula foram sugeridos, o mais comum deles o mecanismo antisifão (PINTO et al., 2012). Mesmo com uso desses sistemas, há uma redução mas não se previne totalmente os efeitos da hiperdrenagem.

É sabido que o uso de DVP leva a uma redução do perímetro cefálico da criança com o passar do tempo. Crianças hidrocefálicas tratadas com DVP no primeiro ano de vida tem perímetro cefálico abaixo daquele observado em crianças normais quando chegam aos três anos de idade (NILSSON et al., 2013). Além do fato de o perímetro das crianças tratadas com DVP seja menor, há uma frequência maior de deformidades cranianas, a maioria posicionais, causadas por hiperdrenagem de LCR. Esses defeitos, se não diagnosticados a tempo sem a família receber orientação adequada quanto ao posicionamento da cabeça da criança, podem resultar em deformidade permanente do crânio da criança. Apesar de não haver relato de dano neurológico decorrente da plagiocefalia posicional, ocorrem problemas psicossociais importantes. Algumas crianças sofrem com o assédio moral ("bullying") provocado pelo crânio dismórfico.

Outras crianças tiveram acavalgamento de suturas e depressão acentuada da fontanela anterior por hiperdrenagem do LCR. Novamente, embora sem déficit neurológico causado pela 
hiperdrenagem, problemas psicossociais podem ocorrer no futuro dessa criança. Para tentar prevenção dessas deformidades, algumas medidas podem ser tomadas. Uma delas seria o uso de válvulas de pressão programáveis externamente, mas não são disponíveis no Serviço Púbico de uma maneira rotineira, dado o seu custo elevado. Uma outra medida seria fazer o tratamento endoscópico da hidrocefalia para evitar o uso da válvula. É de se salientar que nem sempre isso é possível, pois a hiperdrenagem com deformidade craniana ocorre apenas em lactentes com suturas abertas. É sabido que quando mais jovem a criança, maiores as taxas de a TVE não funcionar adequadamente no controle da hidrocefalia.

\subsection{Sobrevida do sistema de derivação liquórica}

Nos nossos casos houve uma tendência de sobrevida do tratamento da hidrocefalia quando foi usada TVE comparada àqueles tratados com DVP. Existe uma queda contínua observada na curva de sobrevida de Kaplan-Meier para os pacientes tratados com DVP já no primeiro ano de acompanhamento. No grupo tratado com TVE a curva tem uma morfologia diferente. Há uma queda rápida nos casos que funcionam adequadamente seguindose uma estabilização sem queda. Esses achados estão de acordo com a literatura médica a respeito do tema (DE RIBAUPIERRE et al., 2007). Nos nossos casos não houve diferença estatisticamente significativa entre as duas curvas, provavelmente porque o tempo de acompanhamento foi apenas de um ano, embora houvesse sido registrado a tendência a melhores resultados com TVE. 
A distribuição da etiologia da hidrocefalia nos grupos tratados com DVP ou TVE foi similar, mas no grupo tratado com DVP tinha crianças mais jovens que no grupo tratado com TVE. É conhecido que quanto mais jovem a criança, maiores as taxas de disfunção da DVP (DI ROCCO et al., 2006). Esse viés de seleção está presente no grupo e pode contribuir para maior frequência de complicações como foi observado.

Nos nossos casos, mesmo quando os grupos foram estratificados de acordo com a idade, em crianças abaixo de um ano houve uma tendência de maior diferença quanto à sobrevida da forma de tratamento da TVE em relação à DVP. Os números não chegaram a ter uma significância estatística, mas sugerem que em casos selecionados a TVE pode ser indicada em crianças mais jovens. A tendência atual é complementar a cirurgia nesses casos com a realização da coagulação endoscópica dos plexos coroides.

\subsection{Custos dos tratamentos}

Embora os médicos através dos tempos desenvolveram conhecimento e experiência relatando os resultados clínicos, os custos do tratamento permanecem a terra de ninguém, com poucos envolvidos no custo do tratamento, seja ele em medicina privada ou pública. Na medicina privada a contenção de custos se dá por meio de glosas e não autorização de procedimentos. $\mathrm{Na}$ medicina pública os custos são calculados principalmente para fins fiscais. Estudos sobre custos visam otimizar o tratamento do ponto de vista econômico, contando que o paciente continue a receber tratamento de saúde de qualidade (MACLAUGHLIN, KHALESSE \& MARTIN, 2014). 
Os valores gastos no tratamento tem influenciado as condutas. O médico tem que estar consciente sobre a maneira de utilizar os recursos disponíveis para determinado tratamento. Isso é particularmente importante quando se trata de tratamento realizado em Hospital Público. Com o envolvimento de todos os participantes do tratamento podemos conseguir saúde pública de qualidade com gastos menores do dinheiro público. Em alguns países o uso de válvulas para hidrocefalia bem mais baratas que as utilizadas no Brasil foi relatado com um índice de sucesso semelhante ao uso de válvulas mais caras (SOTELO, 2012).

A avaliação econômica no tratamento de diferentes patologias ajuda a decidir como alocar recursos e priorizar alternativas de tratamento com o máximo benefício à população com o menor custo possível. $\mathrm{Na}$ verdade os recursos públicos destinados à saúde eram e ainda são insuficientes (MCLAUGHLIN, ONG, TABBUSH et al, 2014), em todos os países do mundo.

Com os custos do tratamento de diversas formas de patologia aumentando substancialmente, hoje em dia existe uma pressão dos financiadores públicos e privados dos serviços médicos no sentido de uma redução dos custos. Os custos passaram a ser calculados não só no procedimento mais importante, mas no tempo de internação, gastos como paciente externo e novas intervenções (LAM, SRINIVASAN, LUERSSEN \& PAN, 2014). Quando se fala em gastos é importante ressaltar, embora difícil de quantificar, os gastos da família de um paciente com uma doença crônica, o tempo dedicado ao paciente que poderia ser empregado de outra maneira, incluindo trabalho remunerado, gastos com transporte, medicamentos. Com isso 
costuma haver uma queda no rendimento familiar quando há um paciente com doença crônica no domicílio.

A responsabilidade pelos gastos em saúde não deve ser restrita aos gestores, mas deve incluir também os prestadores de serviços. As informações geradas pelos prestadores, com comparação de resultados entre tratamentos pode facilitar a identificação de uma maneira mais adequada de tratar uma determinada patologia, com resultados clínicos semelhantes ou melhores, a um custo menor. Esse custo deve ser menor não só para o Erário Público como também para os pacientes e seus familiares.

Os fatores relacionados ao custo do tratamento da hidrocefalia são vários, incluindo acesso do paciente ao Serviço de Saúde. Não há um estudo brasileiro sobre o custo do tratamento da hidrocefalia. Com esse trabalho temos o início de tal estudo, calculando os custos durante o primeiro ano de tratamento com as duas formas mais frequentes de se tratar tal problema.

Os custos iniciais da TVE tendem a ser maiores que os da DVP. Os custos a longo prazo tem a tendência a ficar menores naqueles operados com TVE principalmente porque não necessitarão novas cirurgias e novos períodos de admissão hospitalar. Comparando os custos da TVE com a DVP em um hospital público brasileiro, notamos essa tendência de custos mais altos dos pacientes tratados inicialmente com DVP a medida que 0 tempo vai passando, embora essa diferença não tenha sido estatisticamente significativa, como foi publicado anteriormente (GARTON et al., 2002).

Quando se trata de uma doença crônica da infância como é o caso da hidrocefalia, tem que se levar em consideração também 
a aflição que a patologia causa em toda a família, incluindo custos para a unidade familiar (SHANNON et al., 2011). Esses custos para a família são relativos a gastos com transporte, acesso a serviços de saúde, medicamentos e outras necessidades da criança. Muito frequentemente, como a criança necessita de um acompanhante e não raro é dependente parcial em atividades da vida diária, há uma queda na taxa de emprego da mãe (KUHLTHAU et al., 2005). Esses problemas financeiros que envolvem o tratamento da criança repercutem no bem estar de todo o núcleo familiar (LINDLEY, 2010).

O SUS remunera o Serviço de Saúde que oferece o tratamento da hidrocefalia de acordo com o procedimento realizado. O pagamento é referente a cobertura de todas as despesas hospitalares, incluindo medicações e alimentação. Como os valores não são muito altos, os hospitais prestadores desse serviço tentam otimizar seus custos, reduzindo o tempo de hospitalização e criando metas de evitar complicações.

As complicações cirúrgicas também não são bem remuneradas, resultando em gastos a fundo perdido para $\mathrm{O}$ prestador do serviço. O custo inicial da TVE é maior que o da DVP. Entretanto, já no primeiro dia de seguimento, pela maior frequência de complicações tardias nas crianças hidrocefálicas tratadas com DVP, maior número de novas cirurgias, o custo final se reverte e o tratamento por paciente passa a ficar mais caro naquelas crianças onde a escolha inicial foi a DVP e não a TVE.

Deve ser ressaltado que no presente estudo o que foi mostrado foi apenas uma tendência e os números não tem significância estatística. Para isso ocorrer seria necessário um maior número de casos, mas fundamentalmente seria importante 
ter um prazo maior de acompanhamento dos pacientes. É provável que após alguns anos de seguimento, se continuar a ser observada a tendência registrada no primeiro ano pós operatório, passe a ter significância estatística a diferença de custos por paciente.

O custo no primeiro ano de tratamento para a TVE teve uma média de USD $\$ 2.177,60 \pm 517,73$ comparado aos custos de USD\$ 2.890,69 $\pm 2.835,02$ para as crianças tratadas com DVP. Em termos de planejamento orçamentário, as crianças tratadas com TVE tiveram o custo de tratamento mais estável que as tratadas com DVP, onde algumas crianças necessitaram de um número exageradamente alto de novas cirurgias.

A diferença entre os custos das crianças tratadas com DVP com o passar do tempo deve-se principalmente à ocorrência de infecção. Quando há infecção da válvula, o custo do tratamento fica elevado, pois implica em pelo menos mais duas cirurgias: a primeira para retirada do sistema de derivação ventricular infectado e implante de uma derivação ventricular externa; a segunda para implante de uma nova derivação ventricular com interposição de válvula, após um longo período de internação com uso de antibióticos para esterilização do LCR.

Quando ocorreu infecção, a variação da remuneração paga pelo SUS para o tratamento em um ano de seguimento foi de até nove vezes e meia maior que o tratamento sem intercorrências (USD\$ 12.923,15 comparado a USD\$1.357,75). Apesar de não ter ocorrido infecção nos nossos casos tratados com TVE durante o período de duração do estudo, a experiência mostra que quando isso acontece a duração do tratamento e necessidade de novos 
procedimentos costuma ser bem menor que nas infecções de válvula de hidrocefalia (PHAM, FAN \& OWLER, 2013).

Nosso estudo evidencia que os custos associados com as complicações do tratamento, principalmente nos casos onde ocorreram infecções, foram extremamente elevados. As infecções nas crianças tratadas com implantes de válvula demandaram maior tempo de internação e maior número de novas cirurgias que as infecções nas crianças tratadas com cirurgia endoscópica. A frequência de casos de infecção pós operatória foi também maior nas crianças tratadas com DVP que naquelas tratadas com TVE. A tradução desses achados é que os custos tendem a aumentar nas crianças tratadas com DVP com o passar do tempo, pois tal cirurgia se acompanha de um número maior de complicações. A ação do médico que trata dessa patologia é demonstrar que os recursos públicos destinados ao tratamento da hidrocefalia podem ser otimizados, com um custo menor a longo prazo, dependendo da técnica utilizada.

\subsection{Perímetro cefálico e melhora neurológica}

O emprego de DVP produz um controle mais rápido do perímetro cefálico, mas em compensação causa com maior frequência deformidades posicionais no crânio por hiper funcionamento da válvula. Essas deformidades se não tratadas a tempo podem se tornar permanentes e causar problemas estéticos graves na criança, com repercussões psicossociais. Para tentar remediar o problema, a primeira conduta foi clínica, com orientação aos pais e cuidadores sobre a posição correta de deitar a criança, reduzir o tempo que a criança fica em posição ortostática. Casos 
mais graves necessitam de nova cirurgia ou para trocar a válvula por uma de pressão mais alta ou para trocar por uma válvula de pressão programável, ajustável externamente sem necessidade de nova operação.

Nos nossos casos, nenhuma criança tratada com TVE apresentou sinais de hiperdrenagem e consequentemente dismorfismos cranianos. Existe uma tendência de tratar as crianças mais velhas com TVE. Nas crianças mais velhas o crânio é mais rígido e menos propenso a deformidades posicionais por hiperdrenagem. Na nossa série, apesar de tentar obter grupos os mais similares possíveis, essa tendência também foi demonstrada, com idade média mais baixa nas crianças tratadas com DVP que naquelas com TVE.

Sob o ponto de vista do estado neurológico não houve diferença nos resultados entre os dois grupos. Esse achado também está de acordo com publicações prévias (KULKARNI et al, 2010). Houve melhora no quadro neurológico geral da criança independente se ela foi tratada com DVP ou TVE, observada no primeiro ano após a cirurgia, sem superioridade de uma técnica sobre a outra.

Nessa série observou-se que houve um melhor controle do tamanho da cabeça, comprovado pela redução do perímetro cefálico quando tabulado em percentis, no grupo tratado com DVP que no grupo tratado com TVE. Ao mesmo tempo, houve uma ocorrência maior de deformidades cranianas posicionais como a plagiocefalia posterior e até mesmo deformidades mais grosseiras como acavalgamento de suturas ou crânio dismórfico por depressão acentuada da fontanela anterior. Tais deformidades 
foram secundárias à hiperdrenagem liquórica e foram encontrados apenas nos casos tratados com DVP.

Sob ponto de vista de resultados neurológicos, não houve diferença de resultado entre o grupo tratado com DVP e o grupo tratado com TVE. Pela resposta obtida nessa série, não se pode optar por uma técnica de tratamento da hidrocefalia pensando em melhor resposta neurológica uma vez que elas se equivalem. Outros parâmetros devem ser utilizados na escolha da maneira de tratar, sendo importante ressaltar o fator econômico principalmente em sociedades com fontes limitadas de obtenção de recursos.

\subsection{Pontos mais relevantes na discussão}

Desde que os neurocirurgiões entenderam a fisiologia da produção e circulação liquórica passaram a entender melhor a natureza da hidrocefalia. $\mathrm{O}$ objetivo é derivar o liquor para um local onde possa ser absorvido. Com uso de válvula, o liquor é derivado para uma cavidade corporal onde será absorvido. Com a neuroendoscopia, é criado um estoma dentro da caixa craniana, evitando o local de bloqueio da circulação liquórica, sendo uma forma mais fisiológica de tratamento do problema.

Embora os primeiros procedimentos neuroendoscópicos tenham sido realizados no começo do século passado, a técnica só alcançou popularidade com o avanço tecnológico que levou à miniaturização das câmeras de vídeo, melhor qualidade de imagem e iluminação.

Nenhum estudo até hoje comprovou de maneira definitiva que uma das duas técnicas mais usadas no tratamento da hidrocefalia (TVE e DVP) seja melhor que a outra. 
No presente estudo, comparando-se as duas técnicas em crianças, observa-se uma frequência maior de mal funcionamento da válvula a medida que o tempo passa. Isso significa maior número de internações, exames, cirurgias, sobrecarga emocional, física e financeira para o paciente e sua família. Quando a criança fica internada longos períodos, significa que um de seus pais fica sem trabalhar ou sem cuidar dos demais membros da família para atender a criança doente.

A impressão é que mesmo que a resposta clínica ao tratamento sendo semelhante independente da técnica cirúrgica utilizada, em termos de saúde pública provavelmente ocorrerão menos gastos com o passar do tempo quando o tratamento é feito com o método neuroendoscópico. Isso inclui os gastos do governo e os gastos da família da criança.

Se nos basearmos apenas na independência do uso da válvula, existe um benefício do ponto de vista emocional para a criança e sua família. Mas para que os riscos da cirurgia neuroendoscópica seja semelhante ao implante de válvula, é necessário treinamento.

A sugestão é que novos estudos sejam feitos com um tempo maior de seguimento. Ao mesmo tempo, que se treine um maior número de neurocirurgiões para o uso do neuroendoscópio, não só durante a residência médica, mas também aqueles neurocirurgiões que atuam em centros menores. Com isso, esperase que com 0 tempo os gastos com $\circ$ tratamento neuroendoscópico da hidrocefalia seja menor que os gastos com implantes de válvulas. 
CAPÍTULO VI - CONCLUSÕES 
No presente estudo apesar dos custos iniciais da TVE serem maiores que os da DVP, já durante o primeiro ano de acompanhamento as crianças que receberam válvula necessitaram de um maior número de revisões cirúrgicos com novas e as vezes demoradas internações hospitalares. Com isso, os custos por paciente naqueles tratados inicialmente com DVP passaram a ser maiores que os que inicialmente foram tratados com TVE. Os custos da DVP tendem a ser maiores com o passar do tempo. Ao final do primeiro ano de acompanhamento a tendência do custo médio por paciente tratado com DVP foi maior que o tratado com TVE, embora não tenha sido estatisticamente significante.

No julgamento de qual procedimento deve ser adotado para reduzir despesas públicas, com boa resposta clínica, a tendência é o uso de TVE, embora a correta indicação dessa forma de tratamento deva passar por um novo estudo com maior tempo de observação. 
CAPÍTULO VII - REFERÊNCIAS BIBLIOGRÁFICAS 
1. Aguiar E. A arte de curar. Diagraphic Editora. Rio de Janeiro, 2003; pp 21-31

2. Albucassis. On Surgery and instruments, a definitive edition of the Arabic text with English translation and commentary (trans: Spink MS, Lewis GL). The Wellcome Institute of the History of Medicine, London 1973.

3. Alexander E, Davis $\mathrm{CH}$. Macewen's sign - "the cracked pot sound". Surg Neurol 1987; 27:519-522

4. Alksne JF, Lovings ET. Functional ultrastructure of the arachnoid villus. Arch Neurol. 1972;27:371-377

5. Anei R, Hayashi Y, Hidroshima S, Mitsui N, Orimoto R, Uemori G, Saito M, Sato M, Wada H, Hododuka A, Kamada K. Hydrocephalus due to diffuse villous hyperplasia of the choroid plexus. Neurol Med Chir (Tokyo). 2011;51:347-441

6. Anton G, von Bramann FG. Balkenstich bei Hydrocephalien, Tumoren, und bei epilepsie. Münch med Wschr. 1908; 11:1673-1675

7. Aquilina K, Edwards RJ, Pople I. Routine Placement of a ventricular reservoir at endoscopic third ventriculostomy. Neurosurgery. 2003;53:91-96.

8. Aschoff A, Kremer P, Hashemi B, Kunze S. The scientific history of hydrocephalus and its treatment. Neurosurg Rev 1999; 22:67-93

9. Bateman GA. Hypertensive slit ventricle syndrome: pseudotumor cerebri with a malfunctioning shunt? J Neurosurg. 2013;119:1503-1510

10. Benacerraf BR, Birnholz JC. The diagnosis of fetal hydrocephalus prior to 22 weeks. J Clin Ultrasound. 1987; 15:531-536

11. Bering EA. Circulation of the cerebrospinal fluid. Demonstration of the choroid plexuses as the generator of the force for flow of luid and ventricular enlargement. J Neurosurg. 1962;19:405-413

12. Bonduran CP, Jimenez DF. Epidemiology of cerebrospinal fluid shunting. Pediatr Neurosurg. 1995;23:254-258

13. Boockvar JA, Loudon W, Sutton LN. Development of the Spitz-Holter valve in Philadelphia. J Neurosurg. 2001;95:145-147

14. Bouras T, Sgouros S. Complications of endoscopic third ventriculostomy. World Neurosurg. 2013;79(2 Suppl):S22.e9-12 
15. Brockmeyer D, Abtin K, Carey L, Walker ML. Endoscopic third ventriculostomy: an outcome analysis. Pediatr Neurosurg. 1998;28:236-240

16. Chakraborty A, Crimmins D, Hayward R, Thompson D. Toward reducing shunt placement rates in patients with myelomeningocele. J Neurosurg Pediatr. 2008;1:361-365

17. Chern JJ, Macias CG, Jea A, Curry DJ, Luerssen TG, Whitehead WE. Effectiveness of a clinical pathway for patients with cerebrospinal fluid shunt malfunction. J Neurosurg Pediatr. 2010;6:318-324

18. Chi JH, Fullerton HJ, Gupta N. Time trends and demographics of deaths from congenital hydrocephalus in children in the United States: National Center for Health Statstics data, 1979 to 1998. J Neurosurg. 2005;103 Suppl:113-118

19. Cinalli G, Peretta P, Spenatto P, Savarese L, Varone A, Vedova P, Grimald G, et al. Neuroendoscopic management of interhemispheric cysts in children. J Neurosurg Pediatrics. 2006;105:194-202

20. Coen RW. Preventing germinal matrix layer rupture and intraventricular hemorrhage. Front Pediatr. 2013;1:22-26

21. Dandy WE, Blackfan KD. An experimental and clinical study of internal hydrocephalus. J Am Med Assoc 1913; 61:22162217

22. Dandy WE. An operative procedure for hydrocephalus. John Hopkins Hosp Bull. 1922; 33:189-196

23. Dandy WE. Extirpation of the choroid plexus of the lateral ventricles in communicating hydrocephalus. Ann Surg. 1918; 37:569-579

24. Dandy WE. The diagnosis and treatment of hydrocephalus resulting form strictures of the aqueduct of Sylvius. Surg Gynecol Obstet. 1920; 31:340-358

25. Dandy WE. Ventriculography following the injection of air into the ventricles. Ann Surg 1918; 68:5-11

26. Davidson RI. Peritoneal bypass in the treatment of hydrocephalus: historical review and abdominal complications. J Neurol Neurosurg Psychiatry. 1976;7:640646

27. Davis F, llyasova D, Rankin K, McCarthy B, Bigner DD. Medical diagnostic radiation exposures and risk of gliomas. Radiat Res. 2011;175:790-796 
28. De Lange SA. Progressive hydrocephalus. In Vinken PJ, Bruyn GW, Myrianthopoulos NC (Eds) Congenital malformations of the brain and skull, part I. Amsterdam 1977, North-Holland, pp 525-563

29. De Lange SA. Treatment of hydrocephalus. In Vinken PJ, Bruyn GW, Myrianthopoulos NC (Eds) Congenital malformations of the brain and skull, part II. North-Holand, Amsterdam 1977, pp 565-606

30. de Ribaupierre S, Rilliet B, Vernet O, Regli L, Villemure JG. Third ventriculostomy vs ventriculoperitoneal shunt in pediatric obstructive hydrocephalus: results from a a Swiss series and literature review. Childs Nerv Syst. 2007;23:527533

31. Di Rocco C, Massimi L, Tamburrini G. Shunts vs endoscopic third ventriculostomy in infants: are there different types and/or rates of complications? Childs Nerv Syst. 2006;22:1573-1589

32. Drake J, Chumas P, Kestle J, Pierre-Kahn A, Vinchon M, Brown J, Pollack IF, Arai H. Late deterioration after endoscopic third ventriculostomy: additional cases and review of the literature. J Neurosurg. 2006;105(2 Suppl):118126

33. Drake JM, Sante-Rose, C. The Shunt Book. Cambridge, MA: Blackwell Sciente, 1995, pp 3-12

34. Drake JM. Endoscopic third ventriculostomy in pediatric patients: the Canadian experience. Neurosurgery. 2007;60:881-886

35. Drake JM. The surgical management of pediatric hydrocephalus. Neurosurgery. 2008;62 Suppl 2:633-640

36. Drake JM, Kulkarni AV, Kestle J. Endoscopic third ventriculostomy versus ventriculoperitoneal shunt in pediatric patients: a decision analysis. Childs Nerv Syst 2009;25:407472

37. El Khamlichi. African neurosurgery. Part I: Historical outline. Surg Neurol 1998; 49:222-227

38. El Shafei IL, El Shafei HI. The retrograde ventriculo-sinus shunt (El Shafei RVS shunt). Rationale, evolution, surgical technique and long-term results. Pediatr Neurosurg. 2005;41:305-317

39. Enchev Y, Oi S. Historical trends of neuroendoscopic surgical techniques in the treatment of hydrocephalus. Neurosurg Rev. 2008;31:249-262 
40. Epstein F, Hochwald GM, Ransohoff J. Neonatal hydrocephalus treated by compressive head wrapping. Lancet 1973; 24:634-636

41. Epstein F, Wald A, Hochwald GM. Intracranial pressure during compressive head wrapping in treatment of neonatal hydrocephalus. Pediatrics. 1974; 54:786-790

42. Ersahin Y, Arslan D. Complications of endoscopic third ventriculostomy. Childs Nerv Syst. 2008;24:943-948

43. Evans WA Jr. An encephalographic ratio for estimating ventricular enlargement and cerebral atrophy. Arch neurol Psychiatry. 1942;47:931-937

44. Feeny D, furlong W, Boyle M. Torrance GW. Multi-attribute health status classifiation Systems: Health Utilities Index. PharmacoEconomics. 1995;7:490-502

45. Feinberg DA, Mark AS. Human brain motion and cerebrospinal fluid circulation demonstrated with MR velocity imaging. Radiology. 1987;163:793-799

46. Ferguson $\mathrm{AH}$. Intraperitoneal diversion of the cerebrospinal fluid in cases of hydrocephalus. N Y Med J. 1898; 67:902909

47. Fernell E, Hagberg g. Infantile hydrocephalus: declinig prevalence in pre-term infants. Acta Paediatr 1998;87:392396

48. Fisher RG. Surgery of the congenital anomalies, in Walker AE (ed): A History of Neurological Surgery. Baltimore: Wiliams \& Wilkins, 1951, pp 334-347

49. Fletcher JM, Bohan TP, Brandt ME, Brookshire BL, Beaver SR, Francis DJ, Davidson KC, Thompson NM, Miner ME. Cerebral white matter and cognition in hydrocephalic children. Arch Neurol. 1992;49:818-824

50. Forrest DM, Laurence KM, Macnab GH. Ventriculo-subdural drainage in infantile hydrocephalus. Lancet. 1957; 270:827828

51. Frankenberg WK, Dodds JB. Denver developmental screening test. J Pediatr. 1967;71:181-191

52. Fukushima T, Ishijima B, Hirakawa K, Nakamura N, Sano K. Ventriculofiberscope: a new technique for endoscopic diagnosis and operation. Technical note. J Neurosurg. 1973; 38:251-256

53. Fulmer BB, Grabb PA, Oakes WJ, Mapstone TB. Neonatal Ventriculosubgaleal shunts. Neurosurgery. 2000; 47:80-83 
54. Garton HJL, Kestle JRW, Cochrane DD, Steinbok P. A costeffectiveness analysis of endoscopic third ventriculostomy. Neurosurgery. 2002;51:69-78.

55. Girotti ME, Singh RR, Rodgers BM. The ventriculo-gall bladder shunt in the treatment of refractory hydrocephalus: a review of the current literature. Am Surg. 2009;75:734-737

56. Gjerris F, Snorrason E. The history of hydrocephalus. J Hist Neurosci 1992;1:285-312

57. Goodrich JT, Flamm ES. Historical overview of neurosurgery. In Winn HR (ed). Youmans Neurological Surgery, 6th Ed.New York, Elsevier,2011, pp 3-37

58. Greitz D. Radiological assessment of hydrocephalus: new theories and implications for therapy. Neurosurg Rev. 2004;27-145-165

59. Gupta N, Park J, Solomon C, Kranz DA, Wrensch M, Wu YW. Long-term outcomes in patients with treated childhood hydrocephalus. J Neurosurg. 2007;106(5 Suppl):334-339

60. Hader WJ, Drake J, Cochrane D, Saprrow O, Johnson ES Kestle J. Death after late failure of third ventriculostomy in children. J Neurosurg. 2002;97:211-215

61. Handler MH, Abbott R, Lee, M. A near-fatal complication of endoscopic third ventriculostomy: case report. Neurosurgery. 1994;35:525-528

62. Haynes IS Congenital internal hydrocephalus: its treatment by drainaage of the cisterna magna into the cranial sinuses. Ann Surg 1913;57:449-484

63. Heile B. Zur chirurgischen Behandlung des Hydrocephalus internus durch Ableitung der Cerebrospinalflüssigkeit nach der Bauchhöhle und der Pleurakuppe. Arch Klin Chir. 1914; 105:501-516

64. Henle A. Beitrag zur Pathologie und Therapie des Hydrocephalus. Mitteilungen aus dem Grenzzebiet Medizin und Chirurgie. 1986;1:264-302

65. Hyndman OR. Hydrocephalus, a contribution related to treatment. J Neurosurg. 1946;3:426-443

66. Ingraham FD, Campbell JB. An apparatus for closed drainage of ventricular systems. Ann Surg 1941;114:10961098

67. Ingram ME, Huguenard AI, Miller BA, Chern JJ. Poor correlatin between head circumference and cranial ultrasound findings in premature infants with intraventricular hemorrhage. J Neurosurg Pediatrics. 2014;14:184-189 
68. Jallo GI, Kothbauer KF, Abbott IR. Endoscopic third ventriculostomy. Neurosurg Focus. 2005;19:E11

69. Javadpour M, May P, Mallucci C. Sudden death secondadry to delayed closure of endoscopic third ventriculostomy. $\mathrm{Br} \mathrm{J}$ Neurosurg. 2003;17:266-9

70. Johnston M, Zakharov A, Papaiconomou C, Salmasi G, Armstrong D. Evidence of connections between cerebrospinal fluid and nasal lymphatic vessels in humans, non-humans primates and other mammalian species. Cerebrospinal Fluid Res. 2004;1:2-10

71. Jones RFC. Long-term results in various treatments of hydrocephalus. J Neurosurg. 1967;26:313-315

72. Kanev PM, Sheehan JM. Reflections on shunt infection. Pediatr Neurosurg. 2003;39:285-290

73. Kausch W. Die Behandlung des Hydrocephalus der kleinen Kinder. Arch Clin Chir. 1908;87:709-796

74. Key EAH, Retzius MG. Studien in der anatomie des nervensystems und des bindegewebes. 1875, Samson and Wallin, Stockholm

75. Ko, JM Genetic syndromes associated with overgrowth in childhood. Ann Pediatr Endocrinol Metab. 2013;18:101-105

76. Kombogiorgas D, Sgouros S. Assessment of the influence of operative factors in the success of endoscopic third ventriculostomy in children. Childs Nerv Syst. 2006;22:12561262

77. Krause F. Chirurgie des Gehirns und des Rückenmarks. Urban und Schwarzenberg. 1911. Vienna, pp 146-173

78. Kuhlthau K, Hill KS, Yucel R, Perrin JM. Financial burden for families of children with special health care needs. Matern Child Health J. 2005;9:207-218.

79. Kulkarni AV, Hui S, Shams I, Donnelly R. Quality of life in obstructive hydrocephalus: endoscopic third ventriculostomy compared to cerebrospinal fluid shunt. Childs Nerv Syst. 2010;26:75-79

80. Kulkarni AV, Riva-Cambrin J, Browd SR, Drake JM, Holubkov R, et al. Endoscopic third ventriculostomy and choroid plexus cauterization in infants with hydrocephalus: a retrospective Hydrocephalus Clinical Research Network study. J Neurosurg Pediatrics. 2014;14:224-229

81. Lam S, Harris D, Rocque BG, Ham SA. Pediatric endoscopic third ventriculostomy: a population-based study. J Neurosurg Pediatr. 2014;14:455-464 
82. Lam SK, Srinivasan VM, Luerssen TG, Pan IW.

Cerebrospinal fluid shunt placement in pediatric population: a model of hospitalization cost. Neurosurg Focus. 2014;37(5):E5

83. Laurene KM, Coates S. The natural history of hydrocephalus. Detailed analysis of 182 unoperated cases. Arch Dis Child. 1962;37:345-362

84. Lazorthes G, Anduze-Acher H, Campan L, Espagno J. La ventriculocisternostomie transcalleuse; 4 ans d'expérience; 50 cas opéreés. Neurochirurgie. 1957;3:59-64

85. Lehto H, Dashti R, Karatas A, Niemela M, Hernesniemi JA. Third ventriculostomy through the fenestrated lamina terminalis during microneurosurgical clipping of intracranial aneurysms: an alternative to conventional ventriculostomy. Neurosurgery. 2009;64:430-434

86. Leksell L. A surgical procedure for atresia of the aqueduct of Sylvius. Acta Psychiatr Neurol Scand. 1949;24:559-500

87. Leonard of Bertapalia. Chirurgia. Guy de Chauliac Cyrurgia et Cyrurgia Bruni, Teodorici, Rolandi, Lanfranci, Rogerii, Bertapalie. 1519 Bernardinus Venetus de Vitalibus Venice

88. Levene ML. Measurements of the growth of the lateral ventricles in preterm infants with real-time ultrasound. Arch Dis Child. 1981;56:900-904

89. Lifshutz JI, Johnson WD. History of hydrocephalus and its treatment. Neurosurg Focus. 2001;11:Article 1

90. Lindley LC, Mark BA. Children with special health care needs: impact of health care expenditures on family financial burden. J Child Fam Stud. 2010;19:79-89

91. Lipina R, Palecek T, Reguli S, Kovarova M. Death in consequence of late failure of endoscopic third ventriculostomy. Childs Nerv Syst. 2007;23:815-819

92. Marlin AE. Protection of the cortical mantle in premature infants with posthemorrhagic hydrocephalus. Neurosurgery 1980;7:464-468

93. Massimi L, Tamburrini G, Caldarelli M, Di Rocco F, Federica $\mathrm{N}$, Di Rocco C. Late closure of the stoma by spreading of a periaqueductal glioma: an unusual failure of endoscopic third ventriculostomy. Case report. J Neurosurg. 2006;104(3 Suppl):197-201

94. Matson DD. Ventriculo-ureterostomy. J Neurosurg. 1951;8:398-404 
95. McLaughlin N, Khalessi AA, Martin NA. Health care economics in neurosurgery: there is no turning back. Neurosurg Focus. 2014;37:E1

96. McLaughlin N, Ong MK, Tabbush V, Hagigi F, Masrtin NA. Contemporary health care economics: an overview. Neurosurg Focus. 2014;37:E5

97. McNickle HF. The surgical treatment of hydrocephalus; a simple method of performing third ventriculostomy. $\mathrm{Br} \mathrm{J}$ Surg. 1947;34:302-307

98. Melo R, de Melo EN, de Vasconcellos AG, Pacheco P. Congenital hydrocephalus in the northeast of Brazil: epidemiological aspects, prenatal diagnosis, and treatment. Childs Nerv Syst. 2013;29:1899-1903.

99. Melot A, Curey-Lévêque S, Derrey S, Gérardin E,Borden A, Fréger P, Proust F. Endoscopic 3rd ventriculocisternostomy: procedural complicagions and long-term dysfunctions? Neurochirurgie. 2013;59:165-170

100. Milhorat TH, Clark RG, Hammock MK. Experimental hydrocephalus. Part 2. Gross pathological findings in acute and subacute obstructive hydrocephalus in the dog and monkey. J Neurosurg. 1970;32:390-399

101. Mixter WJ. Ventriculoscopy and puncture of the floor of the third ventricle. Boston Med Surg J. 1923;188:277-278

102. Mobbs RJ, Vonau M, Davies MA. Death after late failure of endoscopic third ventriculostomy: a potential solution. Neurosurgery. 2003;53:384-386.

103. Nanidis N, Korfias S, Sakas DE. Flow-regulated external lumbar drain: applications and complications. Acta Neurochir (Wien) 2014; 156:2201-2205

104. Nilsson D, Svensson J, Korkmaz BA, Nelvig H, Tisell M. Decreased head circumference in shunt-treated compared with healthy children. J Neurosurg Ped. 2013;12:483-490

105. Nulsen FE, Spitz EB. Treatment of hydrocephalus by direct shunt from ventricle to jugular vein. Surg Forum. 1952;2:399403

106. Ogiwara H, Morota N. Endoscopic transaqueductal or interventricular stent placement for the treatment of isolated forth ventricle and pre-isolated forth ventricle. Childs Nerv Syst. 2013; 29:1299-1303

107. Oppenheim H. Lehrbuch der Nervenkrankheiten. Vol II. Karger, Berlin, 1902. pp 1243-1262 
108. Oton-de Lima B. Hidrocefalia infantil. In Melo-Souza SE (ed.) Tratamento das doenças neurológicas. Guanabara Koogan, Rio de Janeiro, 2008; pp 308-310

109. Oton-de Lima B. Infecções de válvula na Infância. In MeloSouza SE (Ed.)Tratamento das doenças neurológicas. Guanabara Koogan, Rio de Janeiro, 2008; pp 32-34

110. Oton-de Lima B. Infecções de válvula na Infância. In MeloSouza SE (Ed.)Tratamento das doenças neurológicas. Guanabara Koogan, Rio de Janeiro, 2008; pp 32-34

111. Payr E. Elfjähriger Dauererfolg einer Ventrikeldrainage bei Hydrocephalus. Med Klin. 1919; 49:1247-1251

112. Peretta P, Ragazzi P, Galarza M, Genitori L, Giordano F, Mussa F, Cinalli G. Complications and pitfalls of neuroendoscopic surgery in children. J Neurosurg. 2006;105(3 Suppl):187-193

113. Pewttorini BL, Tamburrini G. Two hundred years of endoscopic surgery: from Philipp Bozzini's cystoscope do paediatric endoscopic neurosurgery. Childs Nerv Syst. 2007;23:723-724

114. Pham ACQ, Fan C, Owler BK. Treating pediatric hydrocephalus in Australia: a 3-year hospital-based cost analysis and comparison with other studies. J Neurosurg Pediatrics. 2013;11:398-40

115. Pinto FC, Pereira RM, Saad F, Teixeira MJ. Performance of fixed-pressure valve with antisiphon device SPHERA $(\circledR)$ in hydrocephalus treatmen and overdrainage prevention. Arq Neuropsiquiatr. 2012;70:704-709

116. Pollay M. Review of spinal fluid physiology: production and absorption in relation do pressure. Clin Neurosurg. 1977;24:254-269

117. Pople IK, Griffith HB. Control of hydrocephalus by endoscopic choroid plexus coagulation. Long-term results and complications. Eur J Pediatr Surg. 1993;3(Suppl 1):1718

118. Pudenz RH, Russel FE, Hurd AM, Sheldon CM. Ventriculoauriculostomy. A technique for shunting cerebrospinal fluid into the right auricle. Preliminary report. J Neurosurg. 1957; 14:171-179

119. Pudenz RH. The surgical treatment of hydrocephalus - an historical review. Surg Neurol. 1981; 15:15-25 
120. Putnam TJ. Treatment of hydrocephalus by endoscopic coagulation of the choroid plexus. Description of a new instrument and preliminary report of the results. New Engl J Med. 1934;210:1373-1378

121. Raimondi AJ. Hydrocephalus. In Raimondi AJ (Ed.)Pediatric Neurosurgery 1987, Springer, New York Berlin Heidelberg, pp 453-491

122. Richards KE, Anton SC. Craniofacial configuration and postcranial development of a hydrocephalic child (ca 2500 $B C-500 A D$ ) with review of cases and comments on d diagnostic criteria. Am J Phys Antrhopol 1991;85:185-200

123. Rüegger $\mathrm{C}$, Hegglin M, Adams M, Bucher HU. Population based trends in mortality, morbidity and treatment for very preterm - and very low birth weight infants over 12 years. BMC Pediatr. 2012;12:17

124. Sacko O, Boetto S, Lauwers-Cances V, Dupuy M, roux FE. Endoscopic third ventriculostomy: outcome analysis in 368 procedures. J Neurosurg Pediatrics. 2010 Jan;5(1):68-74.

125. Sainte-Rose C, Piatt JH, Renier D, Pierre-Kahn A, Hirsch JF, Hoffman HJ, Humphreys RP, Hendrick EB. Mechanical complications in shunts. Pediatr Neurosurg. 1991-1992;17:29

126. Sävman K, Blennow M, Hagberg H, Tarkowski E, Thoresen $M$, Whitelaw A. Cytokine response in cerebrospinal fluid from preterm infants with posthaemorrhagic ventricular dilatation. Acta Paediatr. 2002;91:1357-1363

127. Scarff JE. The treatment of nonobstructive (communicating) hydrocephalus by endocopic cauterization of the choroid plexuses. J Neurosurg. 1970; 1:1-18

128. Scarff JE. Treatment of hydrocephalus: an historical and critical review of methods and results. J Neurol Neurosurg Psychiatry. 1963;26:1-26

129. Sgouros S, Kulkharni AV, Constantini S. The international infant hydrocephalus study: concept and rational. Childs Nerv Syst. 2006;22:338-345

130. Shannon CN, Simon TD, Reed GT, et al. The economic impact of ventriculoperitoneal shunt failure. J Neurosurg Pediatr. 2011;8:593-599

131. Shitsama S, Wittavanakorn N, Okechi H, Albright AL. Choroid plexus coagulation in infants with extreme hydrocephalus or hydranencephaly. J Neurosurg Pediatr. 2014;14:55-57 
132. Shuangshoti S, Netsky MG. Choroid plexus and paraphysis in lower vertebrates J Morph, 1966;120:157-188

133. Sotelo,J. The hydrokinetic parameters of shunts for hydrocephalus might be inadequate. Surg Neurol International. 2012;3:40-46

134. Srinivasan VM, O'Neill BR, Jho D, Whiting DM, Oh MY. The history of external ventricular drainage. J Neurosurg. 2014; 120:228-236

135. Stone SS, Warf BC. Combined endoscopic third ventriculostomy and choroid plexus cauterization as primary treatment for infant hydrocephalus: a prospective North American series. J Neurosurg Pediatr. 2014; 29:1-8[Epub ahead of print]

136. Sutton LN, Sun P, Adzick NS. Fetal neurosurgery. Neurosurgery. 2001;48:124-142

137. Torack RM. Historical aspcects of normal and abnormal brain fluids. I. Cerebrospinal fluid. Arch Neurol 1982;39:197201

138. Torack RM. Historical aspcects of normal and abnormal brain fluids. II. Hydrocephalus. Arch Neurol 1982;39:276-279

139. Torkildsen A. A new palliative procedure in cases of inoperable occlusion of the Sylvian duct. Acta Chir Scand. 1938;82:177-185

140. Torrance GW, Feeny DH, Furlong WJ, Barr RD, Zhang Y, Wang Q. Multiattribute preference functions for a comprehensive health status classification system: Health Utilities Index Mark 2. Med Care 1996;34:702-722.

141. Trevisi G, Frassanito P, Di Rocco C. Idiopathic cerebrospinal fluid overproduction: case-based review of the pathophysiological mechanism implied in the cerebrospinal fluid production. Croat Med J. 2014;55:377-387

142. Tuli S, Drake JM, Lawless J. Wigg M, Lamberti-Pasculli M. Risk factors for repeated cerebrospinal shunt failures in pediatric patients with hydrocephalus. J Neurosurg. 2000;92:31-38

143. Tuli S, Tuli J, Drake J, Spears J. Predictors of death in pediatric patients requiring cerebrospinal fluid shunts. $J$ Neurosurg. 2004;100 Suppl:442-446

144. Turgut M. Surgical scalpel used in the treatment of "infantile hydrocephalus" by Al Zahrawi (936-1013 a. D.) Childs Nerv Syst 2009;25:1043-1044

145. Vernet O, Rilliet B. Late complications of ventriculoperitoneal or ventriculoatrial shunts. Lancet. 2001;358:1569-1570 
146. Vesailus A. The Fabric of the Human Body: An Annotated Translation of the 1543 and 1555 Editions of De Humani Corporis Fabrica Libri by Garrison $\mathrm{DH}$ and Hast $\mathrm{MH}$. Basel, Karger, 2014

147. Vieten H. Möglishkeiten und Gefahren der Röntgenbestrahlung des Hydrocephalus. Strahlentherapie 1952;88:377-382

148. Vour'ch $\mathrm{G}$. Continuous cerebrospinal fluid drainage by indwelling spinal catheter. Br J Anaesth. 1963; 35:118-120

149. Warf BC, Campbell JW. Combined endoscopic third ventriculostomy and choroid plexus cauterization as primary treatment of hydrocephalus for infants with myelomeningoele: long-term results of a prospective intentto-treat study in 115 East African infants. J Neurosurg Pediatrics. 2008;2:310-316

150. Warf BC. Hydrocephalus in Uganda: the predominance of infectious origin and primary management with endoscopic third ventriculostomy. J Neurosurg Pediatrics. 2005;102(1 Suppl):1-15

151. Welch K. The principles of physiology of the cerebrospinal fluid in relation to hydrocephalus including normal pressure hydrocephalus. Adv Neurol. 1975;13:247-332

152. Weller RO, Shulman K. Infantile hydrocephalus: clinical, histological, and ultrastructural study of brain damage. J Neurosurg. 1972;36:255-265

153. Wernicke C. Lehrbuch der Gehirnkrankheiten. 1881; Fischer, Kassel, pp 377-378

154. Yasuda T, Tomita T, McLone DG, Donovan M. Measurement of cerebrospinal fluid output through external ventricular drainage in one hundred infants and children: correlation with cerebrospinal fluid production. Pediatr Neurosurg. 2002;36:22-28

155. Zahl SM, Egge A, Helseth E, Wester K. Benign external hydrocephalus: a review, with emphasis on management. Neurosurg Rev. 2011;34:417-432 


\section{GOVERNO DO DISTRITO FEDERAL SECRETARIA DE ESTADO DE SAÚDE COMITÊ DE ÉTICA EM PESQUISA}

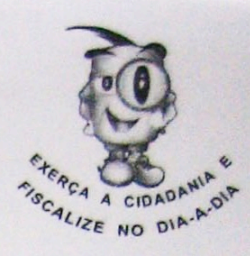

\section{PARECER № 024/2007}

Processo №: 026/07

Projeto de Pesquisa: Comparação dos custos do tratamento da hidrocefalia com implante de válvula versus cirurgia neuroendoscópica

Pesquisador Responsável - Benício Otoṇ de Lima

Instituição Pesquisada: HBDF

Área Temática Especial: Grupo III (não pertencente à área temática especial), Ciências da Saúde;

Validade do Parecer: 20/03/2009;

Tendo como base a Resolução 196/96 CNS/MS, que dispõe sobre as diretrizes e normas regulamentadoras em pesquisa envolvendo seres humanos, assim como as suas resoluções complementares, o Comitê de Ética em Pesquisa da Secretaria de Estado de Saúde do Distrito Federal, após apreciação ética, manifesta-se pela APROVAÇÃO DO PROJETO;

Esclarecemos que o pesquisador deverá observar as responsabilidades que Ihe são atribuídas na Resolução 196/96 CNS/MS, inciso IX.1 e IX.2, em relação ao desenvolvimento do projeto. Ressaltamos a necessidade de encaminhar o relatório parcial e final, além de notificações de eventos adversos quando pertinentes.

Brasilia, 20/de março de 2007.

Maria Rita Carvalho Garbi Novaes Comitê de Ética em Pesquisa/SES-DF Coordenadora<smiles>C1CCCCC1</smiles> 
EXAME NEUROLÓGICO EVOLUTIVO - Adaptação do DENVER ॥

\section{Até um mês de idade}

- Olha para o rosto das pessoas que o observam.

- Segue na horizontal, com os olhos, a luz de uma lanterna colocada a $30 \mathrm{~cm}$ dos olhos.

- Ao ouvir uma voz chamando-o, reage de algum modo: mudando o ritmo da respiração ou abrindo mais os olhos e demonstrando "atenção ou rodando a cabeça para um dos lados como se quisesse localizar a fonte do som".

- Colocado em DV, levanta a cabeça por alguns segundos.

- Reflexos primitivos obrigatórios desde o nascimento: Sucção, voracidade, preensão palmar, preensão plantar, moro, colocação, encurvamento do tronco, cutâneo plantar em extensão. Reflexos primitivos não obrigatórios: Marcha, RTCMK, sustentação, arrastre, endireitamento.

\section{Três meses}

- Sorri reativamente.

- Olha para as próprias mãos.

- Junta as mãos.

- Ao ouvir uma voz, fica atento.

- Colocado em DV, apoia-se sobre os MMSS fletidos

- Desaparece o R. de marcha e tônico-cervical assimétrico.

\section{Quatro meses}

- Sons guturais ("AN GU")

- Colocado sentado, a cabeça fica firme.

- Início de preensão palmar voluntária. 


\section{Seis meses}

- Inicia sons vocálicos: "AAAAAA"

- Localiza som (molho de chaves), na altura dos ouvidos.

- Em DV, estende os membros superiores e eleva o tórax.

- Muda decúbito.

- Sentado, o tronco ainda cai para a frente e para os lados.

- Apanha o objeto e passa para outra mão.

- Reflexos primitivos ausentes, exceto o de preensão plantar e cutâneo-plantar em extensão.

\section{Oito meses}

- Alcança, olha, passa para a outra mão, e explora o objeto.

\section{Nove meses}

- Lalação: "BAA BAA BAA" "TAA TA TA" MA-MA".

- Localiza som ao lado e acima da cabeça (até 13 meses).

- Sentado, fica sozinho, tronco ereto, sem cair.

- Recusa aproximação de pessoas estranhas.

- Descobre objeto que observa ser escondido ao seu alcance.

\section{Doze meses}

- Lalação: "Mama" "Papa" "Dada"

- Procura o objeto que cai ou rola de suas mãos.

- Preensão usando os dedos polegar e indicador (Pinça).

- Põe-se em pé com apoio.

- Em DV, senta-se sem ajuda

- R. de apoio lateral e pára-quedas.

- R. de preensão plantar ausente. 


\section{Dezoito meses}

- Primeiras palavras-frases: "Dá"

- Brinca imitando (telefone no ouvido, tenta rabiscar).

- Aponta para o que quer.

- Torre de 2 cubos.

- Vence obstáculos, abre porta.

- Anda sem ajuda.

- R. Cutâneo-plantar em flexão.

\section{Dois anos}

- Combina 2 palavras

- Associa idéias: aperta o interruptor e olha para a lâmpada. Aponta para a bolsa, por. ex., da mãe e diz "mamãe".

- Imita trabalhos caseiros.

- Retira a roupa.

- Usa a colher.

- Aponta para partes do corpo.

- Aponta para figuras em um livro.

- Faz rabiscos no papel.

- Torre de quatro cubos.

- Chuta um bola.

- Sobe e desce de uma cadeira.

\section{Dois anos e meio}

- Nomeia figuras simples.

- Copia traços, sem direção.

- Joga a bola de cima para baixo.

- Sobe escada, colocando os dois pés em cada degrau.

- Corre. 


\section{Três anos}

- Frases gramaticais.( EU)

- Diz o próprio nome completo.

- Gagueira fisiológica.

- Brinca de faz-de-conta.

- Copia um círculo.

- Copia traço na vertical.

- Torre de 8 cubos. Até $3 a$ e $6 \mathrm{~m}$ faz ponte.

- Anda para trás 3 metros, puxando um carrinho.

- Equilíbrio estático com olhos abertos.

- Pedala triciclos.

- Coloca os sapatos, não faz laço.

Quatro anos

- Vai sozinho ao vaso sanitário.

- Controle da enurese noturna.

- Frases completas. Ainda troca letras: R por L, S por T; ou suprime as letras (sapato por pato).

- Usa plural.

- Senso de humor, noção de perigo.

- Preensão do lápis igual adulto.

- Copia cruz.

- Noção de "mais comprido".

- Lava as mãos e ajuda no banho.

- Agarra uma bola arremessada.

- Sobe escada alternando os pés.

- Equilíbrio estático com olhos fechados.

Quatro anos e meio

- Compreende frio, cansaço, fome.

- Compreende perto, longe, em cima, em baixo.

- Abotoa a roupa

\section{Cinco anos}

\section{Seis anos}

- Copia um quadrado.

- Desenha homem com 6 partes

- Anda para trás colocando um pé atrás do outro (ponta do pé-calcanhar), com olhos abertos, 2 metros.

- Estereognosia. 


\section{Sete anos}

- Noção de hora, dia, mês e ano.

- Fornece o endereço completo.

- Descreve o que vê.

- Copia triângulo e inicia a cópia do losango.

- Amarra o cordão do sapato.

- Reconhece direita e esquerda no próprio corpo.

- Salta e bate duas palmas, antes de tocar os pés no chão.

- Eudiadococinesia.

- Fica parado em pé, por 10 segundos com um pé atrás do outro (ponta de pé-calcanhar).

- Joga bola em uma altura $30 \times 30 \mathrm{~cm}$ e $2 \mathrm{~m}$, fazendo abdução do MS (joga por cima).

- Anda colocando o calcanhar na ponta do outro pé, para frente 2 metros, com olhos abertos.

- Conhece as cores primárias.

- Desenha de memória a figura humana.

- Fica longe da mãe sem protestar.

- Conta histórias, fala sem trocar letras.

- Escolhe amigos.

- Se veste sem ajuda. 


\section{INDICE DE SAÚDE ÚTIL}

\begin{tabular}{|c|c|c|}
\hline Atributo & Nível & Descrição \\
\hline \multirow[t]{4}{*}{ SENSAÇÃO } & 1 & Capaz de ver, ouvir e falar normalmente para a idade \\
\hline & 2 & Necessita equipamento para ver, ouvir ou falar \\
\hline & 3 & Vê, ouve e fala mesmo com limitações apesar do equipamento \\
\hline & 4 & Cego, surdo ou mudo \\
\hline \multirow[t]{5}{*}{ MOBILIDADE } & 1 & $\begin{array}{l}\text { Capaz de andar, abaixar, levantar, pular e correr normalmente para a } \\
\text { idade }\end{array}$ \\
\hline & 2 & Anda, abaixa, levanta,pula ou corre com limitações mas sem ajuda \\
\hline & 3 & $\begin{array}{l}\text { Precisa equipamento (muletas, tutores ou cadeira de rodas) para } \\
\text { locomover-se independentemente }\end{array}$ \\
\hline & 4 & Precisa ajuda de outra pessoa para andar e precisa equipamento \\
\hline & 5 & Incapaz de controlar ou usar braços e pernas \\
\hline \multirow[t]{5}{*}{ EMOÇÃO } & 1 & Geralmente alegre e sem preocupações \\
\hline & 2 & $\begin{array}{l}\text { Ocasionalmente preocupado, zangado, irritado, ansioso, deprimido } \\
\text { ou com terror noturno }\end{array}$ \\
\hline & 3 & $\begin{array}{l}\text { Geralmente preocupado, zangado, irritado, ansioso, deprimido ou } \\
\text { com terror noturno. }\end{array}$ \\
\hline & 4 & Quase sempre preocupado, zangado, irritado, ansioso ou deprimido \\
\hline & 5 & $\begin{array}{l}\text { Extremamente preocupado, zangado, irritado, ansioso, deprimido e } \\
\text { geralmente precisa hospitalização ou cuidado psiquiátrico. }\end{array}$ \\
\hline \multirow[t]{4}{*}{ COGNITIVO } & 1 & Aprende e lembra o trabalho escolar normalmente para a idade \\
\hline & 2 & $\begin{array}{l}\text { Aprende e lembra mais devagar que colegas de aula, pela opinião dos } \\
\text { professores ou pais }\end{array}$ \\
\hline & 3 & $\begin{array}{l}\text { Aprende e lembra muito devagar e geralmente precisa assistência } \\
\text { especial para aprender }\end{array}$ \\
\hline & 4 & Incapaz de aprender e lembrar \\
\hline \multirow[t]{4}{*}{ CUIDADOS } & 1 & Come, toma banho, veste-se e usa toalete normalmente para idade \\
\hline & 2 & $\begin{array}{l}\text { Come, toma banho, veste-se e usa o toalete independentemente com } \\
\text { dificuldade }\end{array}$ \\
\hline & 3 & $\begin{array}{l}\text { Precisa equipamento mecânico para comer, tomar banho, vestir-se } \\
\text { ou usar o toalete independentemente }\end{array}$ \\
\hline & 4 & $\begin{array}{l}\text { Precisa de ajuda de outra pessoa para comer, tomar banho, vestir-se } \\
\text { ou usar toalete }\end{array}$ \\
\hline \multirow[t]{5}{*}{ DOR } & 1 & Livre de dor e desconforto \\
\hline & 2 & $\begin{array}{l}\text { Dor ocasional. Desconforto aliviado por medicamentos comuns ou } \\
\text { atividade de auto-controle sem interferir nas suas atividades diárias }\end{array}$ \\
\hline & 3 & $\begin{array}{l}\text { Dor frequente. Alívio com medicação prescrita com interrupção } \\
\text { ocasional das atividades diárias }\end{array}$ \\
\hline & 4 & $\begin{array}{l}\text { Dor frequente. Interrupção frequente as atividades diárias. } \\
\text { Desconforto necessitando narcóticos para alívio. }\end{array}$ \\
\hline & 5 & $\begin{array}{l}\text { Dor severa. Não aliviada por drogas e constantemente interrompe } \\
\text { atividades diárias }\end{array}$ \\
\hline \multirow[t]{3}{*}{ FERTILIDADE } & 1 & Capaz de ter filhos com conjuge fértil. \\
\hline & 2 & Dificuldade de ter fílhos com cônjuge fértil \\
\hline & 3 & Incapaz de ter filhos \\
\hline
\end{tabular}


Nome:

Reg:

Mãe:

Endereço: Fone:

Nascimento: Diagnóstico: RM: Fluxo:

CT:

Cirurgia: Cirurgia:

Dias de internação pós-op: Infecção: Hora da cirurgia:

Equipe:

TVE: Sem intercorrências Com intercorrências

DVP: Sem intercorrências Com intercorrências:

Marca da válvula:

Exame Evolutivo pré-op: Normal para idade Abaixo da idade

Exame Evolutivo após 2 meses __ Normal para idade __ Abaixo da idade

Exame Evolutivo após 6 meses: Normal para idade Abaixo da idade

Exame Evolutivo após 12 meses: Normal para idade Abaixo da idade

Índice de Saúde Útil: Pré op: 6 meses: 12 meses:

Complicações:

Reinternações: Data da 1a..: Dias: Causas:

PC Cirurgia: 2 meses 6 meses 12 meses

Nova cirurgia em Número de novas cirurgias: 